\title{
AVALIAÇÃO DO ESTADO NUTRICIONAL DA VIDEIRA CULTIVAR ITÁLIA EM TRÊS ESTÁDIOS DE DESENVOLVIMENTO, NA REGIÃO DE JUNDIAÍ-SP, UTILIZANDO O MÉTODO DRIS
}

\section{FABIO COSTA}

Engenheiro Agrônomo

Orientador: Dr. MAURILO MONTEIRO TERRA

Dissertação apresentada à Escola Superior de Agricultura "Luiz de Queiroz", Universidade de São Paulo, para obtenção do título de Mestre em Agronomia, Área de Concentração: Fitotecnia.

PIRACICABA

Estado de São Paulo - Brasil

Janeiro - 1998 
Dados Internacionais de Catalogação na Publicação (CIP) DIVISĀO DE BIBLIOTECA E DOCUMENTAÇĀO - Campus "Luiz de Queiroz"/USP

\author{
Costa, Fabio \\ Avaliação do estado nutricional da videira cultivar Itália em três estádios de \\ desenvolvimento, na regiāo de Jundiai-SP, utilizando o método DRIS / Fabio Costa. - . \\ Piracicaba, 1998. \\ $91 \mathrm{p}$. \\ Dissertação (mestrado) - Escola Superior de Agricultura Luiz de Queiroz, 1998. \\ Bibliografia.
}

1. Avaliação nutricional 2. DRIS 3. Nutriente 4. Uva Itália 1. Título 


\section{AVALIAÇÃO DO ESTADO NUTRICIONAL DA VIDEIRA CULTIVAR ITÁLIA EM TRÊS ESTÁDIOS DE DESENVOLVIMENTO, NA REGIÃO DE JUNDIAÍ-SP, UTILIZANDO O MÉTODO DRIS}

FABIO COSTA

Aprovada em: 10.03.1998

Comissão julgadora:

Prof. Dr. João Alexio Scarpare Filho

ESALQ/USP

Dr. Maurilo Monteiro Terra

IAC

Dr. Erasmo José Paioli Pires

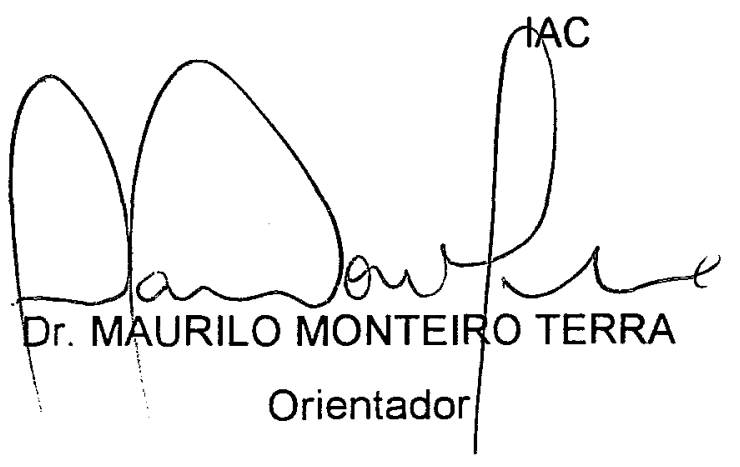




\title{
HOMENAGEM
}

\author{
Instituto Agronômico de Campinas
}

Escola Superior de Agricultura "Luiz de Queiroz"

Conselho Nacional de Desenvolvimento Científico e Tecnológico - CNPq

Fundação de Amparo à Pesquisa do Estado de São Paulo - FAPESP 
A Maria Isabel, esposa e companheira, Fabio Henrique, João Paulo e André Luis, meus filhos, aos meus pais, Natalino e Vali aos sogros, Valdemar e Maria de Lourdes (in memorian)

pelo carinho, apoio e incentivo

\section{DEDICO}




\section{AGRADECIMENTOS}

Agradeço:

- Ao Dr. Maurilo Monteiro Terra pela orientação e incentivo durante a realização e confecção do presente trabalho.

- Aos viticultores da região de Jundiaí-SP, em cujas propriedades foram realizados os experimentos.

- Ao Engenheiro Agrícola Wagner Rodrigues dos Santos, pela colaboração, execução e orientação na discussão do método DRIS.

- Ao Dr. Claudio Costa, que além de irmão, foi muito importante pela cooperação e estímulo à realização deste trabalho.

- Aos funcionários da Seção de Viticultura, do Instituto Agronômico que direta ou indiretamente contribuiram para a realização deste trabalho. 


\section{SUMÁRIO}

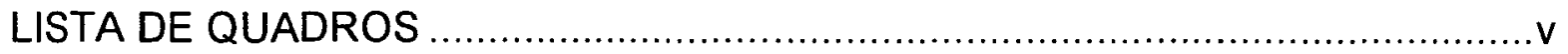

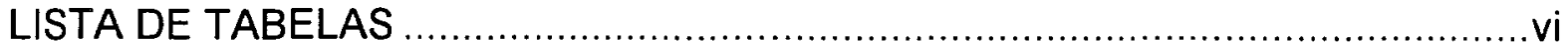

RESUMO

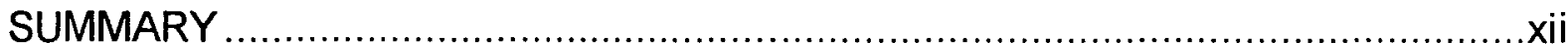

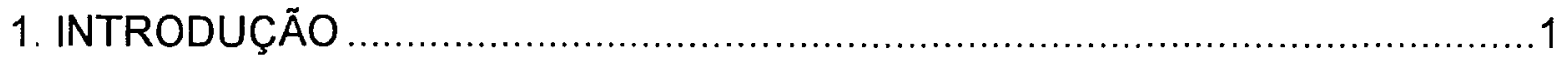

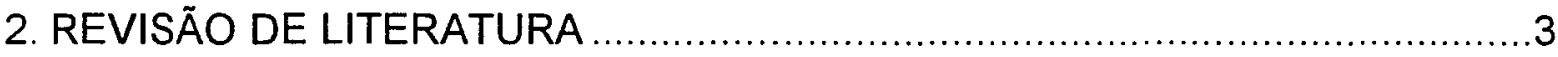

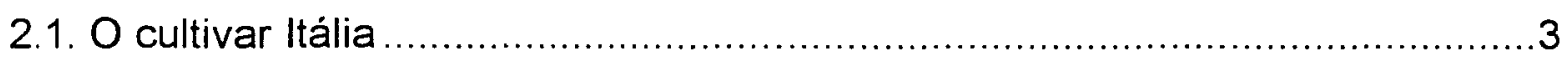

2.2. Concentração e Relação de Nutrientes na Folha ..........................................4

2.3. Sistema Integrado de Diagnose e Recomendação (DRIS) ..........................12

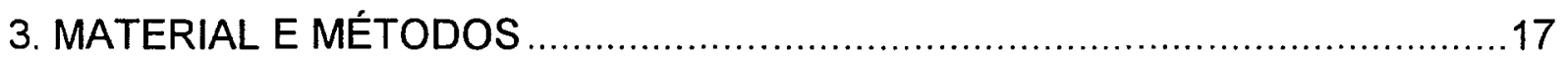

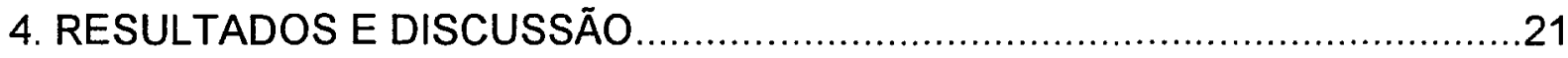

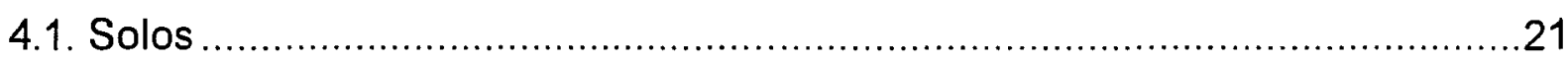

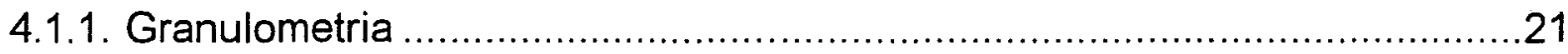

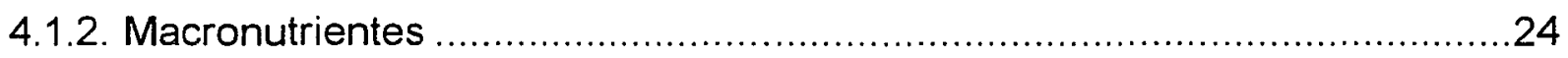

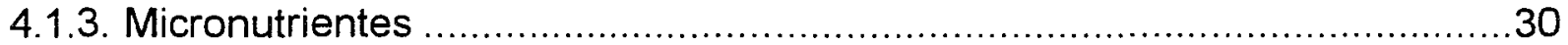

4.2. Sistema Integrado de Diagnose e Recomendação (DRIS) .............................33

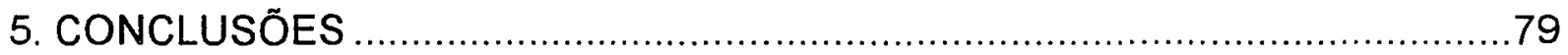

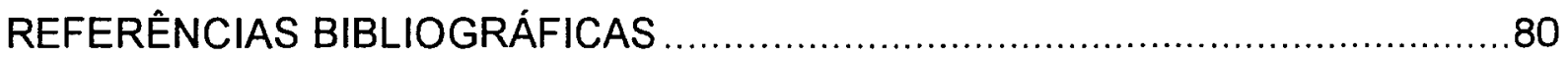




\section{LISTA DE QUADROS}

Página

1 Interpretação para macronutrientes no solo.

27

2 Interpretação para micronutrientes no solo............................... 


\section{LISTA DE TABELAS}

Página

1 Resultados das análises granulométricas de solo para os vinhedos amostrados, profundidade de $0-20 \mathrm{~cm} \mathrm{em}$ levantamento nutricional na região de Jundiaí, ano de 1991

2 Resultados das análises granulométricas de solo para os vinhedos amostrados, profundidade de $(20-40 \mathrm{~cm}) \mathrm{em}$ levantamento nutricional na região de Jundiaí, ano de 1991

3 Resultados das análises químicas de macro e micronutrientes de solo para os vinhedos amostrados, na profundidade de 0$20 \mathrm{~cm}$, em levantamento nutricional na região de Jundiai, ano de 1991

$4 \quad$ Resultados das análises químicas de macro e micronutrientes de solo para os vinhedos amostrados, na profundidade de 20$40 \mathrm{~cm}$, levantamento nutricional na região de Jundiaí, ano de 1991.

5 Interpretação dos resultados de análise de solo para os macronutrientes nas profundidades de $0-20 \mathrm{~cm}$ e $20-40 \mathrm{~cm}$, para os vinhedos amostrados, em um levantamento nutricional na região de Jundiaí, ano de 1991

6 Interpretação dos resultados de análise de solo, para os micronutrientes, nas profundidade de $0-20 \mathrm{~cm}$ e $20-40 \mathrm{~cm}$, para os vinhedos amostrados, em um levantamento nutricional na região de Jundiaí, ano de 1991.

7 Resultados das análises químicas de macro e micronutrientes de limbo, no florescimento ( $1^{\text {a }}$ coleta), para os vinhedos amostrados, em levantamento nutricional na região de Jundiai, ano de 1991

8 Resultados das análises químicas de macro e micronutrientes de limbo, na fase de frutas entre ervilha e meia baga $\left(2^{\mathrm{a}}\right.$ coleta) para os vinhedos amostrados, em levantamento nutricional na região de Jundiaí, ano de 1991 
9 Resultados das análises químicas de macro e micronutrientes de limbo, no início da maturação das bagas ( $3^{\mathrm{a}}$ coleta) para os vinhedos amostrados, em levantamento nutricional na região de Jundiaí, ano de 1991.

10 Resultados das análises químicas de macro e micronutrientes de pecíolo, no florescimento ( $1^{\text {a }}$ coleta) para os vinhedos amostrados, em levantamento nutricional na região de Jundiaí, ano de 1991

11 Resultados das análises químicas de macro e micronutrientes de peciolo, na fase dos frutos entre ervilha e meia-baga $\left(2^{\mathrm{a}}\right.$ coleta) para os vinhedos amostrados, em levantamento nutricional na região de Jundiaí, ano de 1991

12 Resultados das análises químicas de macro e micronutrientes de pecíolo, no início de maturação das bagas ( $3^{\mathrm{a}}$ coleta) para os vinhedos amostrados, em levantamento nutricional na região de Jundiaí, ano de 1991

13 Média , Desvio Padrão e Coeficiente de Variação (Normas) para os nutrientes e para suas relações dois a dois, considerando limbo $-1^{a}$ coleta (florescimento).

14 Média , Desvio Padrão e Coeficiente de Variação (Normas) para os nutrientes e para suas relações dois a dois, considerando limbo - $2^{\mathrm{a}}$ coleta (fruto entre ervilha e meia baga)

15 Média, Desvio Padrão e Coeficiente de Variação (Normas) para os nutrientes e para suas relações dois a dois, considerando limbo - $3^{\text {a }}$ coleta (início de maturação das bagas)

16 Média , Desvio Padrão e Coeficiente de Variação (Normas) para os nutrientes e para suas relações dois a dois, considerando Pecíolo - $1^{\mathrm{a}}$ coleta (florescimento).

17 Média, Desvio Padrão e Coeficiente de Variação (Normas) para os nutrientes e para suas relações dois a dois, considerando Pecíolo - $2^{\mathrm{a}}$ coleta (fruto entre ervilha e meia baga) 
18 Média , Desvio Padrão e Coeficiente de Variação (Normas) para os nutrientes e para suas relações dois a dois, considerando Pecíolo - $3^{\underline{a}}$ coleta (início de maturação das bagas).

19 Média e coeficiente de variação dos nutrientes no limbo para $1^{\text {a }}$ coleta (florescimento).

20 Média e coeficiente de variação dos nutrientes no limbo para $2^{\mathrm{a}}$ coleta (frutos entre ervilha e meia- baga).

21 Média e coeficiente de variação dos nutrientes no limbo para $3^{\mathrm{a}}$ coleta (início de maturação das bagas).

22 Média e coeficiente de variação dos nutrientes no peciolo para $1^{\text {a }}$ coleta (florescimento).

23 Média e coeficiente de variação dos nutrientes no pecíoolo para $2^{\mathrm{a}}$ coleta (frutos entre ervilha e meia- baga).

24 Média e coeficiente de variação dos nutrientes no pecílo para $3^{a}$ coleta (início de maturação das bagas).

25 Sequência decrescente de coeficiente de variação para macro e micronutrientes no limbo, para as três coletas (florescimento, frutos entre ervilha e meia-baga e início da maturação das bagas).

26 Sequência decrescente de coeficiente de variação para macro e micronutrientes no pecíolo, para as três coletas (florescimento, frutos entre ervilha e meia-baga e início da maturação das bagas)

27 Produção, Índices DRIS, Índices de Balanço Nutricional (IBN) e Seqüência de deficiência a excesso nutricional para os vinhedos amostrados considerando limbo - $1^{\text {a }}$ coleta (florescimento)

28 Produção, Índices DRIS, Índices de Balanço Nutricional (IBN) e Seqüência de deficiência a excesso nutricional para os vinhedos amostrados considerando limbo - $2^{a}$ coleta (fruto entre ervilha e meia-baga). 
29 Produção, Índices DRIS, Índices de Balanço Nutricional (IBN) e Seqüência de deficiência a excesso nutricional para os vinhedos amostrados considerando limbo - $3^{\mathrm{a}}$ coleta (início de maturação das bagas)

30 Produção, Índices DRIS, Índices de Balanço Nutricional (IBN) e Seqüência de deficiência a excesso nutricional para os vinhedos amostrados considerando pecíolo - $1^{\text {a }}$ coleta (florescimento).

31 Produção, Índices DRIS, Índices de Balanço Nutricional (IBN) e Seqüencia de deficiência a excesso nutricional para os vinhedos amostrados considerando peciolo - $2^{\mathrm{a}}$ coleta (fruto entre ervilha e meiga-baga)

32 Produção, Índices DRIS, Índices de Balanço Nutricional (IBN) e Seqüência de deficiência a excesso nutricional para os vinhedos amostrados considerando pecíolo - $3^{\text {a }}$ coleta (início de maturação das bagas).

33 Indice de Balanço Nutricional de referência para os vinhedos amostradas limbo $-1^{\mathrm{a}}$ coleta (florescimento).............

34 Índice de Balanço Nutricional de referência para os vinhedos amostradas limbo - $2^{\mathrm{a}}$ coleta (frutos entre ervilha e meia baga)

35 Índice de Balanço Nutricional de referência para os vinhedos amostradas limbo - $3^{\text {a }}$ coleta (início de maturação das bagas).

36 Índice de Balanço Nutricional de referência para os vinhedos amostrados pecíolo - $1^{\text {a }}$ coleta (florescimento).

37 Índice de Balanço Nutricional de referência para os vinhedos amostrados pecíolo - $2^{\mathrm{a}}$ coleta (frutos entre ervilha e meiabaga)

38 Índice de Balanço Nutricional de referência para os vinhedos amostrados peciolo - $3^{\text {a }}$ coleta (início de maturação das bagas) 


\section{AVALIAÇÃO DO ESTADO NUTRICIONAL DA VIDEIRA CULTIVAR ITÁLIA EM TRÊS ESTÁDIOS DE DESENVOLVIMENTO, NA REGIÃO DE JUNDIAÍ-SP, UTILIZANDO O MÉTODO DRIS}

Autor: FABIO COSTA

Orientador: Dr. MAURILO MONTEIRO TERRA

\section{RESUMO}

O objetivo deste trabalho foi a avaliação do estado nutricional da videira cv. Itália na região de Jundiaí, SP, utilizando o Sistema Integrado de Diagnose e Recomendação (DRIS).

O levantamento do estado nutricional em dezenove vinhedos em produção que apresentavam práticas culturais semelhantes, foi realizado em 1991.

O levantamento nutricional consistiu na coleta de amostras de solo, nas profundidades de $0-20 \mathrm{~cm}$ e $20-40 \mathrm{~cm}$, na de folhas em três estádios de desenvolvimento da planta a saber: no florescimento; com frutos entre ervilha e meia baga; no início da maturação dos frutos e na produção.

Essa avaliação, através do método DRIS, permitiu concluir que o método é adequado para a videira 'Itália', pois permitiu obter informações a respeito do melhor órgão e época de amostragem, desordens nutricionais e indices referenciais para balanço nutricional. 
O limbo foi considerado o melhor órgão para amostragem, pois seus indices de balanço nutricional estavam mais ajustados.

O estádio de florescimento foi considerado a época adequada para amostragem de folhas de videira.

O método DRIS refletiu as condições locais do levantamento e os vinhedos apresentaram variabilidade quanto à ordem e o grau de limitação dos nutrientes na produtividade. 


\section{EVALUATION OF THE NUTRITIONAL CONDITIONS OF THE GRAPEVINE CV ITALIA, DURING THREE PHASES OF DEVELOPMENT USING THE DIAGNOSIS AND RECOMENDATION INTEGRATED SYSTEM (DRIS) IN JUNDIAÍ, SP, BRAZIL}

Author: FABIO COSTA Adviser: Dr. MAURILO MONTEIRO TERRA

\section{SUMMARY}

This work aimed to evaluate the nutritional condition of 'Italia' grapevine in the region centered at Jundiaí, SP, Brazil, using the Diagnosis and Recommendation Integrated System (DRIS).

During 1991 nineteen bearing vineyards in that region sharing similar cultural practices were nutritionally surveyed. It consisted in: a) colecting soil samples at $0-20 \mathrm{~cm}$ and $20-40 \mathrm{~cm}$; b) colecting leaf samples (blade and petiole) at three different developing phases (at blooming, between pea and half-berry, and at veraison); and c) evaluating grape yield.

DRIS was shown to be useful for grapevine and it allows reliable informations on sampling tissue, nutritional disorders and reference indexes for the nutritional balance. Leaf blade showed to be better than petiole for tissue sampling, since it has shown better nutritional balance indexes. The method confirmed veraison as the best stage for leaves sampling. DRIS also reflected the local sampling conditions and variabilitiy was found among the vineyards concerned to order and degree of nutrient limitations in productivity. 


\title{
1. INTRODUÇÃO
}

\begin{abstract}
A atual viticultura paulista encontra-se difundida por todo $\circ$ Estado podendo ser analisada sob diferentes aspectos quanto ao produto: produção de uvas finas e rústicas para mesa.
\end{abstract}

Segundo dados do Anuário Estatístico do Brasil (1996), o valor da produção de uvas ocupa a $16^{a}$ posição entre os produtos de origem vegetal produzidos no Estado no ano agrícola de 1995/96, sendo superior à todas as outras frutas.

Atualmente o cultivo de uvas finas de mesa vem encontrando grande oportunidade de expansão no Estado de São Paulo. Dados do Instituto de Economia Agrícola (1996), estimam no ano agrícola de 1995/96, número de 1,9 milhões de pés de uvas finas, ocupando uma área de 2.500 ha com produção total de $49.945 t$.

A produção de uvas finas de mesa em São Paulo baseia-se principalmente no cultivar Itália.

A introdução da uva Itália no Brasil ocorreu em 1940, na cidade de Ferraz de Vasconcelos, SP, sendo então não só difundida às demais regiões do estado, como também aos demais estados brasileiros.

As principais regiões produtoras de uvas finas de mesa no Estado de São Paulo são: sudeste, sudoeste, noroeste e oeste. Tais regiões possuem características edafoclimáticas bastante diferentes entre si, fazendo com que a 
fenologia, tratos culturais, assim como a estrutura de comercialização, também sejam distintos.

$\mathrm{Na}$ região de Jundiaí, devido a condições climáticas, a videira apresenta um ciclo definido, ou seja, passa por um período de dormência no inverno antes de entrar novamente na fase vegetativa e produtiva, que será nos meses de temperaturas e precipitações pluviométricas mais elevadas do ano.

A adubação é uma prática feita regularmente tanto via solo como via foliar. Embora hoje os vinhedos sejam conduzidos com alta tecnologia, a adubação ainda é feita sem orientação técnica, e com uso indiscriminado e inadequado de fertilizantes, o que tem causado desequilíbrios nutricionais, levando a prejuízos devido à queda na produção e na qualidade dos frutos, onerando em demasia a cultura.

A presente pesquisa teve por objetivo fazer um levantamento do estado nutricional em vinhedos produtivos do cultivar Itália, que apresentava práticas culturais semelhantes, na região de Jundiaí, SP, utilizando o Sistema Integrado de Diagnose e Recomendação - DRIS, a fim de avaliar o estado nutricional desse cultivar, em três estádios de desenvolvimento. 


\section{REVISÃO DE LITERATURA}

\subsection{O cultivar Itália}

O cultivar Itália (Piróvano 65) de uva fina de mesa originou-se em 1911, na Itália, do cruzamento entre as variedades Bicane e Moscatel de Hamburgo. Da Itália disseminou-se pela Europa, como cultivar de uva de mesa, tendo sido introduzido no Brasil em 1940, com a expansão dos cultivos comerciais a partir da década de cinqüenta. Dadas as suas qualidades para o consumo in natura e as características de boa adaptação às regiões vitícolas, tornou-se o principal cultivar de uva fina de mesa utilizado no Brasil (Gonçalves et al., 1996).

A planta de uva 'Itália', apesar de susceptivel à doenças fúngicas, é muito vigorosa e no sudeste de São Paulo seu ciclo é de 180 dias. Exige podas longas com 8 a 12 gemas. Os cachos têm forma cilíndrico-cônica e tamanho grande, sendo alongados com peso variando entre 400 e 800 gramas. As bagas ovaladas e grandes, de cor amarelo-esverdeadas quando maduras, têm textura trincante e sabor neutro levemente moscatel, devendo ser colhidas com pelo menos $16^{\circ}$ Brix para maior intensidade e sabor (Terra et al., 1993).

Nas zonas vitícolas paulistas da região sudeste, localizadas nas encostas da serra de Paranapiacaba (com núcleo principal em São Miguel 
Arcanjo) e da Serra do Japi (principalmente em torno de Jundiaí), a colheita ocorre de dezembro a abril (Gonçalves et al., 1996).

\subsection{Concentração e Relação de Nutrientes na Folha}

Ulrich (1942) estudou as relações entre a produção e teor de K nos pecíolos de videiras para experimentos com fertilizantes em dois solos com teores aproximados de K. As produções, foram relacionadas preferencialmente com a adubação nitrogenada do que com a potássica. Estudou-se, também, os teores de várias formas de $\mathrm{N}$ nos pecíolos e limbos das videiras. Foi verificado que, em relação à produção, o teor de nitrato nos pecíolos de folhas recém maduras refletiu melhor o nível de nitrogênio, comparado ao teor de nitrato no limbo ou aos teores de $\mathrm{N}$-solúvel; $\mathrm{N}$-insolúvel e $\mathrm{N}$-total nos pecíolos e limbos foliares.

Depardon \& Buron (1954) obtiveram maiores produções de frutos em teores foliares de $\mathrm{K}$ correspondentes a 0,78\%.

Sauer (1958) estudando toxidez de boro em videiras cultivar Sultana, observou que aplicações de sulfato de amônio e de superfosfato tenderam aumentar os niveis de boro nas folhas.

Cook et al. (1960) obtiveram teores de B nos pecíolos variando de 7 a 9 ppm em folhas cloróticas deficientes das variedades Langnave e Thompson Seedless, sendo que em folhas sadias, opostas aos cachos, no florescimento, apresentavam de 20 a 30 ppm de B.

Gärtel (1961) considerando o teor de 20-30 ppm de B como normal, observou que folhas com teores foliares de 700 ppm apresentavam deformações e necroses.

Gromakovskis (1962), através de uma pesquisa sobre teores de nutrientes foliares das videiras, verificou que as folhas amostradas acima da 
gema floral tiveram teores de $\mathrm{N}$ e $\mathrm{P}$ menores que as folhas retiradas abaixo da inflorescência mas, nos dois casos, as concentrações no peciolo foram maiores que no limbo. No pecíolo, o pico máximo de nutrientes ocorreu no florescimento e o pico mínimo na colheita.

Gallo \& Ribas (1962) estudando o efeito de diferentes combinações copa e porta-enxerto, observaram que os maiores valores foliares de $\mathrm{N}$ e $\mathrm{P}$ foram encontrados em variedades enxertadas sobre Rupestris du Lot; o maior teor foliar de Ca foi associado com o porta-enxerto Riparia $x$ Rupestris 101-14; o teor de $\mathrm{K}$ foi mais dependente da variedade, sendo mais alto em Diamante Negro, Itália e Moscatel de Hamburgo. O cultivar Itália sobre portaenxerto Rupestris du Lot teve teores foliares elevados de P e Mg. O teor de B foi o que mais variou em relação às combinações copa e porta-enxerto e pareceu não ser dependente de nenhuma das duas variáveis.

Dulac (1965) em um ensaio de adubação com 15 anos de duração, indicou que os pecíolos foliares e pedúnculos dos cachos foram mais sensiveis que os limbos foliares em apontar mudanças no teor de potássio no solo. Nos casos de deficiência de $\mathrm{K}$, a relação entre o teor de $\mathrm{K}$ no limbo e o teor de $\mathrm{K}$ no peciolo caiu abaixo de 1 no final da época de crescimento.

Levy (1965), citado por Delmas (1971), estabeleceu o limite crítico de K em $1,25 \%$ no peciolo, correspondendo ao teor de $0,75 \%$ no limbo para as quatro épocas clássicas de amostragem: início de florescimento, florescimento, início de maturação dos frutos e maturação. O nível crítico de $\mathrm{Mg}$ foi estabelecido em $0,20 \%$, e as folhas para análise devem ser coletadas duas vezes ao ano: no início da frutificação e na maturação dos frutos.

Hernando \& Mendiola (1965) em experimentos com a finalidade de relacionar a absorção de $\mathrm{N}, \mathrm{P}, \mathrm{K}, \mathrm{Ca}, \mathrm{Mg}$ e $\mathrm{S}$ nos vários estádios de desenvolvimento e diagnosticados em análise foliar com a produtividade dos vinhedos em duas regiões, La Mancha e La Rioja, Espanha, concluíram que a melhor época de amostragem foi o início de formação dos frutos. 
Guillén et al. (1965) analisaram folhas de Vitis vinifera em três épocas distintas, a fim de estudar a evolução dos nutrientes $\mathrm{N}, \mathrm{P}, \mathrm{K}, \mathrm{Ca} \in \mathrm{Mg}$ ao longo do ciclo da videira, através de equações de regressão e representações gráficas correspondentes. Segundo os autores, os conteúdos foliares de $\mathrm{N}$ e $\mathrm{P}$ diminuiram no começo e fim do período de florescimento, e começo e fim de maturação dos frutos. Durante o ciclo vegetativo os teores variaram de 4,97 a $1,65 \%$ para $\circ \mathrm{N}$ e de 0,40 a $0,11 \%$ para $\circ \mathrm{P}$, e mostrando que existe uma correlação entre ambos. Os conteúdos foliares de potássio apresentaram um ligeiro aumento na primeira etapa e decresceram a um valor inferior ao inicial, posteriormente, variando de 1,45 a 0,32\%. Os conteúdos foliares de $\mathrm{Ca}$ e $\mathrm{Mg}$ aumentaram quase linearmente com o amadurecimento, variando de 1,0 a 5,5\% para $\mathrm{Ca}$ e de 0,3 a 1,0\% para o $\mathrm{Mg}$.

Vanek et al. (1967) estudaram a deficiência de magnésio em plantas de uvas cultivadas em solução nutritiva e concluíram que para análise, o limbo foliar foi o mais indicado que o peciolo. A relação $\mathrm{K} / \mathrm{Mg}$ expressou a deficiência de $\mathrm{Mg}$ com mais exatidão do que o índice de $\mathrm{Mg}$ isolado; no limbo de folhas sem sintomas, a relação $\mathrm{K} / \mathrm{Mg}$ foi de 1,73 e nas plantas deficientes 8,33 sendo que, as diferenças nos pecíolos foram pequenas.

Biblina (1968) constatou em solos chernozem lixiviados na Morávia, Rússia, que as relações NPK 1:1:1 ou 2:1:1 proporcionaram as mais altas produções e boa qualidade de uva, sendo que a maior necessidade de nutrientes ocorreu durante o florescimento com absorção de $K$ aumentando até a maturação dos frutos. Variedades altamente produtivas foram caracterizadas por um teor de nutrientes relativamente alto nos pecíolos e nos limbos. Em vinhedos estabelecidos em solo chernozem calcário, o teor relativo de $\mathrm{K}$ declinou levemente durante a maturação dos frutos enquanto em chernozem lixiviado, o teor de $\mathrm{K}$ nas videiras permaneceu alto.

Kosma et al. (1969) observaram que não houve efeitos significativos no conteúdo de NPK das folhas de videiras sob diferentes 
sistemas de condução. Os autores também observaram que com o envelhecimento das folhas, os teores de N, P e K da matéria seca sempre declinaram. Os autores concluíram que os teores foliares de NPK diferiram nas variedades estudadas sendo que os de $\mathrm{N}$ e $\mathrm{P}$ foram elevados na variedade Riesling Itálico e o teor de $\mathrm{K}$ foi mais baixo na variedade Zinfandel.

Alexander \& Woodham (1970) estudaram a composição química dos diferentes tecidos foliares de videira cultivar Sultana cultivada em soluções nutritivas deficientes em macronutrientes para a escolha dos tecidos de amostragem, com a finalidade de diagnóstico nutricional. Foi verificado que o tecido mais satisfatório para o diagnóstico das deficiências de $\mathrm{P}, \mathrm{K}, \mathrm{Ca}$ e $\mathrm{Mg}$ pareceu ser o peciolo das folhas basais. Concentrações de $0,1 \% \mathrm{P}, 0,8 \% \mathrm{~K}$, 05\% Ca e 0,2\% Mg nesse tecido foram associados com o começo dos sintomas de deficiência.

Honda et al. (1971), no Japão, determinaram os teores médios de macronutrientes nas folhas de videiras de 28 vinhedos do cultivar Muscat Bailey $A$ cujos valores foram $2,16-2,63 \%$ de $N, 0,12-0,15 \%$ de $P, 1,52-$ $1,53 \%$ de $\mathrm{K}, 1,07-1,77 \%$ de Ca e 0,19-0,33\% de Mg.

Shikhamany \& Satyanarayana (1971) estudando relações de nutrientes no pecíolo e limbo de videira 'Anab-e-Shahi', obtiveram correlações positivas para $\mathrm{N}, \mathrm{Mg}, \mathrm{P}$ e $\mathrm{Ca}$. Observaram também que, quando os niveis de $\mathrm{P}$, $\mathrm{K}, \mathrm{Ca}$ e Mg do limbo atingiram 0,$19 ; 0,65 ; 0,8$ e 0,323\%, respectivamente, outras quantidades desses mesmos nutrientes se acumularam desproporcionalmente nos peciolos.

Gonzalo et al. (1973) estudando as variações estacionais normais do teor de nutrientes minerais nos limbos e peciolos de folhas opostas aos cachos da videira cultivar Semillon (Vitis vinifera L.) nos vinhedos de Macul, em Santiago do Chile, encontraram as seguintes variações em diferentes épocas de coleta de amostras: $1,4-3,4 \%$ de $\mathrm{N} ; 0,09-0,25 \%$ de $\mathrm{P} ; 0,56-1,14 \%$ de $\mathrm{K}$; 0,5 - 1,0\% de Mg; 1,0 - 3,3\% de Ca; 45-98 ppm de Mn; 12 ppm de Cu e 20 ppm 
de $\mathrm{Zn}$ para os limbos, e $0,04-0,23 \%$ de $\mathrm{P} ; 0,6$ - 2,0\% de $\mathrm{K} ; 0,33-1,2 \%$ de $\mathrm{Mg}$; 1,0 - 3,0\% de Ca; 24 - 48 ppm de $\mathrm{Mn} ; 5$ - 12 ppm de Zn para os pecíolos.

Cummings (1977) estudando a variação na concentração de certos elementos em folhas de uva muscadínias em relação a época, porção e idade da folha, realizou análises de margens, nervuras centrais e pecíolos de folhas jovens e maduras, amostradas em 6 intervalos de 3 semanas cada, verificando que as concentrações de $\mathrm{P}, \mathrm{K}, \mathrm{Ca}, \mathrm{Mg}, \mathrm{Cu}$ e $\mathrm{Zn}$ foram mais elevadas no peciolo que no limbo foliar. A variação sazonal foi evidente para todos os elementos analisados, mas a inclinação das curvas para um dado elemento nas diferentes partes da folha foi freqüentemente diferente, sendo que, em todos os casos, com exceção ao boro, as concentrações dos nutrientes variaram com a idade da folha.

Fregoni (1977) observou, em diversas pesquisas, que os niveis ótimos de $B$ foram $20-25$ ppm para folhas, 30 ppm para pecíolos, 20 ppm para os ápices dos ramos e $1 \mathrm{ppm}$ para o mosto.

Atalay (1978) estudou as relações entre o pecíolo e o limbo foliar para a determinação do estado nutricional dos vinhedos em relação aos nutrientes fósforo e zinco. Encontrou-se correlações significativas entre o teor de $\mathrm{P}$ e $\mathrm{Zn}$ nos peciolos e nos limbos. Equações de regressão mostraram que $0,215 \%$ de $\mathrm{P}$ e $43 \mathrm{ppm}$ de $\mathrm{Zn}$ foram os teores iguais no limbo e no pecíolo. Em vinhedos com alto teor de $\mathrm{P}$ e $\mathrm{Zn}$ no solo o teor de $\mathrm{P}$ foi maior no pecíolo do que no limbo; já o teor de $\mathrm{Zn}$ foi maior no limbo do que no pecíolo. $\mathrm{O}$ contrário ocorreu onde as reservas de $\mathrm{P}$ e $\mathrm{Zn}$ no solo eram baixas.

Bertoni \& Morard (1982), citados por Guilherme (1995), em estudo com o cultivar Chasselas, determinaram que o conteúdo de $\mathrm{N}$ dos limbos foliares foi duas vezes maior que o dos peciolos, enquanto que para $\mathrm{P}, \mathrm{K}, \mathrm{Mg}$ e $\mathrm{Ca}$, os valores para limbo e pecíolo foram similares. Segundo os autores os efeitos da localidade e época de amostragem no teor de $\mathrm{P}$ e $\mathrm{K}$ foram, porém, melhor refletidas pela análise do pecíolo do que do limbo, de forma que as 
análises de peciolo e limbo poderiam ser usadas para complementarem uma a outra.

Os mesmos autores também examinaram a folha oposta ao $1^{\circ}$ cacho de uva no florescimento e na maturação de plantas cultivar Chasselas, em vinhedos do sudoeste da França, com grande variação na produção e qualidade, obtendo os seguintes teores médios de nutrientes, conforme o órgão da planta:

\begin{tabular}{|l|c|c|c|c|c|}
\hline & N\% & P\% & K\% & Ca\% & Mg\% \\
\hline \multicolumn{5}{|c|}{ FLORESCIMENTO } \\
\hline Folha inteira & $2,4-4,6$ & $0,15-0,43$ & $0,69-1,67$ & $0,8-2,5$ & $0,13-0,38$ \\
\hline Limbo & $2,7-5,3$ & $0,16-0,27$ & $0,06-1,43$ & $0,9-2,7$ & $0,10-0,36$ \\
\hline Pecíolo & $0,8-2,2$ & $0,13-0,35$ & $0,65-3,44$ & $0,7-1,7$ & $0,23-0,76$ \\
\hline & \multicolumn{6}{|c|}{ AMADURECIMENTO } \\
\hline Folha inteira & $1,3-2,6$ & $0,12-0,32$ & $0,38-1,78$ & $1,3-3,5$ & $0,16-0,63$ \\
\hline Limbo & $1,4-2,9$ & $0,13-0,27$ & $0,42-1,35$ & $1,3-3,5$ & $0,11-0,43$ \\
\hline Pecíolo & $0,6-1,5$ & $0,08-0,56$ & $0,20-2,96$ & $1,2-3,1$ & $0,55-1,71$ \\
\hline
\end{tabular}

Os autores concluiram que em condições homogêneas (mesmo cultivar e clima), flutuações consideráveis foram devido ao tipo de solo, período de amostragem e época, de modo que niveis de referência não poderiam ser recomendados, mas ambas as análises, de pecíolo e limbo, poderiam ser usadas para complementar à outra.

Hiroce e Terra (1983) determinaram os teores médios de macronutrientes no pecíolo e limbo da $6^{\mathrm{a}}$ folha a partir do ápice dos ramos da videira 'Niagara Rosada' e observaram a existência de variações das concentrações nos dois tecidos: 


\begin{tabular}{|l|c|c|}
\hline Nutriente & Pecíolo \% & Limbo \% \\
\hline $\mathrm{N}$ & 1,71 & 4,87 \\
$\mathrm{P}$ & 0,63 & 0,62 \\
$\mathrm{~K}$ & 7,12 & 3,29 \\
$\mathrm{Ca}$ & 1,24 & 1,65 \\
$\mathrm{Mg}$ & 0,45 & 0,32 \\
$\mathrm{~S}$ & 0,16 & 0,29 \\
\hline
\end{tabular}

Kovanci \& Atalay (1987) observaram que plantas de videira cultivar Thompson Seedless, desenvolvidas em soluções nutritivas com baixos niveis de $P, \circ$ peciolo apresentou menos $P$ que $\circ$ limbo, porém em niveis adequados ou em excesso o teor de $P$ no pecíolo foi maior que no limbo e 0 peciolo refletiu o teor de $\mathrm{P}$ na planta melhor que o limbo.

Atalay (1988) realizou experimentos com videira cultivar Thompson Seedless desenvolvidas em solução nutritiva com 16 niveis de fósforo variando de 0 a $150 \mathrm{ppm}$. As amostragens de limbo e pecíolo foram realizadas durante o desenvolvimento dos frutos concluindo que nos niveis baixos de $P$ na solução (< 40 ppm de $P$ aplicado), os teores de fósforo nos pecíolos foram mais baixos que nos limbos e nos niveis adequados a altos (>40 ppm de $\mathrm{P}$ ), os teores de fósforo nos peciolos foram maiores que nos limbos.

Ahmed (1989) amostrou limbos e pecíolos de 30 vinhedos do cultivar Anab-e-Shahi a fim de determinar uma possivel relação entre os dois tecidos para diagnose nutricional. Observou-se que os peciolos continham mais $\mathrm{P}, \mathrm{K}, \mathrm{Ca}, \mathrm{Mg}, \mathrm{Zn}$ e $\mathrm{Fe}$, enquanto que os limbos continham mais $\mathrm{N}$. Os teores peciolares de todos os macros e micronutrientes estudados foram positivamente correlacionados com os teores no limbo desses nutrientes. 
Kannenberg (1990), trabalhando com vinhedos do cultivar Gütedel, analisou pecíolos coletados no florescimento, na fase de amolecimento dos frutos e 10 dias antes da colheita, e definiu o teor foliar ótimo de $\mathrm{N}$ variando entre 2,25 e $2,55 \%$.

Terra et al. (1993) relatam que os teores considerados adequados para videira na folha (limbo + pecíolo), no limbo e no pecíolo separadamente e em duas épocas (florescimento e início do amolecimento das bagas) são:

\begin{tabular}{llccc}
\hline Época & Nutriente & Folha & Pecíolo & Limbo \\
\hline Florescimento & N\% & 3,20 & 1,50 & 3,00 \\
& P\% & 0,27 & 0,26 & 0,27 \\
& K\% & 1,80 & 2,50 & 0,85 \\
& Ca\% & 1,60 & 1,24 & 1,45 \\
& Mg\% & 0,50 & 0,45 & 0,32 \\
S\% & 0,35 & 0,16 & 0,29 \\
& B ppm & 50 & 40 & 40 \\
& Cu ppm & 20 & 25 & 25 \\
& Fe ppm & 100 & 100 & - \\
& Mn ppm & 70 & 50 & 70 \\
& Zn ppm & 32 & 35 & 25 \\
\hline
\end{tabular}

\begin{tabular}{llccc}
\hline Época & Nutriente & Folha & Pecíolo & Limbo \\
\hline Início & $\mathrm{N} \%$ & 1,95 & 1,10 & 2,20 \\
amolecimento & $\mathrm{P} \%$ & 0,22 & 0,22 & 0,20 \\
das bagas & $\mathrm{K} \%$ & 1,10 & 2,00 & 0,80 \\
& $\mathrm{Ca} \%$ & 1,30 & 1,30 & 1,45 \\
& Mg\% & 0,40 & 0,35 & 0,27 \\
& S\% & 0,22 & 0,13 & 0,20 \\
& $\mathrm{~B} \mathrm{ppm}$ & 30 & 30 & 30 \\
& Cu ppm & 14 & 10 & 12 \\
& Fe ppm & 60 & 60 & 60 \\
& Mn ppm & 30 & 20 & 30 \\
& Zn ppm & 20 & 20 & 20 \\
\hline
\end{tabular}




\subsection{Sistema Integrado de Diagnose e Recomendação (DRIS)}

O DRIS foi originalmente proposto por Beaufils (1973) como modelo para identificação de fatores limitantes de produtividade. Entretanto, com o tempo, tem-se mostrado muito mais eficiente como uma forma de interpretação de análise de planta do que como modelo de produtividade agrícola (Bataglia, 1989).

Beaufils (1973) considerou que a produtividade e a qualidade de uma cultura particular constituem a resposta da planta a vários estímulos do ambiente e não só diretamente do estímulo provocado, conforme representação esquemática a seguir:

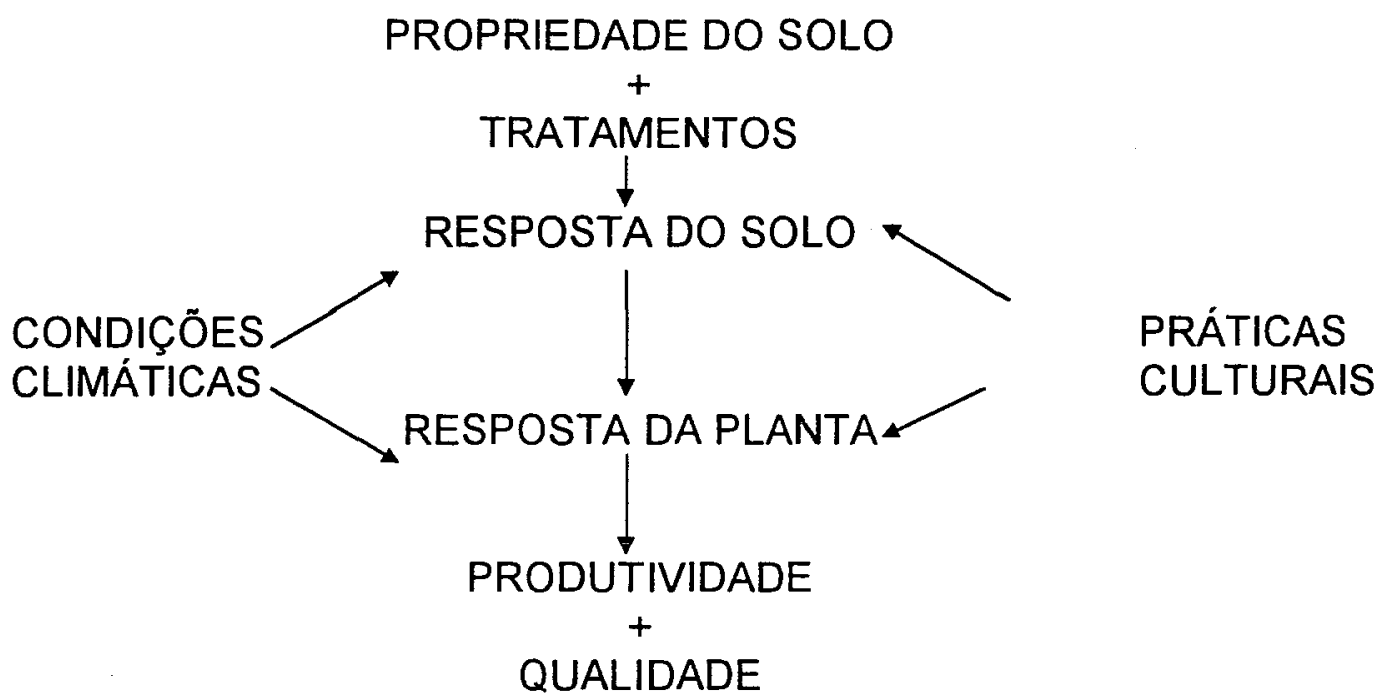

Beaufils (1973) relata ainda que a aplicação desse sistema inclui a seleção da população normal (população B), que passa pela classificação das plantas observadas em, não anormais e anormais, sendo que:

- Plantas não anormais são aquelas que não foram afetadas por condições adversas. 
- Plantas anormais são aquelas que foram afetadas por condições adversas.

Beaufils (1973) afirma que a seleção da população não anormal é baseada em condições vegetativas e produção, sendo o princípio usado na seleção, ilustrado esquematicamente a seguir:

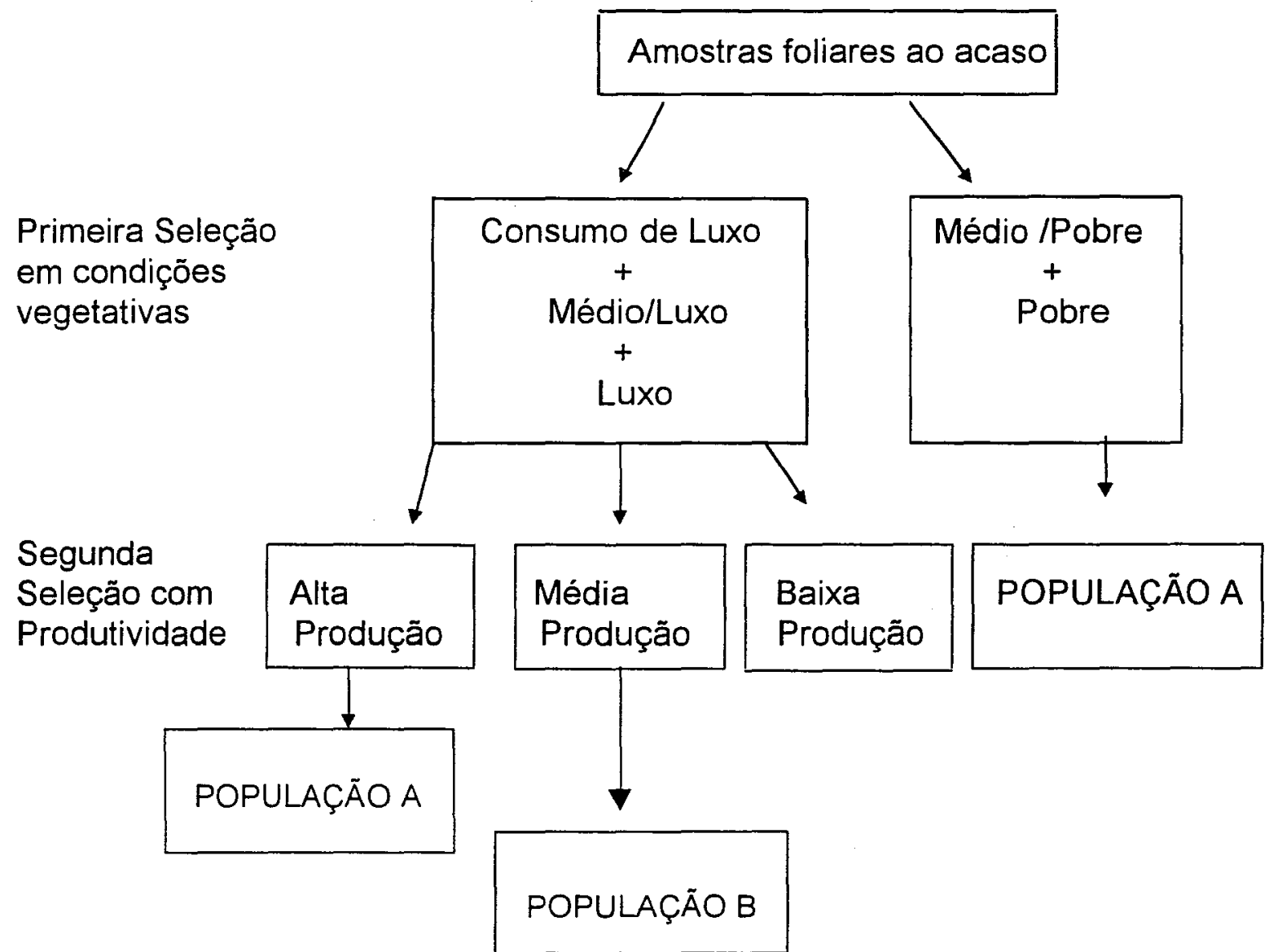

Meyer (1975) trabalhando com cana-de-açúcar na África do Sul, observou efeito significativo da posição da folha na planta, da idade e da época de coleta das amostras e efetivo efeito varietal sobre o DRIS, encontrando melhor diagnóstico da deficiência de $P$ quando analisou, através das relações $\mathrm{N} / \mathrm{P}, \mathrm{K} / \mathrm{P}$ e dos índices de Beaufils, do que simplesmente pelo teor de $\mathrm{P}$ na matéria seca. 
Sumner \& Beaufils (1975), em ensaios desenvolvidos na África do Sul com cana-de-açúcar, observaram que o DRIS poderia ser aplicado independentemente da idade da cultura, da flutuação sazonal e do regime interno de umidade, já que a ordem da necessidade em nutrientes do $1^{\circ}$ ao $10^{\circ}$ mês de idade permaneceu inalterada e foi a seguinte: $P>K>N$. No mesmo trabalho, os autores encontraram certa independência do DRIS com relação à variedade.

Sumner (1977), estudando o DRIS para a cultura do milho, apresentou conclusões onde esta técnica poderia ser aplicada em qualquer estádio de desenvolvimento e sob quaisquer condições.

Sumner (1977a) aplicou o DRIS para a cultura do trigo e observou a validade de sua interpretação independente da variedade utilizada e da idade da planta na época da amostragem foliar.

Sumner (1978) observou o DRIS na cultura da soja e sua independência da variedade, idade da planta na época da amostragem e posição da folha da mesma.

Sumner (1978) concluiu que o DRIS estuda os fatores contribuintes que afetam a produção, resultando em uma calibração da composição do solo e da planta em relação a produtividade. Esta calibração é feita através de índices que avaliam quanto o indice de um determinado nutriente dista do seu ótimo, e, assim, são ordenados os nutrientes segundo sua limitação para a produtividade. Esses índices também indicam o grau em que o solo ou a planta necessitam de um determinado nutriente, considerando automaticamente o equilíbrio de nutrientes na planta.

Zambello Jr. \& Orlando Filho (1979) aplicaram a metodologia do DRIS para a cultura da cana-de-açúcar e verificaram o efeito varietal, sobre os indices.

Zambello Jr. \& Orlando Filho (1980) concluiram que o DRIS pode ser aplicado independente do estado de umidade em que se encontra a cana- 
planta pois esta técnica adaptou-se tanto para a cultura sob regime de irrigação como quando sob as condições normais de precipitação.

Zambello Jr. \& Orlando Filho (1980a) estudaram o DRIS em canade-açúcar, utilizando folhas e internódios, e constataram que a metodologia apresentou-se bastante promissora, embora tenha sido observado que a sensibilidade da técnica reside em parte no elevado número de dados e na vasta experiência e perspicácia do individuo que irá executar as interpretações, principalmente na seleção da população não normal; pois é esta que proporcionará o diagrama interpretativo do balanço nutricional e dos índices primários.

O método DRIS apresentou vantagens sobre o nivel crítico foliar e o nível crítico de solos, quando utilizado em diagnoses com propósito de recomendação de adubação (Escano et al. 1981; Jones, 1981; Jones \& Bowen, 1981; Hanson, 1981; Jones et al., 1986; Walworth \& Sumner, 1987) com as observações:

a) para se fazer diagnose considerasse $o$ equilíbrio nutricional com base em padrões nutricionais de referência ou normas. Isto é particularmente importante em altos níveis de produção, em que o equilibrio nutricional é muitas vezes o fator mais importante e crítico na determinação da produtividade vegetal;

b) as normais, ou composição de referência para o equilibrio nutricional de uma determinada cultura podem ser extrapoladas para diversas regiōes do pais;

c) pode-se fazer diagnoses em diferentes fases de desenvolvimento vegetal independente do cultivar; 
d) os nutrientes limitantes da produção, tanto por deficiência quanto por excesso, podem ser prontamente identificados e ordenados em função de sua importância na limitação da produtividade.

Bataglia \& Dechen (1986) comentaram que as relações de nutrientes em tecidos vegetais tem sido bastante utilizadas em muitos trabalhos, ajudando nos estudos de desbalanço nutricional em culturas, e que em alguns trabalhos têm encontrado boa correlação entre a relação de nutrientes e a produção, enquanto em outros tem tido pouco sucesso. Dessa maneira, o DRIS procura esclarecer essa controvérsia. As relações entre nutrientes não são muito usadas na diagnose foliar, mas se constituem no mecanismo básico para o estabelecimento dos critérios de interpretação pelo DRIS.

Schaller (1988) verificou a superioridade do DRIS para análise foliar em videiras.

Goh \& Malakouti (1992) recomendaram como melhor período de amostragem de folhas de 3 a 5 meses depois do florescimento, em um estudo de DRIS em macieiras.

Malavolta et al. (1997) relataram que a análise de nutrientes em material vegetal de um determinado órgão e estádio fenológico tem sido utilizada para avaliar o estado nutricional das plantas, como também na determinação das práticas de adubação. De acordo com o método clássico a interpretação é feita comparando-se os resultados analíticos com parâmetros previamente estabelecidos. 


\section{MATERIAL E MÉTODOS}

Para a realização do levantamento do estado nutricional da videira 'Itália' na região de Jundiaí, SP, foram selecionadas 19 propriedades localizadas a $23^{\circ} 06^{\prime} \mathrm{S}$ e $46^{\circ} 55^{\prime} \mathrm{W}$ e $715 \mathrm{~m}$ de altitude e clima classificado como Cfa.

Os solos predominantes nas propriedades onde foram realizados os experimentos são Latossolos Vermelho-Amarelos.

A escolha das propriedades foi ao acaso, e de cada propriedade foi escolhido um talhão de vinhedo em produção com práticas culturais semelhantes, sendo essas práticas as preconizadas por Terra et al. (1993). Os talhões amostrados apresentavam área média de 0,35ha, com uma média de 230 pés de videira em produção espaçadas de $4 \times 3 \mathrm{~m}$, com idade variando de 4 a 15 anos e enxertadas sobre o porta-enxerto $420-A$.

De cada talhão foram coletadas amostras de solo em 20 pontos e em duas profundidades $(0-20 \mathrm{~cm}$ e $20-40 \mathrm{~cm})$, distante cerca de $2 \mathrm{~m}$ das plantas nas entrelinhas de plantio, com auxílio de um trado do tipo sondaterra. As coletas das amostras foram realizadas antes da poda, em abril-maio de 1991.

Essas amostras foram enviadas ao Laboratório do Departamento de Ciência do Solo da ESALQ/USP, onde foram submetidas às determinações físicas como granulometria e às determinações químicas como $\mathrm{pH}$ em cloreto de cálcio, matéria orgânica, fósforo $(P)$ por resina, potássio $(K)$, cálcio $(\mathrm{Ca})$, 
magnésio $(\mathrm{Mg})$, acidez potencial $(\mathrm{H}+\mathrm{Al})$, capacidade de troca de cátions (CTC), saturação de bases $(\mathrm{V} \%)$, boro $(\mathrm{B})$, cobre $(\mathrm{Cu})$, ferro $(\mathrm{Fe})$, manganês $(\mathrm{Mn})$ e zinco $(\mathrm{Zn})$.

De cada talhão foram escolhidas 20 plantas ao acaso, das quais foram coletadas 5 folhas por planta, num total de 100 folhas por talhão, que formaram uma amostra. As folhas colhidas foram as mais recém-maduras de cada ramo produtivo, e foram imediatamente separadas em pecíolos e limbos para análise, formando assim amostras distintas.

Cada coleta de folhas foi feita em três épocas distintas de desenvolvimento da planta: no florescimento, onde ocorre um pico de concentração da maioria dos nutrientes nos tecidos; quando as bagas se encontravam na fase entre ervilha e meia baga e no início da troca de cor das bagas, quando há maior estabilidade nos teores de nutrientes, permitindo assim maior amplitude da época de coleta (Dal Bó et al., 1989).

As amostras de limbos e peciolos foram enviadas ao Laboratório de Análises do Departamento de Ciência do Solo da ESALQ/USP, onde após o seu devido preparo, foram submetidas às determinações dos seguintes nutrientes: $\mathrm{N}, \mathrm{P}, \mathrm{K}, \mathrm{Ca}, \mathrm{Mg}, \mathrm{S}, \mathrm{B}, \mathrm{Fe}, \mathrm{Cu}, \mathrm{Mn}, \mathrm{Zn}$.

Os dados da produção, para cada talhão amostrado foram obtidos através de informações criteriosas do produtor e embasada em uma avaliação estimada da produção, realizada anteriormente à colheita.

A interpretação dos resultados de análise foliar, considerando-se a relação de nutrientes no limbo e no peciolo e a produção da videira, foi feita aplicando-se o método DRIS (Sistema Integrado de Diagnose e Recomendação), que é um esquema geral para experimentação e calibração baseados em princípios desenvolvidos em pesquisas de fertilidade do solo e nutrição de plantas e é, uma extensão da técnica de diagnose fisiológica (Beaufils, 1973; Bataglia \& Dechen, 1986; Zambello Jr., 1979 e Leite, 1993). 
Para o cálculo dos indices do DRIS, separaram-se os vinhedos em duas classes:

1) População A - alta produtividade ( $\geq$ que 20,0 t de uva/ha) e 2) População B baixa produtividade (< que 20,0 t de uva/ha), onde o valor 20,0 t de uva/ha é a média de produção encontrada entre os vinhedos amostrados e considerada alta para a cultura da videira na região.

Para a população de alta produtividade (População A), calculouse as relações, entre todos os nutrientes analisados, dois a dois, e para cada relação calculou-se a média (M), variação (V), desvio padrão (SD) e coeficiente de variação (CV).

Com as normas assim estabelecidas, calculou-se os indices DRIS e os indices de balanço nutricional (IBN) de acordo com a metodologia descrita por Bataglia \& Dechen (1986) desenvolvida por Beaufils (1973), utilizando-se as seguintes fórmulas:

Indice $X=\frac{\sum\left[f\left(\frac{X}{A}\right)_{1} \frac{K}{\operatorname{cV}(X / A)}+f\left(\frac{X}{B}\right)_{2} \frac{K}{\operatorname{cV}(X / B)}+\cdots+f\left(\frac{X}{Z}\right)_{n} \frac{K}{\operatorname{CV}(X / Z)}\right]-\sum\left[f\left(\frac{a}{X}\right)_{1} \frac{K}{\operatorname{cV}(a / X)}+f\left(\frac{b}{X}\right)_{2} \frac{K}{\operatorname{cV}(b / X)}+\cdots+f\left(\frac{z}{X}\right)_{m} \frac{k}{\operatorname{cV}(z / X)}\right]}{n+m}$

$\mathrm{IBN}=\Sigma[$ índice $\mathrm{X}]$ em valores absolutos

onde

$A, B, \ldots Z$ e $a, b, \ldots z$ representam qualquer concentração de nutrientes possiveis de diagnose.

CV é o coeficiente de variação da relação na população não anormal

Ké o coeficiente de sensibilidade, de valor arbitrário $(1,10,20 \ldots)$

$X / A, X / B, \ldots X / Z$ são as relações dos nutrientes na amostra

$$
\begin{aligned}
& n=\sum \frac{X}{A}+\frac{X}{B}+\cdots+\frac{X}{Z} \\
& m=\sum \frac{a}{X}+\frac{b}{X}+\cdots+\frac{z}{X}
\end{aligned}
$$


Os dezenove vinhedos foram denominados de JUN 01 a JUN 19, sendo escolhidos para os cálculos dos índices DRIS os vinhedos JUN 04, JUN 15, JUN 16, JUN 17 e JUN 18, com produtividades iguais ou superiores a $20 \mathrm{t} / \mathrm{ha}$. 


\section{RESULTADOS E DISCUSSĀO}

\subsection{Solos}

\subsubsection{Granulometria}

As análises granulométricas das amostras de solos dos vinhedos encontram-se nas Tabelas 1 e 2 . Verifica-se que $89 \%$ dos solos, nas duas profundidades amostradas $(0-20 \mathrm{~cm}, 20-40 \mathrm{~cm})$ encontrava-se nas classes texturais argilosa e muito argilosa. A granulometria indica a proporção de argila, silte e areia presentes no solo. Nesses solos, as propriedades físicoquímicas são afetadas pelos altos teores de argila e conseqüentemente afetam o manejo. A alta atividade físico-química da fração argila, decorrente da alta superfície específica, significa alta capacidade de retenção de cátions, de água e de adsorção de fósforo. Os minerais de argila e a matéria orgânica apresentam cargas elétricas negativas responsáveis pela importante propriedade de troca de cátions. Os óxidos hidratados de ferro e alumínio têm elevada capacidade de adsorção de fósforo e apresenta um caráter anfótero com relação aos íons.

As análises granulométricas deste trabalho são semelhantes às de Gergoletti (1995), estudando vinhedos da região de São Miguel Arcanjo, SP. 
Tabela 1 - Resultados das análises granulométricas de solo para os vinhedos amostrados, profundidade de $0-20 \mathrm{~cm}$ em levantamento nutricional na região de Jundiaí, ano de 1991.

\begin{tabular}{|c|c|c|c|c|c|c|c|}
\hline \multirow{2}{*}{$\begin{array}{l}\text { VINHEDOS } \\
\text { profundidade } \\
(0-20 \mathrm{~cm})\end{array}$} & \multicolumn{3}{|c|}{ Areia $(\%)^{\star}$} & \multirow{2}{*}{$\begin{array}{c}\text { Silte } \\
\%\end{array}$} & \multirow{2}{*}{$\begin{array}{c}\text { Arg. } \\
\%\end{array}$} & \multirow{2}{*}{$\begin{array}{c}\text { Classe } \\
\text { de } \\
\text { Textura** }\end{array}$} & \multirow{2}{*}{$\begin{array}{c}\text { Produção } \\
\text { t/ha }\end{array}$} \\
\hline & $G$ & $F$ & $G+F$ & & & & \\
\hline JUN-01 & 36 & 18 & 54 & 09 & 37 & arg. & 18 \\
\hline JUN-02 & 37 & 21 & 58 & 11 & 31 & md. arg. & 19 \\
\hline JUN-03 & 40 & 16 & 56 & 12 & 32 & md. arg. & 18 \\
\hline JUN-04 & 21 & 05 & 26 & 10 & 64 & m. arg. & 21 \\
\hline JUN-05 & 20 & 13 & 33 & 11 & 56 & arg. & 18 \\
\hline JUN-06 & 18 & 09 & 27 & 11 & 62 & m.arg. & 17 \\
\hline JUN-07 & 20 & 08 & 28 & 10 & 62 & m.arg. & 19 \\
\hline JUN-08 & 22 & 09 & 31 & 10 & 59 & arg. & 18 \\
\hline JUN-09 & 20 & 11 & 31 & 11 & 58 & arg. & 17 \\
\hline JUN-10 & 31 & 21 & 52 & 10 & 38 & arg. & 16 \\
\hline JUN-11 & 27 & 15 & 42 & 14 & 44 & arg. & 17 \\
\hline JUN-12 & 22 & 12 & 34 & 06 & 60 & m.arg. & 18 \\
\hline JUN-13 & 26 & 15 & 41 & 06 & 53 & arg. & 19 \\
\hline JUN-14 & 31 & 18 & 49 & 06 & 45 & arg. & 17 \\
\hline JUN-15 & 35 & 15 & 50 & 05 & 45 & arg. & 34 \\
\hline JUN-16 & 21 & 10 & 31 & 06 & 63 & m.arg. & 35 \\
\hline JUN-17 & 28 & 34 & 62 & 06 & 32 & md.arg. & 20 \\
\hline JUN-18 & 36 & 14 & 50 & 08 & 42 & arg. & 20 \\
\hline JUN-19 & 34 & 16 & 50 & 09 & 41 & arg. & 18 \\
\hline
\end{tabular}

*Areia: $\quad G=$ grossa $F=$ fina

**Textura: arg. = argilosa $\mathrm{md}$. arg. = média argilosa m. arg. = muito argilosa 
Tabela 2 - Resultados das análises granulométricas de solo para os vinhedos amostrados, profundidade de $(20-40 \mathrm{~cm})$ em levantamento nutricional na região de Jundiaí, ano de 1991.

\begin{tabular}{|c|c|c|c|c|c|c|c|}
\hline \multirow{2}{*}{$\begin{array}{l}\text { VINHEDOS } \\
\text { profundidade } \\
(20-40 \mathrm{~cm})\end{array}$} & \multicolumn{3}{|c|}{ Areia $(\%)^{\star}$} & \multirow{2}{*}{$\begin{array}{c}\text { Silte } \\
\%\end{array}$} & \multirow{2}{*}{$\begin{array}{c}\text { Arg. } \\
\%\end{array}$} & \multirow{2}{*}{$\begin{array}{c}\text { Classe } \\
\text { de } \\
\text { Textura** }\end{array}$} & \multirow{2}{*}{$\begin{array}{c}\text { Produção } \\
\text { t/ha }\end{array}$} \\
\hline & $G$ & $F$ & $G+F$ & & & & \\
\hline JUN-01 & 37 & 15 & 52 & 08 & 40 & arg. & 18 \\
\hline JUN-02 & 38 & 20 & 58 & 13 & 29 & md. arg. & 19 \\
\hline JUN-03 & 33 & 17 & 50 & 11 & 39 & arg. & 18 \\
\hline JUN-04 & 21 & 07 & 28 & 10 & 62 & m. arg. & 21 \\
\hline JUN-05 & 18 & 12 & 30 & 11 & 59 & arg. & 18 \\
\hline JUN-06 & 18 & 08 & 26 & 11 & 63 & m.arg. & 17 \\
\hline JUN-07 & 21 & 08 & 29 & 12 & 59 & arg. & 19 \\
\hline JUN-08 & 20 & 09 & 29 & 12 & 59 & arg. & 18 \\
\hline JUN-09 & 19 & 09 & 28 & 11 & 61 & m.arg. & 17 \\
\hline JUN-10 & 31 & 16 & 47 & 10 & 43 & arg. & 16 \\
\hline JUN-11 & 23 & 14 & 37 & 15 & 48 & arg. & 17 \\
\hline JUN-12 & 22 & 14 & 36 & 05 & 59 & arg. & 18 \\
\hline JUN-13 & 24 & 13 & 37 & 07 & 56 & arg. & 19 \\
\hline JUN-14 & 29 & 16 & 45 & 06 & 49 & arg. & 17 \\
\hline \begin{tabular}{|l|} 
JUN-15 \\
\end{tabular} & 30 & 14 & 44 & 06 & 50 & arg. & 34 \\
\hline JUN-16 & 19 & 08 & 27 & 05 & 68 & m.arg. & 35 \\
\hline JUN-17 & 32 & 16 & 48 & 07 & 45 & arg. & 20 \\
\hline \begin{tabular}{|l|} 
JUN-18 \\
\end{tabular} & 30 & 13 & 43 & 07 & 50 & arg. & 20 \\
\hline JUN-19 & 38 & 13 & 51 & 10 & 39 & arg. & 18 \\
\hline
\end{tabular}

*Areia: G=grossa

$F=$ fina

** Textura: arg. = argilosa $\mathrm{md}$. arg. = média argilosa m.arg. = muito argilosa 


\subsubsection{Macronutrientes}

Os resultados das análises químicas de solos para as profundidades de $0-20 \mathrm{~cm}$ e $20-40 \mathrm{~cm}$ encontram-se nas Tabelas 3 e 4 . Observa-se que $\mathrm{opH}$ em $\mathrm{CaCl}_{2}$ a $0,01 \mathrm{M}$ variou de 4,4 a 5,9 para a profundidade de $0-20 \mathrm{~cm}$ e de 3,9 a 5,7 para a profundidade de $20-40 \mathrm{~cm}$. A acidez potencial $(\mathrm{H}+\mathrm{Al})$ para a profundidade de $0-20 \mathrm{~cm}$ variou de 1,8 a $5,2 \mathrm{e}$ para $20-40 \mathrm{~cm}$ de 2,0 a $8,0 \mathrm{meq} / 100 \mathrm{~cm}^{3}$ de solo seco ao ar. A soma de bases (SB) variou de 3,2 a $7,6 \mathrm{meq} / 100 \mathrm{~cm}^{3}$ de solo seco ao ar e de 1,3 a 5,0 meq $/ 100 \mathrm{~cm}^{3}$ para as profundidades de $0-20$ e $20-40 \mathrm{~cm}$, respectivamente. A capacidade de troca de cátions (CTC) variou de 6,4 a $9,8 \mathrm{meq} / 100 \mathrm{~cm}^{3}$ e de 4,7 a $9,6 \mathrm{meq} / 100 \mathrm{~cm}^{3}$ para as profundidades de $0-20 \mathrm{~cm}$ e $20-40 \mathrm{~cm}$, respectivamente. A porcentagem de saturação de bases $(V \%)$ na profundidade de $0-20 \mathrm{~cm}$ variou de 38 a $81 \%$ e de $20-40 \mathrm{~cm}$ de 17 a $68 \%$. A porcentagem de matéria orgânica na profundidade de $0-20 \mathrm{~cm}$ variou de 2,1 a $3,4 \%$ e para 20 $40 \mathrm{~cm}$ de 1,6 a $2,9 \%$. O teor de fósforo para a profundidade de $0-20 \mathrm{~cm}$ variou de 24 a $342 \mu \mathrm{g} / \mathrm{cm}^{3}$ de solo seco ao ar e de $20-40 \mathrm{~cm}$ foi de 4 a $187 \mu \mathrm{g} / \mathrm{cm}^{3}$. O potássio variou de 0,11 a 0,43 e de 0,10 a $0,33 \mathrm{meq} / 100 \mathrm{~cm}^{3}$ de solo seco ao ar para as profundidades de $0-20 \mathrm{~cm}$ e $20-40 \mathrm{~cm}$, respectivamente.

O teor de cálcio para 0-20 e $20-40 \mathrm{~cm}$ variou de 2,0 a 5,4 e de 0,7 a $3,5 \mathrm{meq} / 100 \mathrm{~cm}^{3}$ de solo seco ao ar respectivamente. O teor de magnésio para a profundidade de $0-20 \mathrm{~cm}$ variou de 0,9 a $2,3 \mathrm{meq} / 100 \mathrm{~cm}^{3}$ de solo seco ao ar e de 0,4 a $1,3 \mathrm{meq} / 100 \mathrm{~cm}^{3}$ para a profundidade de $20-40 \mathrm{~cm}$.

O Quadro 1, extraído de Trani \& Drugowich (1989), foi utilizado para interpretar os resultados das análises de solo relativas a macronutrientes, mostrados na Tabela 5. 


\begin{tabular}{|c|c|c|c|c|c|c|c|c|c|c|c|c|c|c|c|c|c|c|c|c|c|}
\hline कृ & $\bar{N}$ & & $\infty$ & 6 & 志 & $1 \infty$ & $\sigma$ & 10 & 10 & 5 & $\infty$ & $1 ㅇ$ & $\approx$ & $r$ & os & or & $\bar{N}$ & $N$ & $\nabla$ & 100 & $\approx$ \\
\hline$\frac{E}{\bar{D}}-$ & 竞 & & 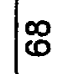 & $R$ & $\stackrel{2}{2}$ & 曲 & \& & $\mathscr{B}$ & م & W & \& & in & 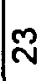 & $\stackrel{\infty}{\infty}$ & $\widetilde{N}$ & I & $\mid \begin{array}{l}\infty \\
q\end{array}$ & $\hat{m}$ & 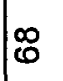 & ष & $\widehat{0}$ \\
\hline 응 뭉 & $L^{\circ}$ & 흥 & 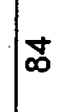 & 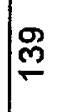 & $\stackrel{\mathscr{P}}{q}$ & N & $\tilde{0}$ & $\tilde{O}$ & 悉 & 政 & 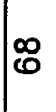 & 뭄 & 策 & $\mathscr{\infty}$ & in & "ષ & 怘 & $\stackrel{0}{0}$ & 占 & 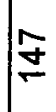 & 守 \\
\hline ○ั & $\overrightarrow{0}$ & & స̃ & $m$ & in & I্ & $\infty$ & $r$ & 10 & 0 & 10 & 0 & $\mp$ & $\infty$ & 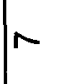 & $r$ & 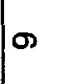 & 100 & $\infty$ & $m$ & $r$ \\
\hline 으 글 & $m$ & & $m$ & $m$ & $m$ & $N$ & m & $m$ & $m$ & $m$ & $m$ & $m$ & $m$ & $m$ & $N$ & $m$ & $m$ & $m$ & - & $N$ & $m$ \\
\hline 电 & $>$ & ○̊ & $R$ & 8 & \$ & 品 & 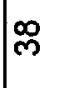 & $\bar{n}$ & $\overline{0}$ & $\infty$ & $\mathscr{0}$ & $\widehat{0}$ & $\mathbb{N}$ & | & $\infty$ & $\infty$ & $\hat{0}$ & $\bar{\emptyset}$ & $\bar{\phi}$ & ठ & $\mathbf{N}$ \\
\hline 寅 & 0 & & $\mid \begin{array}{l}0 \\
\infty\end{array}$ & $\bar{\infty}$ & $\begin{array}{l}0 \\
0 \\
\infty\end{array}$ & 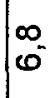 & $\nabla^{+}$ & 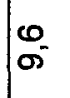 & $\hat{\infty}$ & $\begin{array}{l}\infty \\
\sigma^{-}\end{array}$ & $\nabla^{-}$ & $\stackrel{0}{2}$ & o & 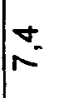 & $\begin{array}{l}n \\
\infty\end{array}$ & m & in & a & 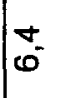 & 0 & $\infty$ \\
\hline 흔 음 & 䍐 & & $\begin{array}{l}\infty \\
0\end{array}$ & $\mid \begin{array}{l}0 \\
6\end{array}$ & $\mid$ & 舟 & m & 舟 & m & $\frac{0}{n}$ & m & $\sigma^{\circ}$ & $\mid \begin{array}{l}n \\
0 \\
0\end{array}$ & $\stackrel{m}{8}$ & i & in & in & $\begin{array}{l}\infty \\
\forall\end{array}$ & $\frac{a}{m}$ & $\begin{array}{l}8 \\
\dot{8}\end{array}$ & \% \\
\hline 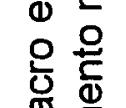 & $\begin{array}{l}\bar{x} \\
\dot{ \pm} \\
\end{array}$ & E & $\stackrel{\infty}{\sim}$ & n & $\bar{m}$ & $\infty$ & in & $\ddot{q}$ & i & $\tilde{N}$ & $\bar{m}$ & in & in & mi & $\infty$ & $\infty$ & no & $\bar{m}$ & no & w & N \\
\hline $\bar{\Phi} \stackrel{\Phi}{\frac{0}{C}}$ & $\sum^{0}$ & 总 & $\bar{i}$ & $\stackrel{\infty}{=}$ & 娄 & $\stackrel{0}{-}$ & o & $\dddot{v}$ & $\stackrel{N}{\sim}$ & m & $\stackrel{0}{-}$ & $\stackrel{m}{=}$ & $\because$ & $\stackrel{\square}{-}$ & o & $\stackrel{9}{=}$ & $=$ & $\stackrel{n}{=}$ & $\stackrel{N}{\simeq}$ & : & 10 \\
\hline .을 & 0 & & in & $\underset{m}{0}$ & $\dot{\forall}$ & o & io & $m$ & $\hat{m}$ & $\begin{array}{l}0 \\
15\end{array}$ & m & m & $\stackrel{0}{\sim}$ & $\infty$ & m & is & $m$ & o & w & $\bar{m}$ & 8 \\
\hline ஹ & $x$ & & $\begin{array}{l}N \\
N \\
0\end{array}$ & $\frac{0}{0}$ & $\frac{9}{0}$ & 足 & 雇 & m & ñ & in & 志 & 果 & $\stackrel{m}{\mathscr{m}}$ & $\overline{0}$ & $\stackrel{N}{0}$ & $\frac{1}{0}$ & $\frac{9}{0}$ & 孚 & $\frac{9}{0}$ & $\mid \begin{array}{l}0 \\
N \\
0\end{array}$ & $\begin{array}{l}\tilde{N} \\
- \\
0\end{array}$ \\
\hline 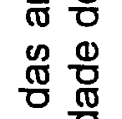 & 0. & 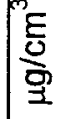 & Ĩ & 志 & 点 & م & 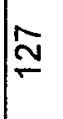 & 禹 & $\stackrel{ \pm}{F}$ & $\underset{N}{N}$ & $\stackrel{+}{0}$ & $\stackrel{\sim}{\sim}$ & $\stackrel{\Xi}{\varpi}$ & 络 & 10 & W & $\bar{\sigma}$ & $\stackrel{\mathscr{N}}{\sim}$ & N & $\stackrel{n}{2}$ & $\stackrel{m}{\sim}$ \\
\hline 吾焉 & $\dot{0}^{\circ}$ & $\alpha^{\circ}$ & $\stackrel{m}{v}$ & $\infty$ & O & a & $m$ & $\dot{m}$ & $m$ & $\bar{m}$ & m & no & $m$ & $m$ & os & $\stackrel{\infty}{\infty}$ & $m$ & $m$ & $\bar{i}$ & $\vec{v}$ & $\stackrel{0}{N}$ \\
\hline$\stackrel{\square}{\mathbb{\Xi}}$ & $\frac{I}{Q}$ & $\overline{\tilde{U}}$ & $\begin{array}{l}\infty \\
\infty\end{array}$ & W & $\overline{6}$ & is & $\dot{\nabla}$ & $\begin{array}{l}\infty \\
\sigma^{-}\end{array}$ & in & $\hat{\omega}$ & $\mid \begin{array}{c}N \\
10\end{array}$ & is & m & $\begin{array}{l}0 \\
15\end{array}$ & 10 & 泉 & $\begin{array}{l}10 \\
150\end{array}$ & $\mid \begin{array}{l}w \\
n^{\circ}\end{array}$ & $\mid$ & m & 咅 \\
\hline$\frac{\pi}{0}$ & 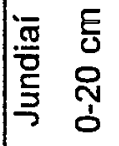 & & $\begin{array}{l}\overline{0} \\
\vdots \\
\vdots \\
\end{array}$ & 贻 & $\mid \begin{array}{l}m \\
0 \\
⿱ 亠 䒑 \\
z \\
\end{array}$ & 吉 & 垈 & $\mid \begin{array}{l}0 \\
1 \\
\vdots \\
\vdots \\
3\end{array}$ & 占 & $\mid \begin{array}{l}\infty \\
0 \\
1 \\
z \\
\\
\end{array}$ & $\mid \begin{array}{l}8 \\
0 \\
⿱ 亠 䒑 \\
\end{array}$ & 旁 & $\frac{\bar{z}}{3}$ & $\frac{N}{z}$ & $\frac{m}{z}$ & $\frac{y}{z}$ & $\frac{n}{2}$ & $\frac{0}{\dot{1}}$ & $\frac{n}{z}$ & $\frac{\infty}{\frac{\infty}{z}}$ & $\frac{0}{\frac{0}{1}}$ \\
\hline
\end{tabular}




\begin{tabular}{|c|c|c|c|c|c|c|c|c|c|c|c|c|c|c|c|c|c|c|c|c|}
\hline $\bar{N}$ & & 9 & $\stackrel{0}{\sigma}$ & 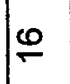 & $\mid \infty$ & os & \pm & $\stackrel{0}{\mathscr{1}}$ & 8 & $\mp$ & กี & 0 & 0 & 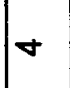 & 0 & m & 0 & N & 0 & م \\
\hline 衣 & & $\stackrel{\infty}{N}$ & 凩 & 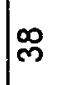 & in & $\cong$ & $\stackrel{2}{2}$ & $\hat{N}$ & ని & g & $\mathbb{N}$ & హ) & $\widehat{m}$ & 夺 & $m$ & $\stackrel{\infty}{=}$ & N & $\approx$ & $\stackrel{\sim}{n}$ & $\stackrel{\infty}{\sim}$ \\
\hline ષا. & 틈 & $\stackrel{N}{\rightleftharpoons}$ & $\frac{0}{i}$ & $\stackrel{\infty}{\stackrel{\infty}{N}}$ & চ্ & $\underset{q}{\infty}$ & $\mp$ & 番 & $\mathscr{8}$ & 18 & $\stackrel{\infty}{\stackrel{\infty}{\circ}}$ & வூ & $\mathscr{\infty}$ & $\infty$ & छे & 心 & $\stackrel{N}{\sim}$ & 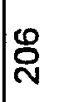 & $\stackrel{\infty}{=}$ & के \\
\hline $\overrightarrow{\mathcal{U}}$ & & $\stackrel{2}{2}$ & $\approx$ & $m$ & $\nabla$ & $\nabla$ & $m$ & 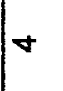 & $\forall$ & $\nabla$ & $N$ & $\nabla$ & in & $\forall$ & 0 & $\nabla$ & $m$ & m & $\nabla$ & $\omega$ \\
\hline $\mathbf{m}$ & & $m$ & $m$ & $m$ & $m$ & $N$ & $\nabla$ & $m$ & $\mathbf{N}$ & $m$ & $m$ & $m$ & $N$ & $m$ & $m$ & $N$ & N & N & $N$ & $N$ \\
\hline$>$ & ○̊ & $\mathscr{m}$ & $\stackrel{\infty}{\sim}$ & 4 & $\bar{m}$ & $\bar{N}$ & $\approx$ & I & \% & I & 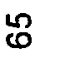 & छ & 歺 & 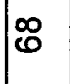 & $\infty$ & $\mathscr{্}$ & $\bar{m}$ & $\bar{m}$ & g & 它 \\
\hline$\frac{0}{0}$ & & $\omega^{-}$ & $\stackrel{v}{*}$ & $\hat{N}$ & $=$ & $\sigma^{\circ}$ & $\begin{array}{l}0 \\
\sigma\end{array}$ & n & $\overline{0}$ & $\begin{array}{l}\infty \\
0\end{array}$ & $\sqrt{5}$ & $\infty$ & $\pi$ & $\underset{\infty}{\sim}$ & 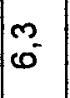 & m & n & $\underset{\dot{f}}{\mathscr{\sigma}}$ & | & 苾 \\
\hline 罗 & & os & $\stackrel{m}{=}$ & n' & $\stackrel{-}{-}$ & $\approx$ & $\stackrel{0}{\sigma}$ & $m$ & $\begin{array}{l}N \\
\dot{v}\end{array}$ & 苜 & $\hat{m}$ & o & $\begin{array}{l}0 \\
\dot{8}\end{array}$ & $\underset{v}{\sim}$ & 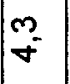 & $\stackrel{\circ}{-}$ & $\stackrel{m}{\infty}$ & $\stackrel{2}{\sim}$ & $\hat{\sim}$ & os \\
\hline $\begin{array}{l}\bar{\alpha} \\
\pm \\
\pm\end{array}$ & $\frac{6}{6}$ & $\infty^{-}$ & m & $\begin{array}{l}N \\
\sigma\end{array}$ & $\stackrel{N}{N}$ & $0^{\circ}$ & $\begin{array}{l}0 \\
\infty\end{array}$ & $\underset{\sim}{N}$ & in & $\begin{array}{l}\infty \\
m\end{array}$ & $\begin{array}{l}\text { o } \\
\text { iv }\end{array}$ & $\begin{array}{l}\infty \\
\sim \\
N\end{array}$ & $\bar{m}$ & i & $\stackrel{0}{N}$ & mi & $\begin{array}{l}N \\
w^{\prime}\end{array}$ & mi & 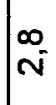 & in \\
\hline$\sum^{\circ}$ & छ् & $0^{\circ}$ & 10 & $\Xi$ & n & 象 & $\begin{array}{l}\Delta \\
0\end{array}$ & $\hat{\sigma}^{-}$ & $\stackrel{m}{=}$ & o & $\Xi$ & $\stackrel{m}{-}$ & $m$ & $\dddot{m}$ & $\stackrel{m}{=}$ & O. & $\begin{array}{l}\infty \\
0 \\
0\end{array}$ & 10 & $\begin{array}{l}0 \\
0\end{array}$ & $\infty$ \\
\hline 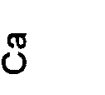 & & $\stackrel{\infty}{-}$ & $\hat{0}^{\circ}$ & m & $=$ & $\sigma^{2}$ & $\begin{array}{l}0 \\
0\end{array}$ & $m$ & $\hat{N}$ & $\stackrel{\infty}{-}$ & $\stackrel{+}{N}$ & m & $\stackrel{0}{N}$ & $\begin{array}{l}\infty \\
\sim \\
\sim\end{array}$ & $\mid \begin{array}{l}a \\
N^{-}\end{array}$ & $\cong$ & $\cong$ & $\sigma^{0}$ & $\stackrel{0}{-}$ & $\stackrel{9}{-}$ \\
\hline$\underline{Y}$ & & $\frac{\infty}{0}$ & $\frac{m}{0}$ & $\frac{ \pm}{0}$ & 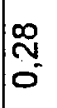 & 证 & 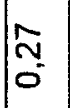 & $\bar{m}$ & $\begin{array}{l}\bar{N} \\
0 \\
0\end{array}$ & 离 & $\begin{array}{c}\stackrel{\mathbb{N}}{0} \\
0\end{array}$ & 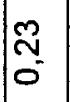 & $\frac{F}{0}$ & $\frac{0}{0}$ & $\frac{N}{0^{-}}$ & $\frac{n}{0}$ & $\begin{array}{l}m \\
\tilde{m} \\
\tilde{0}\end{array}$ & $\frac{N}{0}$ & $\frac{\pi}{0}$ & 惢 \\
\hline 0 & $\frac{\bar{E}}{\mathrm{O}}$ & in & $\infty$ & ले & 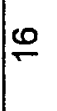 & กิ & [ี & $\bar{\infty}$ & $\mathbb{N}$ & $\infty$ & $m$ & 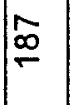 & in & 음 & 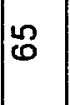 & 0 & 10 & $\forall$ & g & $\bar{m}$ \\
\hline ن் & $0^{\circ}$ & $\stackrel{N}{N}$ & $\stackrel{0}{-}$ & $m^{-}$ & $\hat{i v}$ & $\dot{v}$ & $\infty$ & $\frac{a}{N}$ & 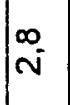 & $\stackrel{\infty}{\infty}$ & $\bar{c}$ & $\dot{N}$ & os & os & m & $\stackrel{N}{N}$ & $\infty$ & $\stackrel{\infty}{-}$ & $\stackrel{\sigma}{-}$ & $\stackrel{\infty}{-}$ \\
\hline$\frac{T}{2}$ & $\underset{\mathbb{J}}{\tilde{J}}$ & $\stackrel{\infty}{\forall}$ & $\dot{v}$ & $\frac{10}{8}$ & 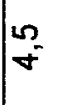 & $\bar{\nabla}$ & $\begin{array}{l}\mathscr{a} \\
m\end{array}$ & $\underset{8}{*}$ & $\mid \begin{array}{l}n \\
10\end{array}$ & $\stackrel{0}{\forall}$ & 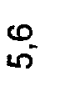 & 権 & $\overline{10}$ & $\sqrt{10}$ & $\begin{array}{l}0 \\
0 \\
15\end{array}$ & 年 & $\underbrace{\infty}$ & $\stackrel{n}{\forall}$ & $\stackrel{\sigma}{\forall}$ & 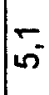 \\
\hline 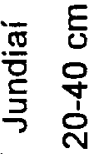 & & 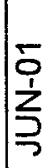 & 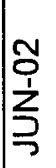 & 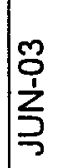 & 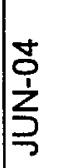 & 告 & 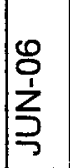 & 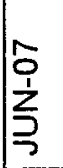 & $\mid \begin{array}{l}\infty \\
0 \\
1 \\
z \\
\supset\end{array}$ & $\begin{array}{l}8 \\
0 \\
\vdots \\
3 \\
7\end{array}$ & $\frac{0}{\frac{1}{3}}$ & $\frac{\bar{\tau}}{\grave{1}}$ & $\frac{N}{\frac{N}{3}}$ & $\frac{m}{\frac{m}{z}}$ & $\frac{ \pm}{\grave{1}}$ & $\frac{n}{\frac{n}{3}}$ & $\frac{0}{z}$ & $\frac{N}{3}$ & $\frac{\infty}{\frac{\infty}{1}}$ & $\frac{0}{\frac{0}{2}}$ \\
\hline
\end{tabular}


Quadro 1 - Interpretação para macronutrientes no solo

\begin{tabular}{|c|c|c|c|c|c|c|}
\hline \multirow[t]{2}{*}{ Parâmetro } & \multirow[t]{2}{*}{ Expressão } & \multicolumn{5}{|c|}{ Classificação } \\
\hline & & $\begin{array}{l}\text { muito } \\
\text { baixo }\end{array}$ & baixo & médio & alto & $\begin{array}{l}\text { muito } \\
\text { alto }\end{array}$ \\
\hline Acidez & $\mathrm{pH}$ em $\mathrm{CaCl}_{2}$ & $>6,0$ & $5,6--6,0$ & $5,1-5,5$ & $4,4-5,0$ & $\leq 4,3$ \\
\hline M.orgânica & $\%$ & & $<1,5$ & $1,5-2,5$ & $>2,5$ & \\
\hline Fósforo(P) & $\mu \mathrm{g} / \mathrm{cm}^{3}$ & 0,6 & $7-15$ & $16-40$ & $41-80$ & $>80$ \\
\hline Enxofre $\left(\mathrm{S}-\mathrm{SO}_{4}\right)$ & $\mu \mathrm{g} / \mathrm{cm}^{3}$ & $0-5,0$ & $5,1-10,0$ & $10,1-15,0$ & $>15$ & \\
\hline Potássio (K) & $\mathrm{meq} / 100 \mathrm{~cm}^{3}$ & $0-0,07$ & $0,08-0,15$ & $0,16-0,30$ & $0,31-0,60$ & $>0,60$ \\
\hline Cálcio (Ca) & $\mathrm{meq} / 100 \mathrm{~cm}^{3}$ & & $<2,0$ & $2,0-4,0$ & $>4,0$ & \\
\hline Magnésio (Mg) & $\mathrm{meq} / 100 \mathrm{~cm}^{3}$ & & $0-0,4$ & $0,5-0,8$ & $>0,8$ & \\
\hline Ac. Potencial & $\mathrm{meq} / 100 \mathrm{~cm}^{3}$ & & $<2,5$ & $2,5-5,0$ & $>5,0$ & \\
\hline Soma de Bases & $\mathrm{meq} / 100 \mathrm{~cm}^{3}$ & & $<2,5$ & $2,5-5,5$ & $>5,5$ & \\
\hline $\operatorname{CTC}(T)$ & $\mathrm{meq} / 100 \mathrm{~cm}^{3}$ & & $<5,0$ & $5,0-8,0$ & $>8,0$ & \\
\hline $\begin{array}{l}\text { Saturação em } \\
\text { bases }\end{array}$ & (\%) & $0-25$ & $26-50$ & $51-70$ & $71-90$ & $>90$ \\
\hline
\end{tabular}

Fonte: Trani \& Drugowich, 1989, compilado. 
Tabela 5 - Interpretação dos resultados de análise de solo para os macronutrientes nas profundidades de $0-20 \mathrm{~cm}$ e $20-40 \mathrm{~cm}$, para os vinhedos amostrados, em um levantamento nutricional na região de Jundiaí, ano de 1991.

\begin{tabular}{|c|c|c|c|c|c|c|c|c|c|c|}
\hline \multirow{3}{*}{\begin{tabular}{|l|} 
Parâmetro \\
Profundidade \\
$(0-20 \mathrm{~cm})$ \\
\end{tabular}} & \multicolumn{10}{|c|}{ Propriedade } \\
\hline & \multicolumn{2}{|c|}{ Muito Baixo } & \multicolumn{2}{|c|}{ Baixo } & \multicolumn{2}{|c|}{ Médio } & \multicolumn{2}{|c|}{ Alto } & \multicolumn{2}{|c|}{ Muito Alto } \\
\hline & $\mathrm{n}^{\circ}$ & $\%$ & $n^{\circ}$ & $\%$ & $\mathrm{n}^{\mathbf{o}}$ & $\%$ & $\mathrm{n}^{\mathrm{o}}$ & $\%$ & $\mathrm{n}^{\circ}$ & $\%$ \\
\hline Acidez $(\mathrm{pH})$ & 0 & 0 & 4 & 21 & 12 & 63 & 3 & 16 & 0 & 0 \\
\hline M. orgânica & 0 & 0 & 0 & 0 & 4 & $\overline{21}$ & 15 & 79 & 0 & 0 \\
\hline Fósforo & 0 & 0 & 0 & 0 & 3 & $\overline{16}$ & 1 & 5 & 15 & 79 \\
\hline Potássio & 0 & 0 & 3 & 16 & 10 & 53 & 6 & 31 & 0 & 0 \\
\hline Cálcio & 0 & 0 & 0 & 0 & 11 & 58 & 8 & 42 & 0 & 0 \\
\hline Magnésio & 0 & 0 & 0 & 0 & 0 & 0 & 19 & 100 & 0 & 0 \\
\hline Ac. Potencial & 0 & 0 & 3 & 16 & 16 & 84 & 0 & 0 & 0 & 0 \\
\hline Soma de Bases & 0 & 0 & 11 & 58 & 8 & 42 & 0 & 0 & 0 & 0 \\
\hline CTC & 0 & 0 & 0 & 0 & 7 & 37 & 12 & 63 & 0 & 0 \\
\hline $\mathrm{V} \%$ & 0 & 0 & 1 & 5 & 12 & 63 & 6 & 32 & 0 & 0 \\
\hline Profundidade & \multicolumn{2}{|c|}{ Muito baixo } & \multicolumn{2}{|c|}{ Baixo } & \multicolumn{2}{|c|}{ Médio } & \multicolumn{2}{|c|}{ Alto } & \multicolumn{2}{|c|}{ Muito alto } \\
\hline$(20-40 \mathrm{~cm})$ & $n^{0}$ & $\%$ & $n^{0}$ & $\%$ & $n^{0}$ & $\%$ & $n^{\circ}$ & $\%$ & $n^{0}$ & $\%$ \\
\hline Acidez $(\mathrm{pH})$ & 0 & 0 & 3 & 16 & 4 & 21 & 9 & 47 & 3 & 16 \\
\hline M. Orgânica & 0 & 0 & 0 & 0 & 11 & 58 & 8 & 42 & 0 & 0 \\
\hline Fósforo & 0 & 0 & 4 & 21 & 4 & 21 & 7 & 37 & 4 & 21 \\
\hline Potássio & 0 & $\overline{0}$ & 7 & 37 & 10 & 53 & 2 & 10 & 0 & 0 \\
\hline Cálcio & 0 & $\overline{0}$ & 11 & 58 & 8 & 42 & 0 & 0 & 0 & 0 \\
\hline Magnésio & 0 & 0 & 1 & 6 & 9 & 47 & 9 & 47 & 0 & 0 \\
\hline Ac. Potencial & 0 & 0 & 3 & 16 & 13 & 68 & 3 & 16 & 0 & 0 \\
\hline Soma de Bases & 0 & 0 & 7 & 37 & 12 & 63 & 0 & 0 & 0 & 0 \\
\hline CTC & 0 & $\overline{0}$ & 2 & 10 & 15 & 80 & 2 & 10 & 0 & 0 \\
\hline $\mathrm{V} \%$ & 2 & 10 & 10 & 53 & 7 & 37 & 0 & 0 & 0 & 0 \\
\hline
\end{tabular}


Quanto à acidez, observou-se que na profundidade de $0-20 \mathrm{~cm}$ $16 \%$ dos vinhedos amostrados apresentaram teores altos e na profundidade de $20-40 \mathrm{~cm}, 16 \%$ dos solos dos vinhedos amostrados apresentaram um teor muito alto de acidez. Na faixa de $0-20 \mathrm{~cm}, 63 \%$ dos solos dos vinhedos amostrados apresentaram um teor médio, e de $20-40 \mathrm{~cm} 21 \%$ deles. Sendo a videira uma cultura perene exigente em calagem, com uma saturação ideal de bases de $80 \%$, somente em condições adequadas de $\mathrm{pH}$ o sistema radicular consegue maior crescimento, com melhor aproveitamento dos nutrientes e da água. A solubilidade dos nutrientes do solo também é diretamente proporcional ao $\mathrm{pH}$. Para o fósforo, a solubilidade é máxima com o pH do solo variando de 6,0 a 7,0 . Os teores de fósforo neste trabalho, de solos coletados na faixa de $0-20 \mathrm{~cm}$, mostraram-se médios em $16 \%$ dos vinhedos, altos em $5 \%$ e muito altos em $79 \%$ dos vinhedos amostrados. Para a faixa de $20-40 \mathrm{~cm}$ foram baixos em $21 \%$, médios também em $21 \%$, altos em $37 \%$ e muito altos em $21 \%$ dos vinhedos amostrados.

O potássio apresentou teores médios em $53 \%$ dos vinhedos, altos em $31 \%$ e baixos em 16, cujas amostras de solo foram coletadas na faixa de 0 $20 \mathrm{~cm}$ e na faixa de $20-40 \mathrm{~cm}$ os teores foram baixos em $37 \%$; médios em $53 \%$ e altos em $10 \%$ dos vinhedos amostrados.

$\mathrm{Na}$ faixa de $0-20 \mathrm{~cm}$ os teores de cálcio foram médios em $58 \%$ dos vinhedos e altos em $42 \%$ e para a faixa de $20-40 \mathrm{~cm}$ foram baixos em $58 \%$ e médios em $42 \%$ dos vinhedos amostrados.

O teor de magnésio foi alto em $100 \%$ dos vinhedos amostrados na faixa de $0-20 \mathrm{~cm}$ de solo e para a faixa de $20-40 \mathrm{~cm}$ foi baixo em $6 \%$ dos vinhedos, médio em $47 \%$ e alto também em $47 \%$ dos vinhedos amostrados.

Para a profundidade de $0-20 \mathrm{~cm}$ a acidez potencial foi média em $84 \%$ dos vinhedos e baixa em $16 \%$ e na profundidade de $20-40 \mathrm{~cm} 68 \%$ dos vinhedos apresentaram teor médio, $16 \%$ apresentaram teor alto e $16 \%$ teor baixo. 
A soma de bases na profundidade de $0-20 \mathrm{~cm}$ foi baixa em $58 \%$ dos vinhedos amostrados e média em $42 \%$ deles; para a profundidade de 20 $40 \mathrm{~cm}$ foi baixa em $37 \%$ dos vinhedos e média em $63 \%$ deles.

A capacidade de troca de cátions na profundidade de $0-20 \mathrm{~cm}$ foi média em $37 \%$ das propriedades amostradas e alta em $63 \%$. Para a profundidade de $20-40 \mathrm{~cm}$ foi baixa em $10 \%$ dos vinhedos, média em $80 \%$ e alta em $10 \%$ das amostras analisadas.

A porcentagem de saturação de bases dos vinhedos amostrados, na profundidade de $0-20 \mathrm{~cm}$, foi baixa em $5 \%$ deles, média em $63 \%$ e alta em $32 \%$. Na profundidade de $20-40 \mathrm{~cm}$ foi muito baixa em $10 \%$ dos vinhedos, baixa em $53 \%$ e média em $37 \%$.

\subsubsection{Micronutrientes}

O Quadro 2 extraído de Dechen \& Carmello (1985) foi utilizado para interpretar os resultados das análises para micronutrientes mostrados na Tabela 6. 
Quadro 2 - Interpretação para micronutrientes no solo

\begin{tabular}{|c|c|c|c|c|c|}
\hline \multirow[t]{2}{*}{ Elemento } & \multicolumn{5}{|c|}{ CIASSIFICAÇÄO $\left(\mathrm{ppm}^{\star}\right)$} \\
\hline & Muito baixo & Baixo & Médio & Alto & Referência Bibliográfica \\
\hline Cobre $(\mathrm{Cu})^{*}$ & $<0,5$ & $0,5-1,5$ & $1,5-2,0$ & $>2,0$ & \multirow{5}{*}{$\begin{array}{l}\text { Dechen, A.R. \& Carmello, Q.A. } \\
\text { (ESALQ, Dep. Química, } 1985\end{array}$} \\
\hline Ferro $(\mathrm{Fe})^{\star}$ & $<2,5$ & $2,5-4,5$ & $4,5-9,0$ & $>9,0$ & \\
\hline Manganês(Mn)* & $<5,0$ & $5,0-1,0$ & $10-130$ & $>130$ & \\
\hline Zinco $(Z n)^{*}$ & $<0,5$ & $0,5-1,0$ & $1,0-2,5$ & $>2,5$ & \\
\hline Boro $(B)^{*}$ & $<0,5$ & $0,5-1,0$ & $1,0-1,5$ & $>1,5$ & \\
\hline
\end{tabular}

* Extração pelo D.I.P.A. (Ácido Dietileno Triamino Pentacético) (Rel. Solo: Solução 1:2)

O teor de boro para a profundidade de $0-20 \mathrm{~cm}$ foi médio em $5 \%$ e alto em $95 \%$ dos vinhedos amostrados e na profundidade de $20-40 \mathrm{~cm}$ foi alto em $100 \%$ dos vinhedos em estudo.

Os teores de cobre e ferro foram altos em $100 \%$ dos vinhedos amostrados na faixa de $0-20 \mathrm{~cm}$ e para a profundidade de $20-40 \mathrm{~cm}$ o teor de cobre foi médio em $10 \%$ das propriedades e alto em $90 \%$ e ferro foi alto em $100 \%$ dos vinhedos amostrados.

O teor de manganês foi médio em $100 \%$ dos vinhedos amostrados tanto nas profundidades de $0-20 \mathrm{~cm}$ e $20-40 \mathrm{~cm}$. 
Tabela 6 - Interpretação dos resultados de análise de solo, para os micronutrientes, nas profundidade de $0-20 \mathrm{~cm}$ e $20-40 \mathrm{~cm}$, para os vinhedos amostrados, em um levantamento nutricional na região de Jundiaí, ano de 1991.

\begin{tabular}{|l|c|c|c|c|c|c|c|c|}
\hline Parâmetro & \multicolumn{9}{|c|}{ Propriedade } \\
\hline Profundidade & \multicolumn{2}{|c|}{ Muito Baixo } & \multicolumn{2}{|c|}{ Baixo } & \multicolumn{2}{c|}{ Médio } & \multicolumn{2}{|c|}{ Alto } \\
\hline$(0-20 \mathrm{~cm})$ & $\mathrm{n}^{0}$ & $\%$ & $\mathrm{n}^{\circ}$ & $\%$ & $\mathrm{n}^{\circ}$ & $\%$ & $\mathrm{n}^{0}$ & $\%$ \\
\hline Boro & 0 & 0 & 0 & 0 & 1 & 5 & 18 & 95 \\
\hline Cobre & 0 & 0 & 0 & 0 & 0 & 0 & 19 & 100 \\
\hline Ferro & 0 & 0 & 0 & 0 & 0 & 0 & 19 & 100 \\
\hline Manganês & 0 & 0 & 0 & 0 & 19 & 100 & 0 & 0 \\
\hline Zinco & 0 & 0 & 0 & 0 & 0 & 0 & 19 & 100 \\
\hline Profundidade & Muito Baixo & \multicolumn{2}{|c|}{ Baixo } & & Médio & & Alto \\
\hline (20-40cm) & $\mathrm{n}^{\circ}$ & $\%$ & $\mathrm{n}^{\circ}$ & $\%$ & $\mathrm{n}^{\circ}$ & $\%$ & $\mathrm{n}^{\circ}$ & $\%$ \\
\hline Boro & 0 & 0 & 0 & 0 & 0 & 0 & 19 & 100 \\
\hline Cobre & 0 & 0 & 0 & 0 & 2 & 10 & 17 & 90 \\
\hline Ferro & 0 & 0 & 0 & 0 & 0 & 0 & 19 & 100 \\
\hline Manganês & 0 & 0 & 0 & 0 & 19 & 100 & 0 & 0 \\
\hline Zinco & 0 & 0 & 0 & 0 & 1 & 5 & 18 & 95 \\
\hline
\end{tabular}

O teor de zinco foi alto em $100 \%$ das propriedades para a profundidade de $0-20 \mathrm{~cm}$ e para a profundidade de $20-40 \mathrm{~cm}$ foi média em $5 \%$ e alta em $95 \%$ das propriedades amostradas.

Observou-se que tanto para as profundidades de $0-20 \mathrm{~cm}$ quanto para a de $20-40 \mathrm{~cm}$ de amostragem de solo que os teores de micronutrientes foram considerados médios e altos. 


\subsection{Sistema Integrado de Diagnose e Recomendação (DRIS)}

O método clássico de análise foliar apresenta a desvantagem dos nutrientes serem interpretados individualmente, não levando em consideração as interações existentes entre eles, a variação das concentrações dos nutrientes com a idade e o grau de desenvolvimento da planta e as diferenças varietais. Quando mais de dois nutrientes encontram-se abaixo dos níveis críticos, o método interpretativo não permite avaliar qual nutriente foi o mais limitante na produção (Malavolta et al., 1997).

O método DRIS - Diagnosis and Recommendation Integrated System - utiliza todas as interpretações existentes entre os nutrientes, além de minimizar os principais fatores limitantes pelo método do nível crítico. Utiliza as razões entre as concentrações dos nutrientes na interpretação dos resultados de análise foliar e do solo. Relatam também que o método DRIS não indica se determinado nutriente se encontra em concentração de toxidez ou deficiência, mas qual o nutriente mais limitante e a ordem de limitação dos nutrientes (Malavolta et al., 1997).

Beaufils (1973) referindo-se ao Sistema Integrado de Diagnose e Recomendação (DRIS), observou que a escolha da população padrão, ou população de referência ou também chamada de população B é primordial para - sucesso do DRIS e deve constituir-se de plantas não anormais, isto é, plantas, que não tenham sido afetadas por condições anormais de cultivo.

O presente trabalho, cujo objetivo foi o de levantar as condições nutricionais de vinhedos sem um controle experimental maior, usou como população padrão, ou seja a população $B$, vinhedos de média produtividade, segundo recomendações de Bataglia \& Dechen (1986).

Os resultados das análises químicas de amostras de limbo e peciolo de folhas dos vinhedos em estudo, encontram-se nas Tabelas $7,8,9$, 10,11 e 12. Esses resultados são correspondentes às três coletas e foram 
utilizados para se calcular a média e o coeficiente de variação para os teores de macro e micronutrientes encontrados em limbos e pecíolos, nas três épocas de amostragem.

As tabelas $13,14,15,16,17$ e 18 mostram a média, desvio padrão e coeficiente de variação para os nutrientes e suas relações dois a dois considerando limbo (3 coletas) e peciolo (3 coletas), respectivamente.

Esses resultados levaram ao cálculo das médias e coeficientes de variação dos nutrientes no limbo ( 3 coletas) e peciolo ( 3 coletas), mostrados nas Tabelas $19,20,21,22,23$ e 24, respectivamente. 


\begin{tabular}{|c|c|c|c|c|c|c|c|c|c|c|c|c|c|c|c|c|c|c|c|c|c|c|}
\hline$\frac{\tilde{\boldsymbol{\Phi}}}{\frac{\mathbb{\Phi}}{0}}$ & & $\bar{N}$ & & $\bar{\sigma}$ & $\mp$ & 品 & 象 & 8 & $\varnothing$ & $\mathscr{q}$ & 웃 & $\bar{r}$ & $\mathbb{N}$ & $\mathbb{N}$ & $\mathbb{N}$ & $\mathscr{R}$ & $\stackrel{\Omega}{\Omega}$ & $\infty$ & $\bar{\sigma}$ & $\mathbb{R}$ & $\approx$ & $\sqrt{0}$ \\
\hline 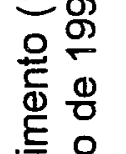 & & $\Sigma$ & & $\stackrel{e}{N}$ & \$్ర & $\frac{m}{\pi}$ & $\mathscr{1}$ & 亩 & 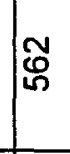 & Io & 舟 & $\bar{\varphi}$ & $\frac{1}{6}$ & $\mid \begin{array}{l}\mathscr{\pi} \\
\mathscr{ల}\end{array}$ & 용 & 8 & 悉 & $\frac{0}{10}$ & $\stackrel{\mathbb{N}}{\mp}$ & 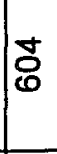 & $\frac{m}{6}$ & 18 \\
\hline 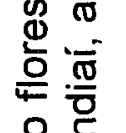 & & ஷ & 틈 & జి & \%̊ & \& & 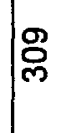 & 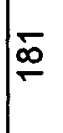 & Nָ & 吕 & 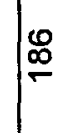 & $\stackrel{\mathscr{m}}{\mathscr{\sigma}}$ & $\ddot{0}$ & $\stackrel{\infty}{\stackrel{\infty}{F}}$ & $\ddot{\sigma}$ & $\mathscr{O}$ & $\stackrel{\mathscr{N}}{\sim}$ & $\underset{\mathcal{F}}{\mathcal{F}}$ & $\check{0}$ & $\frac{\mathscr{O}}{\Gamma}$ & 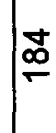 & $\stackrel{\infty}{\infty}$ \\
\hline 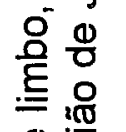 & & $\overrightarrow{0}$ & & $\stackrel{2}{\sim}$ & $\begin{array}{l}0 \\
\infty \\
\infty\end{array}$ & న్ & $\underset{N}{\stackrel{N}{N}}$ & $m$ & $\stackrel{m}{\leftarrow}$ & $\mp$ & 으 & $\mp$ & 0 & $\mp$ & $F$ & $1 ㅇ$ & $\stackrel{N}{F}$ & I & 12 & $\bar{N}$ & $\stackrel{\mathscr{C}}{6}$ & $\mathcal{F}$ \\
\hline 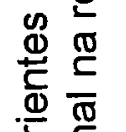 & & $\infty$ & & 10 & 유 & I & $\bar{m}$ & og & $\stackrel{\oplus}{\circ}$ & 尽 & $\approx$ & $\nabla$ & 은 & $\mp$ & $\cong$ & $\bar{N}$ & 岻 & $\stackrel{20}{-}$ & $\cong$ & 10 & $m$ & 원 \\
\hline 을 & $\frac{\sqrt[5]{z}}{\overline{\underline{\alpha}}}$ & 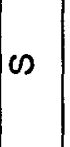 & & m & 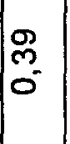 & $\bar{z}$ & in & $\begin{array}{l}m \\
m \\
0\end{array}$ & ח̃ & 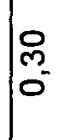 & m & $\begin{array}{l}m \\
m \\
0^{-}\end{array}$ & N & $\begin{array}{l}\stackrel{\infty}{N} \\
0 \\
0\end{array}$ & 怤 & 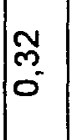 & m & 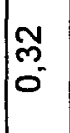 & $\bar{m}_{0}$ & $\tilde{m}_{\tilde{\infty}}^{m}$ & $\begin{array}{l}\mathcal{N} \\
\tilde{m}^{-}\end{array}$ & $\begin{array}{l}m \\
m \\
0\end{array}$ \\
\hline 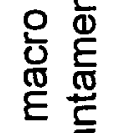 & & $\sum^{0}$ & & $\mid \begin{array}{c}\bar{m} \\
0\end{array}$ & $\begin{array}{l}\infty \\
m \\
0 \\
0\end{array}$ & $\mid \begin{array}{c}n \\
0 \\
0\end{array}$ & $\sigma^{\sigma}$ & 尽 & $\begin{array}{l}m \\
m \\
0\end{array}$ & $\begin{array}{l}\text { ले } \\
0\end{array}$ & 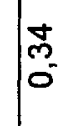 & $\mid \begin{array}{l}\mathscr{N} \\
-1 \\
0\end{array}$ & $\bar{N}_{\bar{N}}$ & 趽 & $\mid \begin{array}{c}n \\
m \\
0\end{array}$ & $\mid \begin{array}{l}8 \\
0\end{array}$ & 孞 & $\mid \begin{array}{l}\mathscr{N} \\
0\end{array}$ & స్ & $\bar{m}$ & ָ̃ & $\bar{m}$ \\
\hline 离 $\frac{\Phi}{E}$ & & 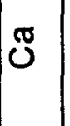 & & 就 & $\stackrel{O}{\stackrel{O}{*}}$ & $\frac{\sigma}{n}$ & $\underset{m}{\mathfrak{v}}$ & 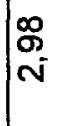 & 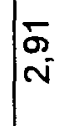 & 总 & 志 & $\begin{array}{l}\infty \\
N \\
N\end{array}$ & m & $\begin{array}{l}\hat{\omega} \\
\hat{N}\end{array}$ & $\begin{array}{l}\mathfrak{m} \\
\infty \\
\sim\end{array}$ & $\frac{ \pm}{m^{-}}$ & $\begin{array}{l}\text { J } \\
m^{-}\end{array}$ & $\underset{\sim}{m}$ & $\begin{array}{l}8 \\
\stackrel{\circ}{*} \\
\text { i }\end{array}$ & \begin{tabular}{l}
0 \\
\hdashline \\
N
\end{tabular} & $\begin{array}{l}\text { S } \\
\text { iv }\end{array}$ & "20 \\
\hline 怘芯 & & $צ$ & & $\stackrel{R}{=}$ & $\stackrel{n}{m}$ & $\ddot{-}$ & $\frac{m}{2}$ & 息 & $\stackrel{N}{\sim}$ & m & 吕 & 官 & $\stackrel{R}{=}$ & 安 & 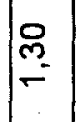 & $\stackrel{m}{m}$ & $\underset{\mathcal{F}}{\mathcal{Y}}$ & $\ddot{0}$ & $\stackrel{8}{6}$ & ֻ & 㟶 & $\stackrel{n}{\infty}$ \\
\hline 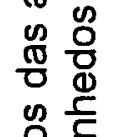 & & a & & đ̃ & N & $\mid \begin{array}{c}\infty \\
\tilde{o} \\
0\end{array}$ & 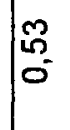 & $\begin{array}{c}\mathcal{N} \\
\text { N } \\
0\end{array}$ & 里 & $\bar{m}$ & $\mid \bar{m}$ & 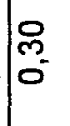 & 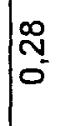 & $\mid \begin{array}{l}\hat{N} \\
0 \\
0\end{array}$ & న్ & $\underset{\mathscr{Y}}{\mathscr{Y}}$ & $\begin{array}{l}\mathcal{Y} \\
\sigma \\
0\end{array}$ & $\mid$ & 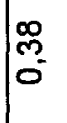 & 兽 & of & $\begin{array}{l}8 \\
0 \\
0\end{array}$ \\
\hline 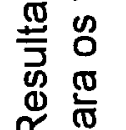 & & $z$ & & $\mid \begin{array}{l}\infty \\
\infty \\
m\end{array}$ & $\begin{array}{l}\bar{\sigma} \\
m\end{array}$ & 胥 & $\stackrel{\sigma}{\sigma}$ & $\mid \begin{array}{l}\infty \\
\infty \\
m^{-}\end{array}$ & $\mid \begin{array}{l}\mathbb{3} \\
6 \\
m\end{array}$ & $\mid \begin{array}{l}0 \\
0 \\
m^{-}\end{array}$ & $\mid \begin{array}{l}0 \\
6 \\
m\end{array}$ & 怘 & $\mid \begin{array}{l} \\
m^{\prime}\end{array}$ & $\mid \begin{array}{l}8 \\
0 \\
m\end{array}$ & w & $\begin{array}{l}\frac{\pi}{N} \\
m^{-}\end{array}$ & $\mid \begin{array}{l}- \\
\infty \\
m^{-}\end{array}$ & $\begin{array}{l}8 \\
\dot{m}\end{array}$ & $\mid \begin{array}{l}\mathbf{0} \\
0 \\
m\end{array}$ & $\frac{0}{8}$ & ळ. & $\stackrel{0}{\pi}$ \\
\hline$\stackrel{0}{0}$ & 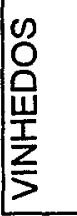 & & & 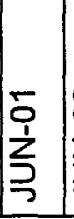 & 秛 & 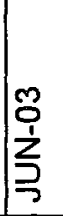 & 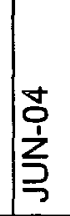 & 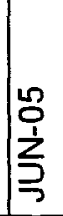 & $\begin{array}{l}8 \\
0 \\
1 \\
3 \\
\end{array}$ & 合 & 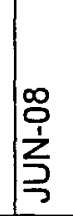 & 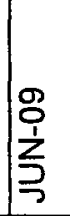 & $\frac{0}{\dot{z}}$ & $\frac{\check{I}}{\frac{5}{2}}$ & $\frac{N}{\grave{z}}$ & $\frac{m}{\frac{m}{1}}$ & $\frac{y}{\frac{J}{z}}$ & $\frac{n}{1}$ & $\frac{0}{3}$ & $\frac{n}{3}$ & $\underset{\frac{\infty}{3}}{\frac{\infty}{3}}$ & $\frac{9}{\frac{9}{1}}$ \\
\hline
\end{tabular}




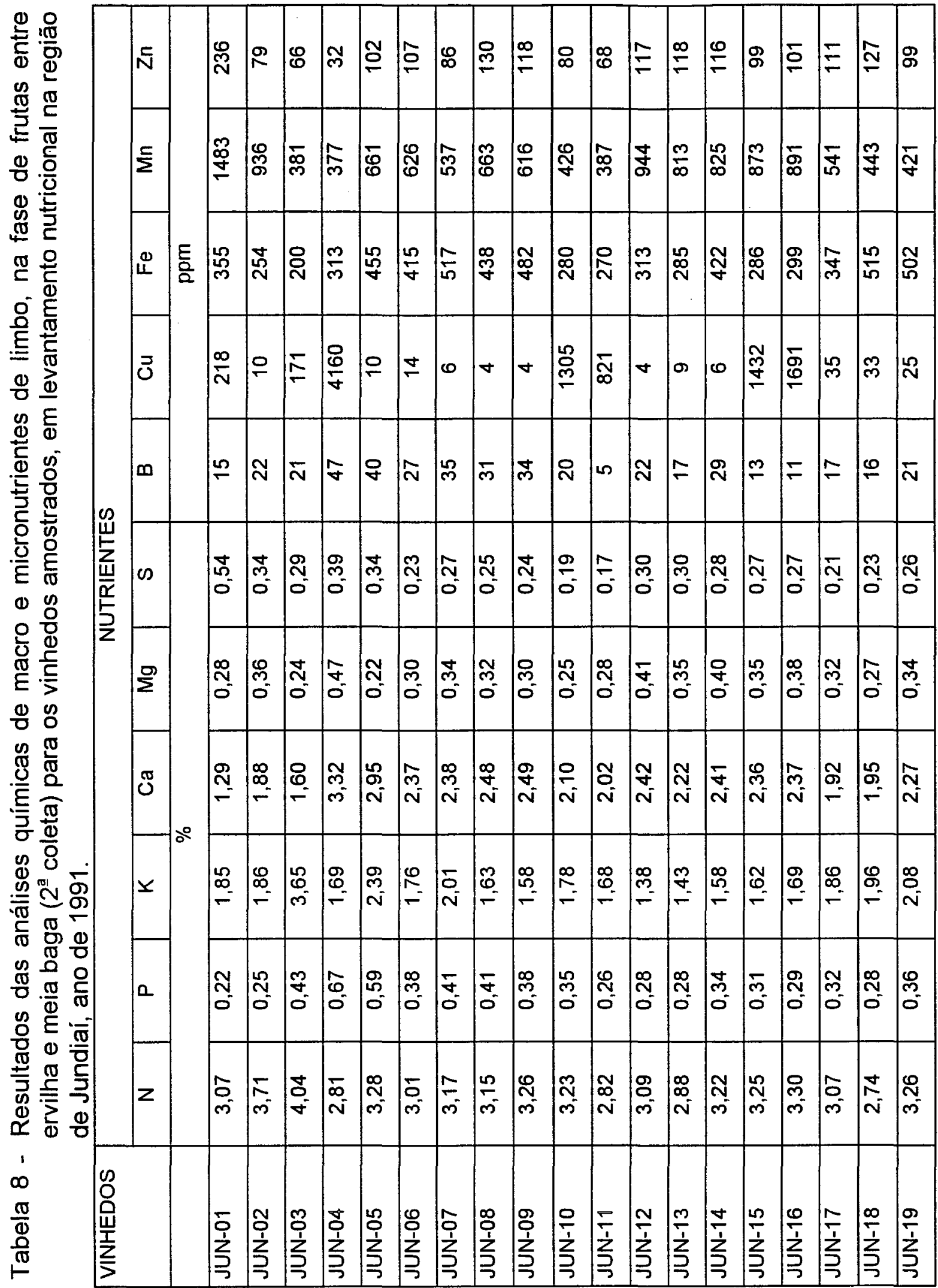




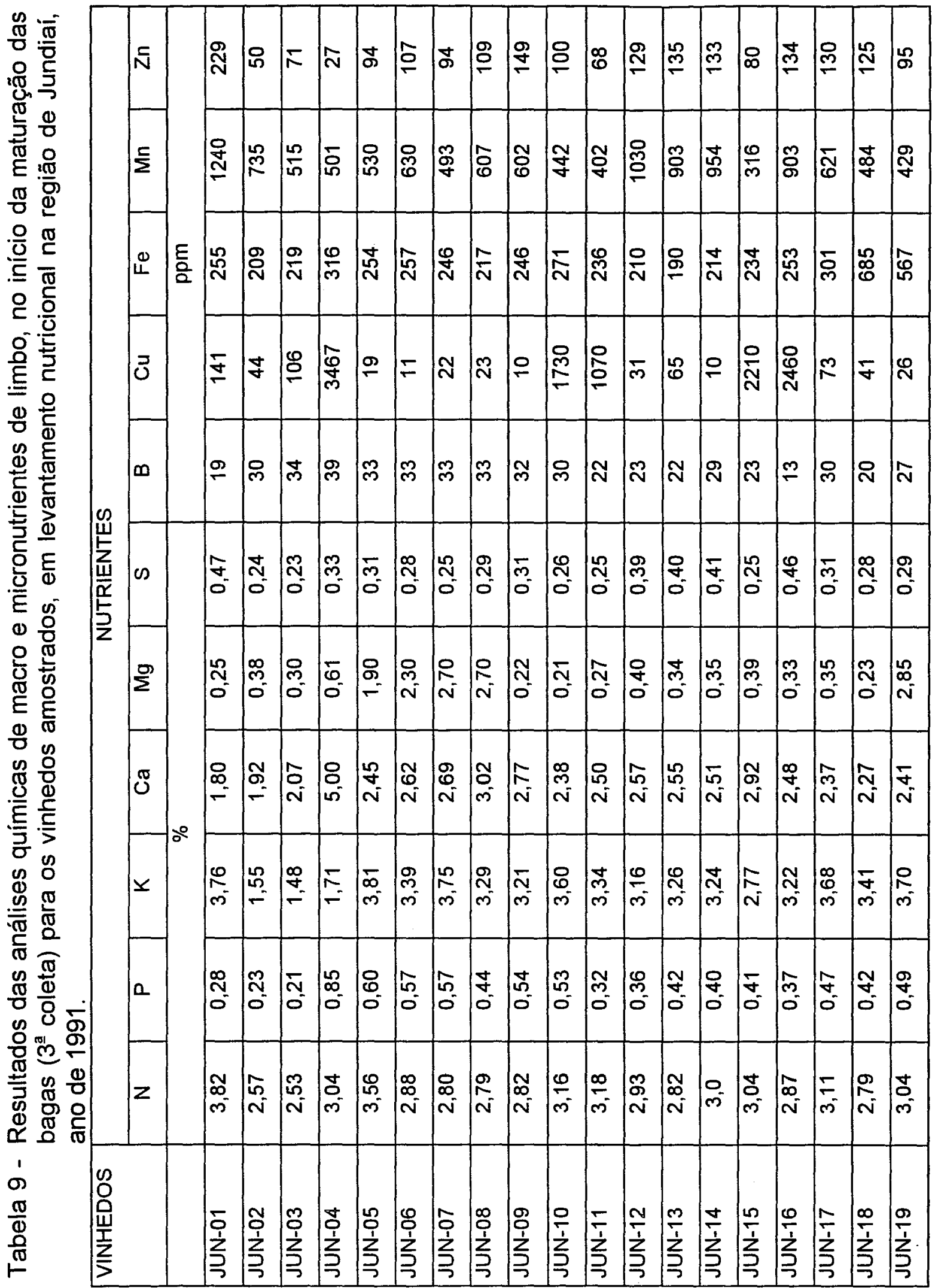




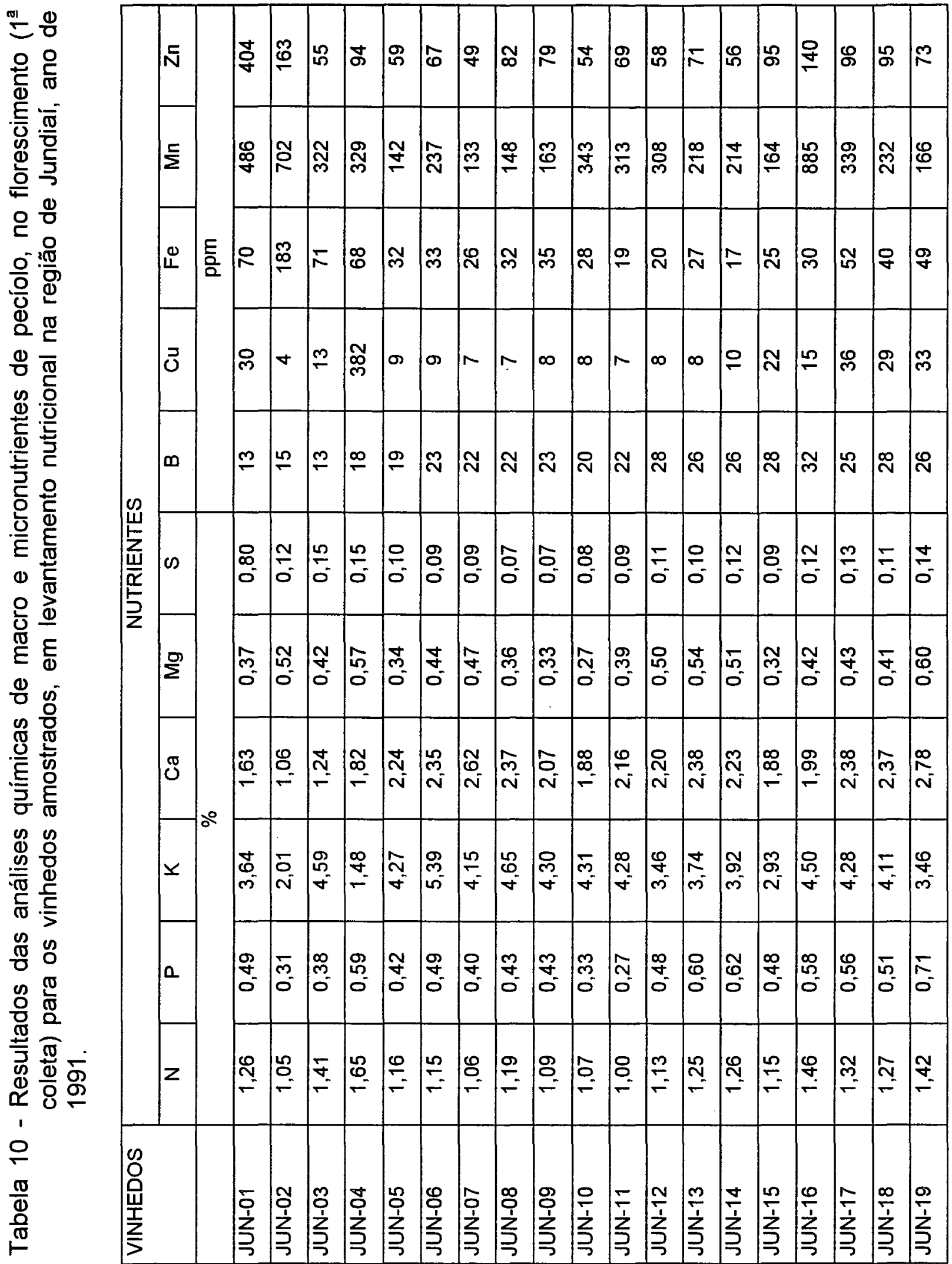




\begin{tabular}{|c|c|c|c|c|c|c|c|c|c|c|c|c|c|c|c|c|c|c|c|c|c|c|}
\hline 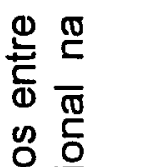 & & $\bar{N}$ & & 怘 & 1 & \%̆ & 只 & 12 & $\bar{m}$ & $\mathscr{\infty}_{\infty}$ & $\stackrel{\sim}{\sim}$ & Y & $\stackrel{m}{N}$ & $\bar{\sigma}$ & 음 & $\mathscr{\infty}$ & $\mathbb{N}$ & कू & 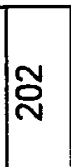 & ঙ & 串 & ম \\
\hline 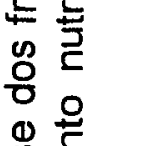 & & 官 & & $\mid \mathbb{P}$ & $\stackrel{\mathscr{O}}{\rightleftharpoons}$ & 面 & స్తి & $\widehat{N}$ & \& & $\hat{\mathscr{N}}$ & 必 & 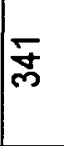 & 荵 & $\sqrt[5]{5}$ & 足 & 过 & $\frac{10}{8}$ & 导 & 略 & $\hat{8}$ & $\underset{乛}{\mathscr{~}}$ & $\tilde{\mathscr{N}}$ \\
\hline 竞 & & $\stackrel{0}{\longleftarrow}$ & है & $N$ & 10 & 응 & m & 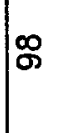 & $\bar{T}$ & 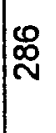 & $\stackrel{\infty}{\infty}$ & $\stackrel{\mathbb{N}}{\text { | }}$ & 奋 & 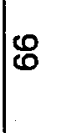 & 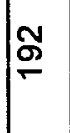 & 吕 & $\stackrel{m}{\mathscr{m}}$ & హ) & L2 & $\underset{\mathscr{g}}{\stackrel{g}{g}}$ & कि & 皿 \\
\hline 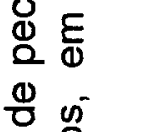 & & $\overrightarrow{0}$ & & $\stackrel{n}{N}$ & $\infty$ & బ్లి & జి & 18 & $F$ & $\omega$ & $\sim$ & $\sim$ & $\stackrel{8}{\infty}$ & 号 & $r$ & $\forall$ & 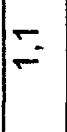 & $\underset{\sim}{\infty}$ & ల్ల & $\stackrel{m}{N}$ & 음 & $\theta$ \\
\hline 总总 & & $\boldsymbol{m}$ & & $\cong$ & స్లు & $\stackrel{N}{N}$ & $\stackrel{m}{2}$ & 요 & 次 & IN & $\approx$ & I & 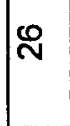 & $\approx$ & $\approx$ & $\stackrel{2}{\circ}$ & 오 & 10 & \pm & $\stackrel{2}{2}$ & 10 & I \\
\hline 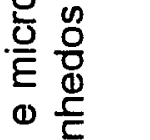 & $\frac{\frac{5}{w}}{\frac{w}{5}}$ & $\infty$ & & 总 & $\Xi_{0}$ & $\frac{0}{0^{-}}$ & $\frac{ \pm}{\sigma}$ & ${ }_{0}^{\infty}$ & $\mid \begin{array}{l}2 \\
0 \\
0\end{array}$ & 票 & 舟 & $\begin{array}{l}8 \\
0 \\
0\end{array}$ & 总 & 足 & $\begin{array}{l}\mathscr{8} \\
0^{-}\end{array}$ & 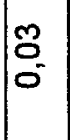 & 古 & 年 & 志 & $\mid \begin{array}{l}\infty \\
0 \\
0\end{array}$ & 응 & $\mid \begin{array}{l}\mathbf{0} \\
0\end{array}$ \\
\hline 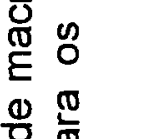 & & $\sum^{\circ}$ & & m & $\mid \begin{array}{l}\tilde{N} \\
0 \\
0\end{array}$ & m & $\mid \begin{array}{l}n \\
0 \\
0\end{array}$ & 离 & $\mid \begin{array}{l}0 \\
0 \\
0 \\
0 \\
0\end{array}$ & 官 & $\mid \begin{array}{l}N \\
N \\
0\end{array}$ & $\begin{array}{l}0 \\
\infty \\
0 \\
0\end{array}$ & 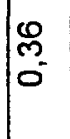 & $\frac{\mathscr{O}}{0}$ & $\mid \begin{array}{l}m \\
? \\
0\end{array}$ & $\mid \begin{array}{l}\sigma \\
0\end{array}$ & $\frac{R}{0}$ & $\mid \begin{array}{l}1 \\
0 \\
0\end{array}$ & 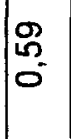 & $\mid \begin{array}{l}\widetilde{N} \\
0 \\
0\end{array}$ & $\stackrel{q}{q}$ & 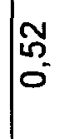 \\
\hline 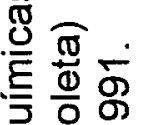 & & $\mathbb{O}$ & & $\frac{8}{8}$ & m & $\approx$ & $\underset{N}{N}$ & $\stackrel{\sim}{i}$ & O & \%్ & $\hat{0}$ & $\frac{0}{i}$ & 号 & No & $\stackrel{m}{\stackrel{m}{2}}$ & $\stackrel{8}{\circledR}$ & $\Phi_{-}^{\infty}$ & $\stackrel{\widetilde{Z}}{\widetilde{-}}$ & $\underset{\sigma}{\sigma}$ & 管 & 吕 & $\stackrel{0}{=}$ \\
\hline 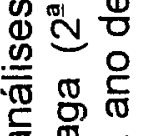 & & $x$ & & $\begin{array}{l}\infty \\
\infty \\
\forall\end{array}$ & 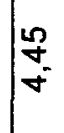 & f & 芯 & 哇 & $\frac{0}{6}$ & $\begin{array}{l}0 \\
m \\
\omega^{-}\end{array}$ & $\mid \begin{array}{l}\infty \\
m \\
\omega^{-1}\end{array}$ & $\mid \begin{array}{l}8 \\
6 \\
65\end{array}$ & $\mid \begin{array}{l}m \\
\infty \\
\infty \\
\infty\end{array}$ & $\mid \begin{array}{l}\mathbb{N} \\
\text { in }\end{array}$ & $\begin{array}{l}\mathscr{E} \\
8 \\
8\end{array}$ & $\begin{array}{l}+ \\
\infty \\
+\end{array}$ & $\begin{array}{l}n \\
0 \\
\infty\end{array}$ & m & $\mid \begin{array}{l}n \\
m \\
\text { in }\end{array}$ & $\frac{0}{\text { is }}$ & 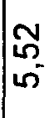 & $\sqrt{10}$ \\
\hline 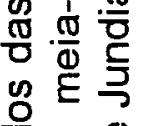 & & 0 & & m & 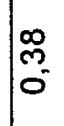 & $\begin{array}{l}m \\
\text { [n } \\
0 \\
0\end{array}$ & $\mid \begin{array}{l}0 \\
0 \\
0\end{array}$ & $\begin{array}{l}n \\
0 \\
0\end{array}$ & $\begin{array}{l}n \\
n \\
0\end{array}$ & $\frac{10}{8}$ & 怘 & $\mid \begin{array}{l}0 \\
\infty \\
0 \\
0\end{array}$ & 告 & $\mid \begin{array}{l}0 \\
\tilde{m} \\
0\end{array}$ & W & $\begin{array}{l}0 \\
4 \\
0\end{array}$ & $\begin{array}{l}8 \\
0 \\
0\end{array}$ & $\begin{array}{l}m \\
\text { in } \\
0\end{array}$ & $\mid \begin{array}{l}\text { 怘 } \\
0\end{array}$ & $\begin{array}{l}n \\
\omega \\
0 \\
0\end{array}$ & 孚 & 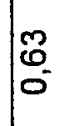 \\
\hline 蛋 & & $z$ & & 命 & 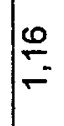 & $\stackrel{0}{\circ}$ & $\stackrel{m}{=}$ & 隹 & $\stackrel{8}{\circ}$ & $\mid \begin{array}{l}\bar{\infty} \\
0 \\
0\end{array}$ & $\mid \begin{array}{l}\infty \\
\infty \\
0 \\
0\end{array}$ & $\mid$ & 思 & $\frac{N}{\sigma^{\circ}}$ & $\mid \begin{array}{l}\infty \\
\infty \\
0 \\
0\end{array}$ & $\mid \begin{array}{l}- \\
\infty \\
0\end{array}$ & $\bar{\sigma}_{0}$ & 票 & $\begin{array}{l}\tilde{\sigma} \\
\sigma \\
0\end{array}$ & 而 & $\frac{\infty}{\infty}$ & बे \\
\hline$\frac{\mathbb{a}}{\mathbb{a}}$ & 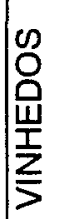 & & & 立 & 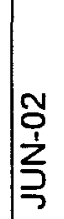 & 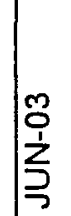 & 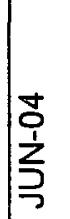 & $\mid \begin{array}{l}n \\
0 \\
1 \\
z \\
2\end{array}$ & 若 & 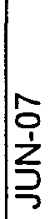 & 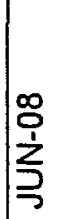 & 量 & 卓 & $\sum_{3}^{\frac{1}{3}}$ & $\underset{\substack{N \\
z}}{\bar{z}}$ & $\frac{m}{1}$ & $\underset{\frac{\pi}{1}}{\frac{\pi}{3}}$ & $\frac{n}{2}$ & $\stackrel{\infty}{\frac{0}{1}}$ & 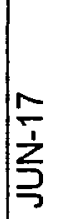 & $\frac{\infty}{\vdots}$ & $\underset{\frac{0}{3}}{\frac{9}{1}}$ \\
\hline
\end{tabular}




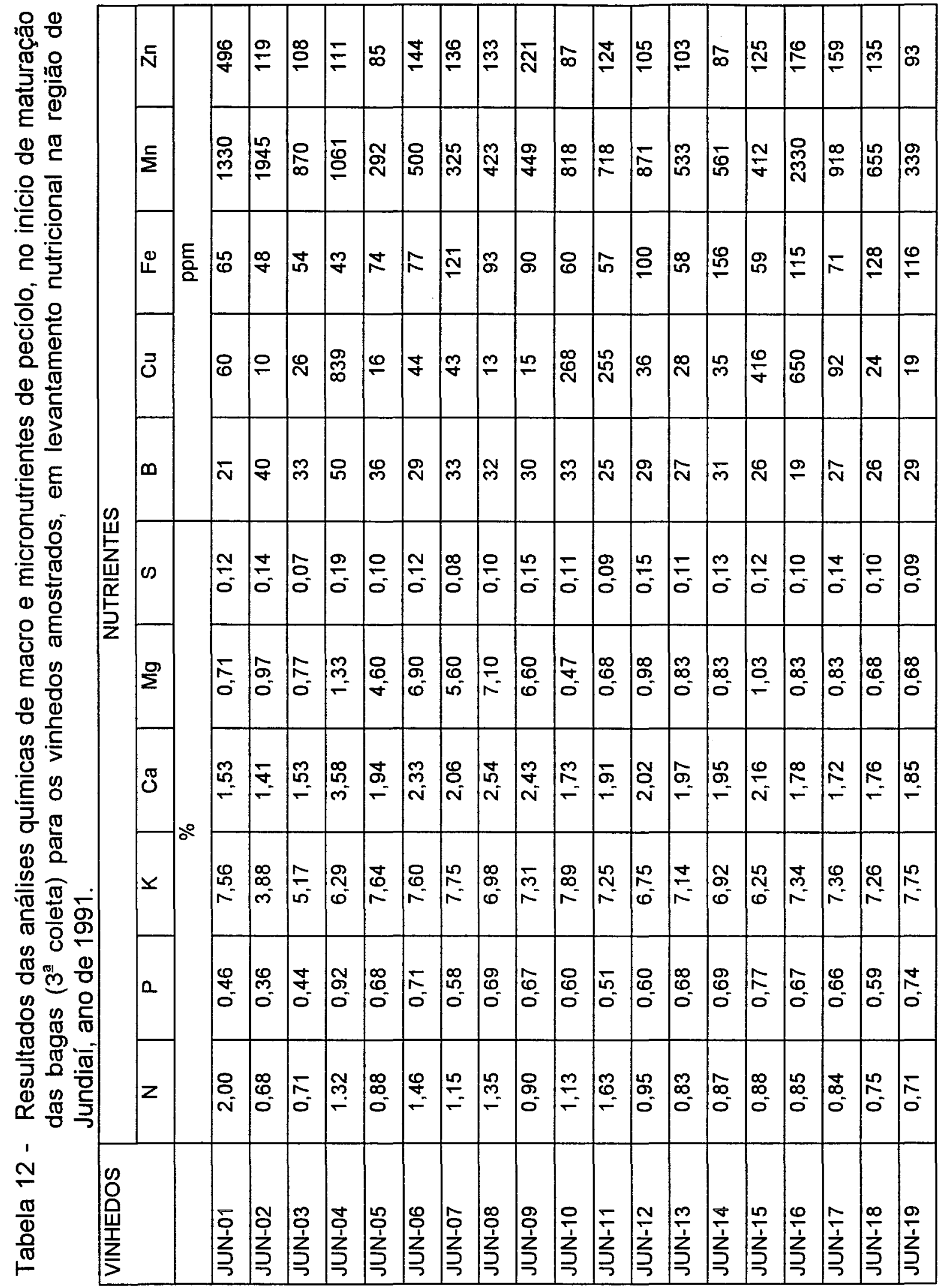


Tabela 13 - Média, Desvio Padrão e Coeficiente de Variação (Normas) para os nutrientes e para suas relações dois a dois, considerando limbo - $1^{\text {a }}$ coleta (florescimento).

\begin{tabular}{|c|c|c|c|}
\hline NUTRIENTES & MÉDIA & DESVIO PADRÃO & COEF. VARIAÇÃO (\%) \\
\hline$N(\%)$ & 3,4120 & 0,84461 & 24,7541 \\
\hline $\mathrm{P}(\%)$ & 0,4100 & 0,0696 & 16,9858 \\
\hline$K(\%)$ & 1,5720 & 0,2653 & 16,8809 \\
\hline $\mathrm{Ca}(\%)$ & 2,5920 & 0,1920 & 7,4080 \\
\hline $\mathrm{Mg}(\%)$ & 0,3140 & 0,0594 & 18,9215 \\
\hline$S(\%)$ & 0,3700 & 0,1120 & 30,2775 \\
\hline$B \ln (p p m)$ & 2,8272 & 0,3814 & 13,4924 \\
\hline $\mathrm{Cu} \ln (\mathrm{ppm})$ & 4,9193 & 1,7855 & 36,2963 \\
\hline$F e \ln (\mathrm{ppm})$ & 5,2312 & 0,2976 & 5,6897 \\
\hline Mn In (ppm) & 6,6019 & 0,3065 & 4,6432 \\
\hline $\mathrm{Zn} \ln (\mathrm{ppm})$ & 4,5019 & 0,1299 & 2.8870 \\
\hline RELAÇÃO & MÉDIA & DESVIO PADRÃO & COEF. VARIAÇÃO (\%) \\
\hline $\mathrm{N} / \mathrm{P}$ & 8,6824 & 2,7980 & 32,2268 \\
\hline $\mathrm{N} / \mathrm{K}$ & 2,1462 & 0,2829 & 13,1814 \\
\hline $\mathrm{N} / \mathrm{Ca}$ & 1,3103 & 0,2920 & 22,2919 \\
\hline $\mathrm{N} / \mathrm{Mg}$ & 11,4235 & 3,8624 & 33,8112 \\
\hline N/S & 10,1182 & 3,7798 & 37,3568 \\
\hline N/B & 1,2490 & 0,4047 & 32,4033 \\
\hline $\mathrm{N} / \mathrm{Cu}$ & 0,8031 & 0,3855 & 48,0049 \\
\hline $\mathrm{N} / \mathrm{Fe}$ & 0,6593 & 0,1804 & 27,3602 \\
\hline N/Mn & 0,5194 & 0,1371 & 26,4054 \\
\hline $\mathrm{N} / \mathrm{Zn}$ & 0,7620 & 0,2026 & 26,5917 \\
\hline$P / N$ & 0,1345 & 0,0752 & 55,9596 \\
\hline $\mathrm{P} / \mathrm{K}$ & 0,2747 & 0,1091 & 39,7273 \\
\hline $\mathrm{P} / \mathrm{Ca}$ & 0,1592 & 0,0331 & 20,8444 \\
\hline $\mathrm{P} / \mathrm{Mg}$ & 1,3131 & 0,1103 & 8,3996 \\
\hline $\mathrm{P} / \mathrm{S}$ & 1,1362 & 0,1298 & 11,4288 \\
\hline P/B & 0,1452 & 0,0154 & 10,6316 \\
\hline
\end{tabular}




\begin{tabular}{|c|c|c|c|}
\hline RELAÇÃO & MÉDIA & DESVIO PADRÃO & COEF. VARIAÇÃO (\%) \\
\hline $\mathrm{P} / \mathrm{Cu}$ & 0,0900 & 0,0285 & 31,7189 \\
\hline $\mathrm{P} / \mathrm{Fe}$ & 0,0780 & 0,0083 & 10,7579 \\
\hline $\mathrm{P} / \mathrm{Mn}$ & 0,0620 & 0,0098 & 15,7851 \\
\hline $\mathrm{P} / \mathrm{Zn}$ & 0,0908 & 0,0133 & 14,6573 \\
\hline $\mathrm{K} / \mathrm{N}$ & 0,4727 & 0,0648 & 13,7187 \\
\hline $\mathrm{K} / \mathrm{P}$ & 3,9715 & 1,0506 & 26,4533 \\
\hline $\mathrm{K} / \mathrm{Ca}$ & 0,6047 & 0,0803 & 13,2836 \\
\hline $\mathrm{K} / \mathrm{Mg}$ & 5,2393 & 1,5691 & 29,9490 \\
\hline KJS & 4,6049 & 1,5015 & 32,6084 \\
\hline $\mathrm{K} / \mathrm{B}$ & 0,5716 & 0,1494 & 26,1496 \\
\hline $\mathrm{K} / \mathrm{Cu}$ & 0,3651 & 0,1614 & 44,2080 \\
\hline $\mathrm{K} / \mathrm{Fe}$ & 0,3029 & 0,0612 & 20,2043 \\
\hline $\mathrm{K} / \mathrm{Mn}$ & 0,2390 & 0,0452 & 18,9065 \\
\hline $\mathrm{K} / \mathrm{Zn}$ & 0,3502 & 0,0637 & 18,2076 \\
\hline $\mathrm{Ca} / \mathrm{N}$ & 0,8060 & 0,2422 & 30,0570 \\
\hline $\mathrm{Ca} / \mathrm{P}$ & 6,4573 & 1,0679 & 16,5383 \\
\hline $\mathrm{Ca} / \mathrm{K}$ & 1,6817 & 0,2657 & 15,8043 \\
\hline $\mathrm{Ca} / \mathrm{Mg}$ & 8,5051 & 1,7685 & 20,7940 \\
\hline $\mathrm{Ca} / \mathrm{S}$ & 7,4370 & 1,8599 & 25,0094 \\
\hline $\mathrm{Ca} / \mathrm{B}$ & 0,9339 & 0,1695 & 18,1557 \\
\hline $\mathrm{Ca} / \mathrm{Cu}$ & 0,5896 & 0,2318 & 39,3093 \\
\hline $\mathrm{Ca} / \mathrm{Fe}$ & 0,4969 & 0,0478 & 9,6183 \\
\hline $\mathrm{Ca} / \mathrm{Mn}$ & 0,3934 & 0,0371 & 9,4366 \\
\hline $\mathrm{Ca} / \mathrm{Zn}$ & 0,5763 & 0,0482 & 8,3716 \\
\hline $\mathrm{Mg} / \mathrm{N}$ & 0,1032 & 0,0590 & 57,1566 \\
\hline $\mathrm{Mg} / \mathrm{P}$ & 0,7656 & 0,0622 & 8,1297 \\
\hline $\mathrm{Mg} / \mathrm{K}$ & 0,2111 & 0,0873 & 41,3720 \\
\hline $\mathrm{Mg} / \mathrm{Ca}$ & 0,1222 & 0,0285 & 23,3276 \\
\hline $\mathrm{Mg} / \mathrm{S}$ & 0,8694 & 0,1202 & 13,8316 \\
\hline $\mathrm{Mg} / \mathrm{B}$ & 0,1112 & 0,0153 & 13,8270 \\
\hline $\mathrm{Mg} / \mathrm{Cu}$ & 0,0698 & 0,0274 & 39,2795 \\
\hline
\end{tabular}




\begin{tabular}{|c|c|c|c|}
\hline RELAÇÃO & MÉDIA & DESVIO PADRÃO & COEF. VARIAÇÃO(\%) \\
\hline $\mathrm{Mg} / \mathrm{Fe}$ & 0,0597 & 0,0081 & 13,6379 \\
\hline $\mathrm{Mg} / \mathrm{Mn}$ & 0,0474 & 0,0079 & 16,6759 \\
\hline $\mathrm{Mg} / \mathrm{Zn}$ & 0,0696 & 0,0118 & 16,9986 \\
\hline$S / N$ & 0,1259 & 0,0914 & 72,6000 \\
\hline$S / P$ & 0,8903 & 0,1123 & 12,6223 \\
\hline $\mathrm{S} / \mathrm{K}$ & 0,2535 & 0,1407 & 55,5054 \\
\hline $\mathrm{S} / \mathrm{Ca}$ & 0,1445 & 0,0509 & 35,2587 \\
\hline $\mathrm{S} / \mathrm{Mg}$ & 1,1678 & 0,1612 & 13,8089 \\
\hline S/B & 0,1292 & 0,0216 & 16,7243 \\
\hline $\mathrm{s} / \mathrm{Cu}$ & 0,0788 & 0,0204 & 25,9370 \\
\hline $\mathrm{S} / \mathrm{Fe}$ & 0,0700 & 0,0165 & 23,5543 \\
\hline S/Mn & 0,0559 & 0,0160 & 28,7422 \\
\hline $\mathrm{S} / \mathrm{Zn}$ & 0,0818 & 0,0224 & 27,4857 \\
\hline $\mathrm{B} / \mathrm{N}$ & 0,9196 & 0,4677 & 50,8579 \\
\hline $\mathrm{B} / \mathrm{P}$ & 6,9574 & 0,8394 & 12,0652 \\
\hline $\mathrm{B} / \mathrm{K}$ & 1,8855 & 0,6636 & 35,1964 \\
\hline $\mathrm{B} / \mathrm{Ca}$ & 1,1013 & 0,2128 & 19,3269 \\
\hline $\mathrm{B} / \mathrm{Mg}$ & 9,1402 & 1,3729 & 15,0212 \\
\hline $\mathrm{B} / \mathrm{S}$ & 7,8926 & 1,1544 & 14,6270 \\
\hline $\mathrm{B} / \mathrm{Cu}$ & 0,6224 & 0,1856 & 29,8288 \\
\hline $\mathrm{B} / \mathrm{Fe}$ & 0,5395 & 0,0538 & 9,9752 \\
\hline $\mathrm{B} / \mathrm{Mn}$ & 0,4290 & 0,0596 & 13,9056 \\
\hline $\mathrm{B} / \mathrm{Zn}$ & 0,6272 & 0,0735 & 11,7230 \\
\hline $\mathrm{Cu} / \mathrm{N}$ & 1,6730 & 1,2568 & 75,1267 \\
\hline Cu/P & 11,8025 & 2,7534 & 23,3295 \\
\hline $\mathrm{Cu} / \mathrm{K}$ & 3,3629 & 1,9720 & 58,6410 \\
\hline $\mathrm{Cu} / \mathrm{Ca}$ & 1,9161 & 0,7640 & 39,8775 \\
\hline $\mathrm{Cu} / \mathrm{Mg}$ & 15,6354 & 4,2508 & 27,1870 \\
\hline $\mathrm{Cu} / \mathrm{S}$ & 13,2382 & 2,7055 & 20,4373 \\
\hline $\mathrm{Cu} / \mathrm{B}$ & 1,7102 & 0,4442 & 25,9731 \\
\hline $\mathrm{Cu} / \mathrm{Fe}$ & 0,9297 & 0,2858 & 30,7478 \\
\hline
\end{tabular}




\begin{tabular}{|l|c|c|c|}
\hline RELAÇÃO & MÉDIA & DESVIO PADRÃO & COEF. VARIAÇÃO (\%) \\
\hline $\mathrm{Cu} / \mathrm{Zn}$ & 1,0885 & 0,3718 & 34,1547 \\
\hline $\mathrm{Cu} / \mathrm{Zn}$ & 1,0885 & 0,3718 & 34,1547 \\
\hline $\mathrm{Fe} / \mathrm{N}$ & 1,6683 & 0,6975 & 41,8110 \\
\hline $\mathrm{Fe} / \mathrm{P}$ & 12,9288 & 1,2538 & 9,6977 \\
\hline $\mathrm{Fe} / \mathrm{K}$ & 3,4484 & 0,9192 & 26,6568 \\
\hline $\mathrm{Fe} / \mathrm{Ca}$ & 2,0280 & 0,2059 & 10,1565 \\
\hline $\mathrm{Fe} / \mathrm{Mg}$ & 16,9835 & 2,2394 & 13,1857 \\
\hline $\mathrm{Fe} / \mathrm{S}$ & 14,7803 & 2,6682 & 18,0528 \\
\hline $\mathrm{Fe} / \mathrm{B}$ & 1,8680 & 0,1829 & 9,7918 \\
\hline $\mathrm{Fe} / \mathrm{Cu}$ & 1,1736 & 0,4203 & 35,8196 \\
\hline $\mathrm{Fe} / \mathrm{Mn}$ & 0,7932 & 0,0479 & 6,0453 \\
\hline $\mathrm{Fe} / \mathrm{Zn}$ & 1,1617 & 0,0488 & 4,2058 \\
\hline $\mathrm{Mn} / \mathrm{N}$ & 2,0852 & 0,7692 & 36,8909 \\
\hline $\mathrm{Mn} / \mathrm{P}$ & 16,3971 & 2,3057 & 14,0617 \\
\hline $\mathrm{Mn} / \mathrm{K}$ & 4,3287 & 0,9763 & 22,5554 \\
\hline $\mathrm{Mn} / \mathrm{Ca}$ & 2,5587 & 0,2279 & 8,9088 \\
\hline $\mathrm{Mn} / \mathrm{Mg}$ & 21,4915 & 3,1580 & 14,6942 \\
\hline $\mathrm{Mn} / \mathrm{S}$ & 18,7977 & 4,0952 & 21,7856 \\
\hline $\mathrm{Mn} / \mathrm{B}$ & 2,3678 & 0,3341 & 14,1113 \\
\hline $\mathrm{Mn} / \mathrm{Cu}$ & 1,5103 & 0,6511 & 43,1156 \\
\hline $\mathrm{Mn} / \mathrm{Fe}$ & 1,2644 & 0,0793 & 6,2776 \\
\hline $\mathrm{Mn} / \mathrm{Zn}$ & 1,4667 & 0,0615 & 4,1984 \\
\hline $\mathrm{Zn} / \mathrm{N}$ & 1,4254 & 0,5399 & 37,8769 \\
\hline $\mathrm{Zn} / \mathrm{P}$ & 11,1744 & 1,4668 & 13,1270 \\
\hline $\mathrm{Zn} / \mathrm{K}$ & 2,9534 & 0,6774 & 22,9390 \\
\hline $\mathrm{Zn} / \mathrm{Ca}$ & 1,7448 & 0,1451 & 16,0685 \\
\hline $\mathrm{Zn} / \mathrm{Mg}$ & 14,6823 & 2,3592 & 20,4439 \\
\hline $\mathrm{Zn} / \mathrm{S}$ & 12,7942 & 2,6156 & 38,4933 \\
\hline $\mathrm{Zn} / \mathrm{B}$ & 1,6113 & 0,1834 & \\
\hline $\mathrm{Zn} / \mathrm{Cu}$ & 1,0192 & 0,3923 & 0,17868 \\
\hline $\mathrm{Zn} / \mathrm{Fe}$ & 0,8619 & 0,0360 & \\
\hline $\mathrm{Zn} / \mathrm{Mn}$ & 0,6827 & 0,0277 & \\
\hline & & & \\
\hline
\end{tabular}


Tabela 14 - Média , Desvio Padrão e Coeficiente de Variação (Normas) para os nutrientes e para suas relações dois a dois, considerando limbo - $2^{\mathrm{a}}$ coleta (fruto entre ervilha e meia baga).

\begin{tabular}{|c|c|c|c|}
\hline NUTRIENTES & MÉDIA & DESVIO PADRÃO & COEF. VARIAÇÄO (\%) \\
\hline$N(\%)$ & 3,0340 & 0,2526 & 8,3271 \\
\hline $\mathrm{P}(\%)$ & 0,3740 & 0,1662 & 44,4445 \\
\hline$K(\%)$ & 1,7640 & 0,1408 & 7,9829 \\
\hline $\mathrm{Ca}(\%)$ & 2,3840 & 0,5658 & 23,7332 \\
\hline $\mathrm{Mg}(\%)$ & 0,3580 & 0,0746 & 20,8470 \\
\hline$S(\%)$ & 0,2740 & 0,0698 & 25,4952 \\
\hline $\mathrm{B} \ln (\mathrm{ppm})$ & 2,8837 & 0,5671 & 19,6661 \\
\hline Cu In (ppm) & 6,0170 & 2,3100 & 38,3917 \\
\hline $\mathrm{Fe} \ln (\mathrm{ppm})$ & 5,8392 & 0,2374 & 4,0668 \\
\hline $\mathrm{Mn} \ln (\mathrm{ppm})$ & 6,3767 & 0,3916 & 6,1421 \\
\hline $\mathrm{Zn} \ln (\mathrm{ppm})$ & 4,4459 & 0,5567 & 12,5220 \\
\hline RELAÇÃO & MÉDIA & DESVIO PADRÃO & COEF. VARIAÇÃO (\%) \\
\hline N/P & 9,0873 & 2,8236 & 31,0724 \\
\hline $\mathrm{N} / \mathrm{K}$ & 1,7340 & 0,2484 & 14,3266 \\
\hline $\mathrm{N} / \mathrm{Ca}$ & 1,3240 & 0,2818 & 21,2892 \\
\hline $\mathrm{N} / \mathrm{Mg}$ & 8,7381 & 1,6307 & 18,6624 \\
\hline N/S & 11,5993 & 2,6974 & 23,2555 \\
\hline N/B & 1,0889 & 0,2516 & 23,1115 \\
\hline $\mathrm{N} / \mathrm{Cu}$ & 0,5751 & 0,2328 & 40,4808 \\
\hline $\mathrm{N} / \mathrm{Fe}$ & 0,5212 & 0,0592 & 11,3579 \\
\hline $\mathrm{N} / \mathrm{Mn}$ & 0,4753 & 0,0154 & 3,2406 \\
\hline $\mathrm{N} / \mathrm{Zn}$ & 0,6901 & 0,0900 & 13,0491 \\
\hline $\mathrm{P} / \mathrm{N}$ & 0,1256 & 0,0633 & 50,4580 \\
\hline $\mathrm{P} / \mathrm{K}$ & 0,2148 & 0,1029 & 47,9269 \\
\hline $\mathrm{P} / \mathrm{Ca}$ & 0,1531 & 0,0318 & 20,8130 \\
\hline P/Mg & 1,0222 & 0,2495 & 24,4119 \\
\hline$P / S$ & 1,3362 & 0,2734 & 20,4642 \\
\hline P/B & 0,1259 & 0,0280 & 22,2940 \\
\hline
\end{tabular}




\begin{tabular}{|c|c|c|c|}
\hline RELAÇÃO & MÉDIA & DESVIO PADRÃO & COEF. VARIAÇÃO (\%) \\
\hline $\mathrm{P} / \mathrm{Cu}$ & 0,0664 & 0,0237 & 35,7323 \\
\hline $\mathrm{P} / \mathrm{Fe}$ & 0,0643 & 0,0294 & 45,7995 \\
\hline $\mathrm{P} / \mathrm{Mn}$ & 0,0596 & 0,0299 & 50,1960 \\
\hline $\mathrm{P} / \mathrm{Zn}$ & 0,0898 & 0,0579 & 64,5061 \\
\hline $\mathrm{K} / \mathrm{N}$ & 0,5866 & 0,0872 & 14,8794 \\
\hline K/P & 5,2776 & 1,6695 & 31,6336 \\
\hline $\mathrm{K} / \mathrm{Ca}$ & 0,7764 & 0,2079 & 26,7752 \\
\hline $\mathrm{K} / \mathrm{Mg}$ & 5,1486 & 1,4203 & 27,5859 \\
\hline KIS & 6,7942 & 1,8850 & 27,7438 \\
\hline $\mathrm{K} / \mathrm{B}$ & 0,6277 & 0,1103 & 17,5755 \\
\hline $\mathrm{K} / \mathrm{Cu}$ & 0,3473 & 0,1782 & 51,3244 \\
\hline $\mathrm{K} / \mathrm{Fe}$ & 0,3017 & 0,0135 & 4,4836 \\
\hline $\mathrm{K} / \mathrm{Mn}$ & 0,2780 & 0,0339 & 12,2191 \\
\hline $\mathrm{K} / \mathrm{Zn}$ & 0,4011 & 0,0527 & 13,1389 \\
\hline $\mathrm{Ca} / \mathrm{N}$ & 0,7925 & 0,2211 & 27,9070 \\
\hline $\mathrm{Ca} / \mathrm{P}$ & 6,7409 & 1,2842 & 19,0512 \\
\hline $\mathrm{Ca} / \mathrm{K}$ & 1,3701 & 0,3926 & 28,6591 \\
\hline $\mathrm{Ca} / \mathrm{Mg}$ & 6,6531 & 0,5245 & 7,8837 \\
\hline $\mathrm{Ca} / \mathrm{S}$ & 8,7304 & 0,2661 & 3,0487 \\
\hline $\mathrm{Ca} / \mathrm{B}$ & 0,8303 & 0,1355 & 16,3241 \\
\hline $\mathrm{Ca} / \mathrm{Cu}$ & 0,4279 & 0,1149 & 26,8524 \\
\hline $\mathrm{Ca} / \mathrm{Fe}$ & 0,4102 & 0,1054 & 25,6987 \\
\hline $\mathrm{Ca} / \mathrm{Mn}$ & 0,3764 & 0,1041 & 27,6653 \\
\hline $\mathrm{Ca} / \mathrm{Zn}$ & 0,5590 & 0,2294 & 41,0496 \\
\hline $\mathrm{Mg} / \mathrm{N}$ & 0,1185 & 0,0278 & 23,5057 \\
\hline $\mathrm{Mg} / \mathrm{P}$ & 1,0210 & 0,2242 & 21,9620 \\
\hline $\mathrm{Mg} / \mathrm{K}$ & 0,2057 & 0,0535 & 26,0201 \\
\hline $\mathrm{Mg} / \mathrm{Ca}$ & 0,1510 & 0,0121 & 8,0126 \\
\hline $\mathrm{Mg} / \mathrm{S}$ & 1,3213 & 0,1451 & 10,9849 \\
\hline $\mathrm{Mg} / \mathrm{B}$ & 0,1254 & 0,0232 & 18,5519 \\
\hline $\mathrm{Mg} / \mathrm{Cu}$ & 0,0645 & 0,0181 & 28,1675 \\
\hline $\mathrm{Mg} / \mathrm{Fe}$ & 0,0616 & 0,0143 & 23,1939 \\
\hline
\end{tabular}




\begin{tabular}{|c|c|c|c|}
\hline RELAÇÃO & MÉDIA & DESVIO PADRÃO & COEF. VARIAÇÃO (\%) \\
\hline $\mathrm{Mg} / \mathrm{Mn}$ & 0,0564 & 0,0134 & 23,7967 \\
\hline $\mathrm{Mg} / \mathrm{Zn}$ & 0,0835 & 0,0307 & 36,8060 \\
\hline$S / N$ & 0,0912 & 0,0273 & 29,9823 \\
\hline S/P & 0,7723 & 0,1474 & 19,0939 \\
\hline$S / K$ & 0,1574 & 0,0475 & 30,2168 \\
\hline $\mathrm{S} / \mathrm{Ca}$ & 0,1146 & 0,0034 & 2,9981 \\
\hline $\mathrm{S} / \mathrm{Mg}$ & 0,7639 & 0,0815 & 10,6682 \\
\hline S/B & 0,0952 & 0,0160 & 16,8919 \\
\hline $\mathrm{S} / \mathrm{Cu}$ & 0,0490 & 0,0131 & 26,7650 \\
\hline $\mathrm{S} / \mathrm{Fe}$ & 0,0471 & 0,0128 & 27,3034 \\
\hline S/Mn & 0,0433 & 0,0128 & 29,6131 \\
\hline$S / Z n$ & 0,0643 & 0,0276 & 42,9795 \\
\hline $\mathrm{B} / \mathrm{N}$ & 0,9641 & 0,2529 & 26,2306 \\
\hline $\mathrm{B} / \mathrm{P}$ & 8,2090 & 1,5292 & 18,6286 \\
\hline $\mathrm{B} / \mathrm{K}$ & 1,6436 & 0,3618 & 22,0160 \\
\hline $\mathrm{B} / \mathrm{Ca}$ & 1,2311 & 0,2062 & 16,7544 \\
\hline $\mathrm{B} / \mathrm{Mg}$ & 8,1906 & 1,5031 & 18,3522 \\
\hline $\mathrm{B} / \mathrm{S}$ & 10,7598 & 1,9393 & 18,0237 \\
\hline $\mathrm{B} / \mathrm{Cu}$ & 0,5454 & 0,2335 & 42,8122 \\
\hline $\mathrm{B} / \mathrm{Fe}$ & 0,4945 & 0,1007 & 20,3723 \\
\hline $\mathrm{B} / \mathrm{Mn}$ & 0,4572 & 0,1160 & 25,3787 \\
\hline $\mathrm{B} / \mathrm{Zn}$ & 0,6725 & 0,2468 & 36,7035 \\
\hline $\mathrm{Cu} / \mathrm{N}$ & 1,9776 & 0,7553 & 38,1935 \\
\hline $\mathrm{Cu} / \mathrm{P}$ & 17,0216 & 6,9255 & 40,6865 \\
\hline $\mathrm{Cu} / \mathrm{K}$ & 3,5020 & 1,5243 & 43,5266 \\
\hline $\mathrm{Cu} / \mathrm{Ca}$ & 2,4740 & 0,6436 & 26,0150 \\
\hline $\mathrm{Cu} / \mathrm{Mg}$ & 16,4227 & 4,2032 & 25,5940 \\
\hline $\mathrm{Cu} / \mathrm{S}$ & 21,5887 & 5,6168 & 26,0174 \\
\hline $\mathrm{Cu} / \mathrm{B}$ & 2,1226 & 0,8597 & 40,5034 \\
\hline $\mathrm{Cu} / \mathrm{Fe}$ & 1,0413 & 0,4228 & 40,6022 \\
\hline $\mathrm{Cu} / \mathrm{Mn}$ & 0,9421 & 0,3647 & 38,7170 \\
\hline $\mathrm{Cu} / \mathrm{Zn}$ & 1,4146 & 0,7002 & 49,4981 \\
\hline
\end{tabular}




\begin{tabular}{|l|c|c|c|}
\hline RELAÇÃO & MÉDIA & DESVIO PADRÃO & COEF. VARIAÇÃO(\%) \\
\hline $\mathrm{Fe} / \mathrm{N}$ & 1,9393 & 0,2302 & 11,8743 \\
\hline $\mathrm{Fe} / \mathrm{P}$ & 17,4116 & 5,2069 & 29,9052 \\
\hline $\mathrm{Fe} / \mathrm{K}$ & 3,3190 & 0,1477 & 4,4509 \\
\hline $\mathrm{Fe} / \mathrm{Ca}$ & 2,5562 & 0,5889 & 23,0376 \\
\hline $\mathrm{Fe} / \mathrm{Mg}$ & 16,9585 & 4,0821 & 24,0711 \\
\hline $\mathrm{Fe} / \mathrm{S}$ & 22,3594 & 5,3577 & 23,9617 \\
\hline $\mathrm{Fe} / \mathrm{B}$ & 2,0783 & 0,3460 & 16,6517 \\
\hline $\mathrm{Fe} / \mathrm{Cu}$ & 1,1331 & 0,5350 & 47,2153 \\
\hline $\mathrm{Fe} / \mathrm{Mn}$ & 0,9194 & 0,0823 & 8,9569 \\
\hline $\mathrm{Fe} / \mathrm{Zn}$ & 1,3310 & 0,1842 & 13,8444 \\
\hline $\mathrm{Mn} / \mathrm{N}$ & 2,1054 & 0,0704 & 3,3456 \\
\hline $\mathrm{Mn} / \mathrm{P}$ & 19,1101 & 5,8864 & 30,8029 \\
\hline $\mathrm{Mn} / \mathrm{K}$ & 3,6404 & 0,4472 & 12,2860 \\
\hline $\mathrm{Mn} / \mathrm{Ca}$ & 2,7850 & 0,5849 & 21,0020 \\
\hline $\mathrm{Mn} / \mathrm{Mg}$ & 18,4161 & 3,6587 & 19,8671 \\
\hline $\mathrm{Mn} / \mathrm{S}$ & 24,3822 & 5,4970 & 22,5451 \\
\hline $\mathrm{Mn} / \mathrm{B}$ & 2,2865 & 0,4978 & 21,7746 \\
\hline $\mathrm{Mn} / \mathrm{Cu}$ & 1,2140 & 0,5026 & 41,4027 \\
\hline $\mathrm{Mn} / \mathrm{Fe}$ & 1,0946 & 0,0978 & 8,9349 \\
\hline $\mathrm{Mn} / \mathrm{Zn}$ & 1,4502 & 0,1727 & 11,9097 \\
\hline $\mathrm{Zn} / \mathrm{N}$ & 1,4695 & 0,1982 & 13,4871 \\
\hline $\mathrm{Zn} / \mathrm{P}$ & 13,5855 & 4,8169 & 35,4563 \\
\hline $\mathrm{Zn} / \mathrm{K}$ & 2,5243 & 0,3030 & 12,0032 \\
\hline $\mathrm{Zn} / \mathrm{Ca}$ & 1,9750 & 0,5822 & 29,4809 \\
\hline $\mathrm{Zn} / \mathrm{Mg}$ & 13,0613 & 3,8648 & 29,5901 \\
\hline $\mathrm{Zn} / \mathrm{S}$ & 17,2973 & 5,2758 & 30,5009 \\
\hline $\mathrm{Zn} / \mathrm{B}$ & 1,6051 & 0,4053 & 25,2535 \\
\hline $\mathrm{Zn} / \mathrm{Cu}$ & 0,8758 & 0,4463 & 11,7675 \\
\hline $\mathrm{Zn} / \mathrm{Fe}$ & 0,7612 & 0,0895 & \\
\hline $\mathrm{Zn} / \mathrm{Mn}$ & 0,6971 & 0,0800 & \\
\hline & & & \\
\hline
\end{tabular}


Tabela 15 - Média , Desvio Padrão e Coeficiente de Variação (Normas) para os nutrientes e para suas relações dois a dois, considerando limbo - $3^{\mathrm{a}}$ coleta (início de maturação das bagas).

\begin{tabular}{|c|c|c|c|}
\hline NUTRIENTES & MÉDIA & DESVIO PADRÃO & COEF. VARIAÇÃO (\%) \\
\hline$N(\%)$ & 2,9700 & 0,1339 & 4,5110 \\
\hline $\mathrm{P}(\%)$ & 0,5040 & 0,1967 & 39,0222 \\
\hline$K(\%)$ & 2,9580 & 0,7725 & 26,1159 \\
\hline $\mathrm{Ca}(\%)$ & 3,0080 & 1,1408 & 37,9276 \\
\hline $\mathrm{Mg}(\%)$ & 0,3820 & 0,1404 & 36,7612 \\
\hline$S(\%)$ & 0,3260 & 0,0808 & 24,7878 \\
\hline$B \ln (p p m)$ & 3,1521 & 0,4162 & 13,2056 \\
\hline Cu In (ppm) & 6,3327 & 2,1438 & 33,8537 \\
\hline Fe In (ppm) & 5,7962 & 0,4279 & 7,3827 \\
\hline Mn In (ppm) & 6,2783 & 0,3833 & 6,1054 \\
\hline $\mathrm{Zn} \ln (\mathrm{ppm})$ & 4,4543 & 0,6809 & 15,2868 \\
\hline RELAÇÃO & MÉDIA & DESVIO PADRÃO & COEF. VARIAÇÃO (\%) \\
\hline $\mathrm{N} / \mathrm{P}$ & 6,4015 & 1,6544 & 25,8443 \\
\hline $\mathrm{N} / \mathrm{K}$ & 1,0859 & 0,4019 & 37,0157 \\
\hline $\mathrm{N} / \mathrm{Ca}$ & 1,0695 & 0,2765 & 25,8552 \\
\hline $\mathrm{N} / \mathrm{Mg}$ & 8,4983 & 2,5607 & 30,1324 \\
\hline $\mathrm{N} / \mathrm{S}$ & 9,5215 & 2,1382 & 22,4568 \\
\hline N/B & 0,9528 & 0,1060 & 11,1255 \\
\hline $\mathrm{N} / \mathrm{Cu}$ & 0,5222 & 0,1974 & 37,8085 \\
\hline $\mathrm{N} / \mathrm{Fe}$ & 0,5152 & 0,0513 & 9,9716 \\
\hline N/Mn & 0,4747 & 0,0403 & 8,4899 \\
\hline $\mathrm{N} / \mathrm{Zn}$ & 0,6837 & 0,1412 & 20,6603 \\
\hline $\mathrm{P} / \mathrm{N}$ & 0,1690 & 0,0625 & 37,0273 \\
\hline $\mathrm{P} / \mathrm{K}$ & 0,2021 & 0,1653 & 81,7623 \\
\hline $\mathrm{P} / \mathrm{Ca}$ & 0,1685 & 0,0241 & 14,3027 \\
\hline $\mathrm{P} / \mathrm{Mg}$ & 1,3469 & 0,3041 & 22,5832 \\
\hline PIS & 1,6072 & 0,6331 & 39,3937 \\
\hline P/B & 0,1570 & 0,0421 & 26,8478 \\
\hline
\end{tabular}




\begin{tabular}{|l|c|c|c|}
\hline $\mathrm{RELAÇÃO}$ & MÉDIA & DESVIO PADRÃO & COEF. VARIAÇÃO (\%) \\
\hline $\mathrm{P} / \mathrm{Cu}$ & 0,0855 & 0,0323 & 37,8298 \\
\hline $\mathrm{P} / \mathrm{Fe}$ & 0,0872 & 0,0345 & 39,5378 \\
\hline $\mathrm{P} / \mathrm{Mn}$ & 0,0806 & 0,0321 & 39,8971 \\
\hline $\mathrm{P} / \mathrm{Zn}$ & 0,1221 & 0,0763 & 62,5141 \\
\hline $\mathrm{K} / \mathrm{N}$ & 1,0002 & 0,2725 & 27,2491 \\
\hline $\mathrm{KJP}$ & 6,6838 & 2,7056 & 40,4803 \\
\hline $\mathrm{K} / \mathrm{Ca}$ & 1,1287 & 0,4998 & 44,2825 \\
\hline $\mathrm{K} \mathrm{Mg}$ & 9,0007 & 4,4387 & 49,3152 \\
\hline $\mathrm{K} / \mathrm{S}$ & 9,4622 & 3,1694 & 33,4958 \\
\hline $\mathrm{K} / \mathrm{B}$ & 0,9651 & 0,3094 & 32,0573 \\
\hline $\mathrm{K} / \mathrm{Cu}$ & 0,5515 & 0,3166 & 57,4162 \\
\hline $\mathrm{K} / \mathrm{Fe}$ & 0,5107 & 0,1311 & 25,6818 \\
\hline $\mathrm{K} / \mathrm{Mn}$ & 0,4706 & 0,1175 & 24,9675 \\
\hline $\mathrm{K} / \mathrm{Zn}$ & 0,6541 & 0,0893 & 13,6519 \\
\hline $\mathrm{Ca} / \mathrm{N}$ & 1,0090 & 0,3628 & 35,9615 \\
\hline $\mathrm{Ca} / \mathrm{P}$ & 6,0308 & 0,8707 & 14,4378 \\
\hline $\mathrm{Ca} / \mathrm{K}$ & 1,2116 & 0,9710 & 80,1487 \\
\hline $\mathrm{Ca} / \mathrm{Mg}$ & 7,9680 & 1,1764 & 14,7648 \\
\hline $\mathrm{Ca} / \mathrm{S}$ & 9,5950 & 3,8376 & 39,9957 \\
\hline $\mathrm{Ca} / \mathrm{B}$ & 0,9435 & 0,2615 & 27,7166 \\
\hline $\mathrm{Ca} / \mathrm{Cu}$ & 0,4947 & 0,1375 & 27,8058 \\
\hline $\mathrm{Ca} / \mathrm{Fe}$ & 0,5230 & 0,2047 & 39,1380 \\
\hline $\mathrm{Ca} / \mathrm{Mn}$ & 0,4823 & 0,1900 & 39,3921 \\
\hline $\mathrm{Ca} / \mathrm{Zn}$ & 0,7293 & 0,4472 & 61,3220 \\
\hline $\mathrm{Mg} / \mathrm{N}$ & 0,1277 & 0,0440 & 34,4769 \\
\hline $\mathrm{Mg} / \mathrm{P}$ & 0,7706 & 0,1585 & 20,5724 \\
\hline $\mathrm{Mg} / \mathrm{K}$ & 0,1525 & 0,1171 & 76,7977 \\
\hline $\mathrm{Mg} / \mathrm{Ca}$ & 0,1275 & 0,0172 & 13,5279 \\
\hline $\mathrm{Mg} / \mathrm{S}$ & 1,2152 & 0,4822 & 39,6820 \\
\hline $\mathrm{Mg} / \mathrm{B}$ & 0,1198 & 0,0332 & 27,7285 \\
\hline $\mathrm{Mg} / \mathrm{Cu}$ & 0,0622 & 0,0163 & 38,4639 \\
\hline $\mathrm{Mg} / \mathrm{Fe}$ & 0,0667 & 0,0256 & \\
\hline & & & \\
\hline
\end{tabular}




\begin{tabular}{|c|c|c|c|}
\hline RELAÇÃO & MÉDIA & DESVIO PADRÃO & COEF. VARIAÇÃO (\%) \\
\hline $\mathrm{Mg} / \mathrm{Mn}$ & 0,0612 & 0,0234 & 38,2313 \\
\hline $\mathrm{Mg} / \mathrm{Zn}$ & 0,0922 & 0,0539 & 58,5367 \\
\hline $\mathrm{S} / \mathrm{N}$ & 0,1102 & 0,0295 & 26,8376 \\
\hline S/P & 0,7135 & 0,3171 & 44,4475 \\
\hline $\mathrm{S} / \mathrm{K}$ & 0,1184 & 0,0485 & 40,9925 \\
\hline $\mathrm{S} / \mathrm{Ca}$ & 0,1182 & 0,0460 & 38,9808 \\
\hline $\mathrm{S} / \mathrm{Mg}$ & 0,9358 & 0,3655 & 39,0608 \\
\hline S/B & 0,1067 & 0,0409 & 38,3306 \\
\hline $\mathrm{S} / \mathrm{Cu}$ & 0,0559 & 0,0190 & 33,9820 \\
\hline $\mathrm{S} / \mathrm{Fe}$ & 0,0567 & 0,0159 & 28,0791 \\
\hline S/Mn & 0,0515 & 0,0096 & 18,8150 \\
\hline $\mathrm{S} / \mathrm{Zn}$ & 0,0745 & 0,0207 & 27,8758 \\
\hline $\mathrm{B} / \mathrm{N}$ & 1,0595 & 0,1127 & 10,6413 \\
\hline $\mathrm{B} / \mathrm{P}$ & 6,6518 & 1,3348 & 20,0671 \\
\hline $\mathrm{B} / \mathrm{K}$ & 1,1747 & 0,5549 & 47,2383 \\
\hline $\mathrm{B} / \mathrm{Ca}$ & 1,1191 & 0,2732 & 24,4160 \\
\hline $\mathrm{B} / \mathrm{Mg}$ & 8,9121 & 2,6490 & 29,7242 \\
\hline $\mathrm{B} / \mathrm{S}$ & 10,1780 & 2,6702 & 26,2356 \\
\hline $\mathrm{B} / \mathrm{Cu}$ & 0,5569 & 0,2259 & 40,5649 \\
\hline $\mathrm{B} / \mathrm{Fe}$ & 0,5459 & 0,0804 & 14,7446 \\
\hline $\mathrm{B} / \mathrm{Mn}$ & 0,5048 & 0,0807 & 15,9964 \\
\hline $\mathrm{B} / \mathrm{Zn}$ & 0,7340 & 0,2243 & 30,5605 \\
\hline $\mathrm{Cu} / \mathrm{N}$ & 2,1291 & 0,7100 & 33,3492 \\
\hline Cu/P & 13,4889 & 5,9539 & 44,1396 \\
\hline $\mathrm{Cu} / \mathrm{K}$ & 2,4452 & 1,4981 & 61,2663 \\
\hline $\mathrm{Cu} / \mathrm{Ca}$ & 2,1724 & 0,6858 & 31,5698 \\
\hline $\mathrm{Cu} / \mathrm{Mg}$ & 17,0345 & 4,6993 & 27,5872 \\
\hline $\mathrm{Cu} / \mathrm{S}$ & 19,9159 & 7,6035 & 38,1779 \\
\hline $\mathrm{Cu} / \mathrm{B}$ & 2,0452 & 0,7845 & 38,3599 \\
\hline $\mathrm{Cu} / \mathrm{Fe}$ & 1,1118 & 0,4173 & 37,5325 \\
\hline Cu/Mn & 1,0128 & 0,3543 & 34,9817 \\
\hline $\mathrm{Cu} / \mathrm{Zn}$ & 1,4950 & 0,6962 & 46,5669 \\
\hline
\end{tabular}




\begin{tabular}{|l|c|c|c|}
\hline RELAÇÃO & MÉDIA & DESVIO PADRÄO & COEF. VARIAÇÃO(\%) \\
\hline Fe/N & 1,9582 & 0,2197 & 11,2190 \\
\hline Fe/P & 12,5442 & 3,4960 & 27,8699 \\
\hline Fe/K & 2,1038 & 0,7247 & 34,4478 \\
\hline $\mathrm{Fe} / \mathrm{Ca}$ & 2,1070 & 0,6458 & 30,6541 \\
\hline $\mathrm{Fe} / \mathrm{Mg}$ & 16,9772 & 7,0094 & 41,2872 \\
\hline $\mathrm{Fe} / \mathrm{S}$ & 18,6042 & 4,3932 & 23,6143 \\
\hline $\mathrm{Fe} / \mathrm{B}$ & 1,8651 & 0,2834 & 15,1984 \\
\hline $\mathrm{Fe} / \mathrm{Cu}$ & 1,0423 & 0,4825 & 46,2910 \\
\hline $\mathrm{Fe} / \mathrm{Mn}$ & 0,9260 & 0,0889 & 9,6087 \\
\hline $\mathrm{Fe} / \mathrm{Zn}$ & 1,3291 & 0,2479 & 18,6576 \\
\hline $\mathrm{Mn} / \mathrm{N}$ & 2,1186 & 0,1817 & 8,5760 \\
\hline $\mathrm{Mn} / \mathrm{P}$ & 13,6297 & 3,9983 & 29,3352 \\
\hline $\mathrm{Mn} / \mathrm{K}$ & 2,2775 & 0,7757 & 34,0625 \\
\hline $\mathrm{Mn} / \mathrm{Ca}$ & 2,2791 & 0,6652 & 29,1887 \\
\hline $\mathrm{Mn} / \mathrm{Mg}$ & 18,1653 & 6,2690 & 34,5109 \\
\hline $\mathrm{Mn} / \mathrm{S}$ & 19,8962 & 3,2559 & 16,3645 \\
\hline $\mathrm{Mn} / \mathrm{B}$ & 2,0280 & 0,3734 & 18,4124 \\
\hline $\mathrm{Mn} / \mathrm{Cu}$ & 1,1090 & 0,4381 & 39,5061 \\
\hline $\mathrm{Mn} / \mathrm{Fe}$ & 1,0877 & 0,1033 & 9,5031 \\
\hline $\mathrm{Mn} / \mathrm{Zn}$ & 1,4381 & 0,2535 & 17,6318 \\
\hline $\mathrm{Zn} / \mathrm{N}$ & 1,5055 & 0,2628 & 17,4557 \\
\hline $\mathrm{Zn} / \mathrm{P}$ & 9,9310 & 3,5630 & 35,8777 \\
\hline $\mathrm{Zn} / \mathrm{K}$ & 1,5538 & 0,2312 & 14,8808 \\
\hline $\mathrm{Zn} / \mathrm{Ca}$ & 1,6631 & 0,6122 & 36,8128 \\
\hline $\mathrm{Zn} / \mathrm{Mg}$ & 13,2761 & 5,6688 & 42,6994 \\
\hline $\mathrm{Zn} / \mathrm{S}$ & 14,2217 & 3,6387 & 25,5857 \\
\hline $\mathrm{Zn} / \mathrm{B}$ & 1,4499 & 0,3685 & 25,4193 \\
\hline $\mathrm{Zn} / \mathrm{Cu}$ & 0,8070 & 0,3877 & 48,0494 \\
\hline $\mathrm{Zn} / \mathrm{Fe}$ & 0,7706 & 0,1236 & 16,0400 \\
\hline $\mathrm{Zn} / \mathrm{Mn}$ & 0,7098 & 0,1028 & 14,4888 \\
\hline & & & \\
\hline
\end{tabular}


Tabela 16 - Média, Desvio Padrão e Coeficiente de Variação (Normas) para os nutrientes e para suas relações dois a dois, considerando Pecíolo - $1^{\underline{a}}$ coleta (florescimento).

\begin{tabular}{|c|c|c|c|}
\hline NUTRIENTES & MÉDIA & DESVIO PADRÃO & COEF. VARIAÇÃO (\%) \\
\hline$N(\%)$ & 1,3700 & 0,1919 & 14,0119 \\
\hline$P(\%)$ & 0,5440 & 0,0472 & 8,6806 \\
\hline$K(\%)$ & 3,4600 & 1,2627 & 36,4946 \\
\hline $\mathrm{Ca}(\%)$ & 2,0880 & 0,2690 & 12,8839 \\
\hline $\mathrm{Mg}(\%)$ & 0,4300 & 0,0897 & 20,8655 \\
\hline$S(\%)$ & 0,1200 & 0,0223 & 18,6339 \\
\hline $\mathrm{B} \ln (\mathrm{ppm})$ & 3,2478 & 0,2181 & 6,7163 \\
\hline Cu ln (ppm) & 3,7390 & 1,2760 & 34,1278 \\
\hline $\mathrm{Fe} \ln (\mathrm{ppm})$ & 3,6959 & 0,4042 & 10,9388 \\
\hline Mn In (ppm) & 5,7908 & 0,6298 & 10,8759 \\
\hline $\mathrm{Zn} / \mathrm{n}$ (ppm) & 4,6314 & 0,1735 & 3,7480 \\
\hline RELAÇĀO & MÉDIA & DESVIO PADRÃO & COEF. VARIAÇÃO (\%) \\
\hline $\mathrm{N} / \mathrm{P}$ & 2,5114 & 0,1724 & 6,8673 \\
\hline $\mathrm{N} / \mathrm{K}$ & 0,4898 & 0,3511 & 71,6776 \\
\hline $\mathrm{N} / \mathrm{Ca}$ & 0,6684 & 0,1538 & 23,0197 \\
\hline $\mathrm{N} / \mathrm{Mg}$ & 3,2264 & 0,2951 & 9,1482 \\
\hline $\mathrm{N} / \mathrm{S}$ & 11,5287 & 1,0170 & 8,8215 \\
\hline N/B & 0,4256 & 0,0863 & 20,2813 \\
\hline $\mathrm{N} / \mathrm{Cu}$ & 0,3868 & 0,0946 & 24,4547 \\
\hline $\mathrm{N} / \mathrm{Fe}$ & 0,3711 & 0,0389 & 10,4879 \\
\hline N/Mn & 0,2370 & 0,0274 & 11,5656 \\
\hline $\mathrm{N} / \mathrm{Zn}$ & 0,2958 & 0,0410 & 13,8760 \\
\hline $\mathrm{P} / \mathrm{N}$ & 0,3996 & 0,0259 & 6,5005 \\
\hline $\mathrm{P} / \mathrm{K}$ & 0,1892 & 0,1181 & 62,4045 \\
\hline $\mathrm{P} / \mathrm{Ca}$ & 0,2642 & 0,0437 & 16,5541 \\
\hline P/Mg & 1,2924 & 0,1729 & 13,3788 \\
\hline P/S & 4,6088 & 0,5298 & 11,4968 \\
\hline P/B & 0,1685 & 0,0231 & 13,7165 \\
\hline
\end{tabular}




\begin{tabular}{|c|c|c|c|}
\hline RELAÇÄO & MÉDIA & DESVIO PADRÃO & COEF. VARIAÇÃO (\%) \\
\hline $\mathrm{P} / \mathrm{Cu}$ & 0,1552 & 0,0407 & 26,2084 \\
\hline $\mathrm{P} / \mathrm{Fe}$ & 0,1478 & 0,0133 & 9,0076 \\
\hline $\mathrm{P} / \mathrm{Mn}$ & 0,0942 & 0,0058 & 6,2287 \\
\hline $\mathrm{P} / \mathrm{Zn}$ & 0,1174 & 0,0094 & 8,0357 \\
\hline $\mathrm{K} / \mathrm{N}$ & 2,6011 & 0,9941 & 38,2184 \\
\hline K/P & 6,4145 & 2,3115 & 36,0355 \\
\hline $\mathrm{K} / \mathrm{Ca}$ & 1,6331 & 0,5267 & 32,2563 \\
\hline $\mathrm{K} / \mathrm{Mg}$ & 8,4889 & 3.3399 & 39.3444 \\
\hline KJS & 30,0417 & 11,5205 & 38,3483 \\
\hline K/B & 1,0505 & 0,3507 & 33,3865 \\
\hline $\mathrm{K} / \mathrm{Cu}$ & 1,0546 & 0,5186 & 49,1790 \\
\hline $\mathrm{K} / \mathrm{Fe}$ & 0,9562 & 0,3689 & 38,5762 \\
\hline K/Mn & 0,5964 & 0,2033 & 34,0912 \\
\hline $\mathrm{K} / \mathrm{Zn}$ & 0,7440 & 0,2624 & 35,2717 \\
\hline $\mathrm{Ca} / \mathrm{N}$ & 1,5540 & 0,3185 & 20,4968 \\
\hline $\mathrm{Ca} / \mathrm{P}$ & 3,8659 & 0,6244 & 16,1521 \\
\hline $\mathrm{Ca} / \mathrm{K}$ & 0,6892 & 0,3105 & 45,0589 \\
\hline $\mathrm{Ca} / \mathrm{Mg}$ & 5,0242 & 1,1171 & 22,2344 \\
\hline $\mathrm{Ca} / \mathrm{S}$ & 17,8917 & 3,7873 & 21,1682 \\
\hline $\mathrm{Ca} / \mathrm{B}$ & 0,6437 & 0,0791 & 12,2975 \\
\hline $\mathrm{Ca} / \mathrm{Cu}$ & 0,6034 & 0,1728 & 28,6380 \\
\hline $\mathrm{Ca} / \mathrm{Fe}$ & 0,5690 & 0,0805 & 14,1536 \\
\hline $\mathrm{Ca} / \mathrm{Mn}$ & 0,3639 & 0,0603 & 16,5810 \\
\hline $\mathrm{Ca} / \mathrm{Zn}$ & 0,4516 & 0,0634 & 14,0532 \\
\hline $\mathrm{Mg} / \mathrm{N}$ & 0,3120 & 0,0280 & 9,0031 \\
\hline $\mathrm{Mg} / \mathrm{P}$ & 0,7857 & 0,1130 & 14,3923 \\
\hline $\mathrm{Mg} / \mathrm{K}$ & 0,1575 & 0,1273 & 80,8037 \\
\hline $\mathrm{Mg} / \mathrm{Ca}$ & 0,2096 & 0,0601 & 28,6825 \\
\hline $\mathrm{Mg} / \mathrm{S}$ & 3,5781 & 0,1944 & 5,4340 \\
\hline $\mathrm{Mg} / \mathrm{B}$ & 0,1342 & 0,0378 & 28,1780 \\
\hline $\mathrm{Mg} / \mathrm{Cu}$ & 0,1192 & 0,0228 & 19,1473 \\
\hline $\mathrm{Mg} / \mathrm{Fe}$ & 0,1155 & 0,0138 & 12,0002 \\
\hline
\end{tabular}




\begin{tabular}{|c|c|c|c|}
\hline RELAÇÃO & MÉDIA & DESVIO PADRÃO & COEF. VARIAÇÃO (\%) \\
\hline $\mathrm{Mg} / \mathrm{Mn}$ & 0,0744 & 0,0147 & 19,7791 \\
\hline $\mathrm{Mg} / \mathrm{Zn}$ & 0,0929 & 0,0202 & 21,8053 \\
\hline$S / N$ & 0,0872 & 0,0078 & 8,9910 \\
\hline$S / P$ & 0,2192 & 0,0253 & 11,5446 \\
\hline $\mathrm{S} / \mathrm{K}$ & 0,0431 & 0,0325 & 75,4575 \\
\hline $\mathrm{S} / \mathrm{Ca}$ & 0,0583 & 0,0145 & 24,9816 \\
\hline $\mathrm{S} / \mathrm{Mg}$ & 0,2801 & 0,0154 & 5,5104 \\
\hline S/B & 0,0373 & 0,0094 & 25,1632 \\
\hline $\mathrm{s} / \mathrm{Cu}$ & 0,0335 & 0,0073 & 21,7658 \\
\hline $\mathrm{S} / \mathrm{Fe}$ & 0,0323 & 0,0033 & 10,3600 \\
\hline S/Mn & 0,0207 & 0,0034 & 16,7144 \\
\hline$S / Z n$ & 0,0259 & 0,0050 & 19,3336 \\
\hline$B / N$ & 2,4170 & 0,4238 & 17,5357 \\
\hline $\mathrm{B} / \mathrm{P}$ & 6,0196 & 0,7821 & 12,9930 \\
\hline $\mathrm{B} / \mathrm{K}$ & 1,0846 & 0,5102 & 47,0392 \\
\hline $\mathrm{B} / \mathrm{Ca}$ & 1,5721 & 0,1903 & 12,1084 \\
\hline $\mathrm{B} / \mathrm{Mg}$ & 7,8697 & 1,9145 & 24,3283 \\
\hline $\mathrm{B} / \mathrm{S}$ & 28,0456 & 6,5989 & 23,5294 \\
\hline $\mathrm{B} / \mathrm{Cu}$ & 0,9463 & 0,2934 & 31,0099 \\
\hline $\mathrm{B} / \mathrm{Fe}$ & 0,8914 & 0,1462 & 16,4093 \\
\hline $\mathrm{B} / \mathrm{Mn}$ & 0,5654 & 0,0661 & 11,6975 \\
\hline $\mathrm{B} / \mathrm{Zn}$ & 0,7012 & 0,0390 & 5,5722 \\
\hline $\mathrm{Cu} / \mathrm{N}$ & 2,7024 & 0,6190 & 22,9074 \\
\hline $\mathrm{Cu} / \mathrm{P}$ & 6,8374 & 1,9749 & 28,8845 \\
\hline $\mathrm{Cu} / \mathrm{K}$ & 1,4661 & 1,4350 & 97,8844 \\
\hline $\mathrm{Cu} / \mathrm{Ca}$ & 1,8396 & 0,8048 & 43,7490 \\
\hline $\mathrm{Cu} / \mathrm{Mg}$ & 8,6169 & 1,5268 & 17,7192 \\
\hline $\mathrm{Cu} / \mathrm{S}$ & 30,9450 & 6,4964 & 20,9935 \\
\hline Cu/B & 1,1779 & 0,5061 & 42,9699 \\
\hline $\mathrm{Cu} / \mathrm{Fe}$ & 0,9970 & 0,2380 & 23,8733 \\
\hline $\mathrm{Cu} / \mathrm{Mn}$ & 0,6528 & 0,2281 & 349519 \\
\hline $\mathrm{Cu} / \mathrm{Zn}$ & 0,8119 & 0,2915 & 35,9084 \\
\hline
\end{tabular}




\begin{tabular}{|l|c|c|c|}
\hline RELAÇÃO & MÉDIA & DESVIO PADRÃO & COEF. VARIAÇÃO(\%) \\
\hline $\mathrm{Fe} / \mathrm{N}$ & 2,7167 & 0,2710 & 9,9775 \\
\hline $\mathrm{Fe} / \mathrm{P}$ & 6,8021 & 0,5615 & 8,2555 \\
\hline $\mathrm{Fe} / \mathrm{K}$ & 1,3052 & 0,8726 & 66,8590 \\
\hline $\mathrm{Fe} / \mathrm{Ca}$ & 1,7912 & 0,3013 & 16,8217 \\
\hline $\mathrm{Fe} / \mathrm{Mg}$ & 8,7491 & 1,0256 & 11.7224 \\
\hline $\mathrm{Fe} / \mathrm{S}$ & 31,2336 & 3,3363 & 10,6818 \\
\hline $\mathrm{Fe} / \mathrm{B}$ & 1,1483 & 0,2038 & 17,7473 \\
\hline $\mathrm{Fe} / \mathrm{Cu}$ & 1,0410 & 0,2017 & 19,3749 \\
\hline $\mathrm{Fe} / \mathrm{Mn}$ & 0,6431 & 0,0864 & 13,4365 \\
\hline $\mathrm{Fe} / \mathrm{Zn}$ & 0,7999 & 0,1026 & 12.8325 \\
\hline $\mathrm{Mn} / \mathrm{N}$ & 4,2595 & 0,4369 & 10,2574 \\
\hline $\mathrm{Mn} / \mathrm{P}$ & 10,6462 & 0,6792 & 6,3805 \\
\hline $\mathrm{Mn} / \mathrm{K}$ & 1,9702 & 1,1000 & 55,8332 \\
\hline $\mathrm{Mn} / \mathrm{Ca}$ & 2,8106 & 0,4750 & 16,9017 \\
\hline $\mathrm{Mn} / \mathrm{Mg}$ & 13,8190 & 2,4306 & 17,5894 \\
\hline $\mathrm{Mn} / \mathrm{S}$ & 49,2366 & 7,7544 & 15,7492 \\
\hline $\mathrm{Mn} / \mathrm{B}$ & 1,7876 & 0,2039 & 11,4103 \\
\hline $\mathrm{Mn} / \mathrm{Cu}$ & 1,6747 & 0,5446 & 32,5215 \\
\hline $\mathrm{Mn} / \mathrm{Fe}$ & 1,5808 & 0,2432 & 15,3888 \\
\hline $\mathrm{Mn} / \mathrm{Zn}$ & 1,2482 & 0,0953 & 7,6364 \\
\hline $\mathrm{Zn} / \mathrm{N}$ & 3,4283 & 0,4374 & 12,7601 \\
\hline $\mathrm{Zn} / \mathrm{P}$ & 8,5575 & 0,6899 & 8,0621 \\
\hline $\mathrm{Zn} / \mathrm{K}$ & 1,5793 & 0,8571 & 54,2737 \\
\hline $\mathrm{Zn} / \mathrm{Ca}$ & 2,2482 & 0,3012 & 13,3999 \\
\hline $\mathrm{Zn} / \mathrm{Mg}$ & 11,1378 & 2,2509 & 20,2096 \\
\hline $\mathrm{Zn} / \mathrm{S}$ & 39,7153 & 7,6402 & 19,2375 \\
\hline $\mathrm{Zn} / \mathrm{B}$ & 1,4297 & 0,0841 & 5,8850 \\
\hline $\mathrm{Zn} / \mathrm{Cu}$ & 1,3376 & 0,3837 & 28,6840 \\
\hline $\mathrm{Zn} / \mathrm{Fe}$ & 1,2668 & 0,1629 & 7,7337 \\
\hline $\mathrm{Zn} / \mathrm{Mn}$ & 0,8049 & 0,0622 & \\
\hline & & & \\
\hline
\end{tabular}


Tabela 17 - Média , Desvio Padrão e Coeficiente de Variação (Normas) para os nutrientes e para suas relações dois a dois, considerando Peciolo - $2^{\mathrm{a}}$ coleta (fruto entre ervilha e meia baga).

\begin{tabular}{|c|c|c|c|}
\hline NUTRIENTES & MÉDIA & DESVIO PADRÃO & COEF. VARIAÇÃO (\%) \\
\hline$N(\%)$ & 0,9280 & 0,1263 & 13,6177 \\
\hline$P(\%)$ & 0,5520 & 0,0729 & 13,2134 \\
\hline$K(\%)$ & 5,1620 & 0,3785 & 7,3339 \\
\hline $\mathrm{Ca}(\%)$ & 1,7000 & 0,2363 & 13,9015 \\
\hline $\mathrm{Mg}(\%)$ & 0,5780 & 0,0725 & 12,5596 \\
\hline$S(\%)$ & 0,0760 & 0,0391 & 51,4673 \\
\hline $\mathrm{B} \ln (\mathrm{ppm})$ & 2,7129 & 0,1423 & 5,2453 \\
\hline Cu In (ppm) & 4,7744 & 1,9455 & 40,7483 \\
\hline $\mathrm{Fe} \ln (\mathrm{ppm})$ & 4,8624 & 0,5794 & 11,9172 \\
\hline $\mathrm{Mn} \ln (\mathrm{ppm})$ & 6,6986 & 0,5842 & 8,7225 \\
\hline $\mathrm{Zn} \ln (\mathrm{ppm})$ & 4,8686 & 0,5671 & 11,6482 \\
\hline RELAÇÃO & MÉDIA & DESVIO PADRÃO & COEF. VARIAÇÃO (\%) \\
\hline N/P & 1,6805 & 0,0223 & 1,3295 \\
\hline$N / K$ & 0,1820 & 0,0399 & 21,9571 \\
\hline $\mathrm{N} / \mathrm{Ca}$ & 0,5469 & 0,0387 & 7,0893 \\
\hline $\mathrm{N} / \mathrm{Mg}$ & 1,6080 & 0,1090 & 6,7831 \\
\hline N/S & 14,3178 & 6,0559 & 42,2962 \\
\hline N/B & 0,3437 & 0,0588 & 17,1091 \\
\hline $\mathrm{N} / \mathrm{Cu}$ & 0,2216 & 0,0865 & 39,0619 \\
\hline $\mathrm{N} / \mathrm{Fe}$ & 0,1949 & 0,0501 & 25,7410 \\
\hline $\mathrm{N} / \mathrm{Mn}$ & 0,1394 & 0,0236 & 16,9313 \\
\hline $\mathrm{N} / \mathrm{Zn}$ & 0,1952 & 0,0532 & 27,2862 \\
\hline $\mathrm{P} / \mathrm{N}$ & 0,5951 & 0,0079 & 1,3330 \\
\hline$P / K$ & 0,1083 & 0,0234 & 21,6655 \\
\hline $\mathrm{P} / \mathrm{Ca}$ & 0,3254 & 0,0226 & 6,9718 \\
\hline $\mathrm{P} / \mathrm{Mg}$ & 0,9569 & 0,0651 & 6,8127 \\
\hline$P / S$ & 8,4950 & 3,5012 & 41,2155 \\
\hline$P / B$ & 0,2043 & 0,0337 & 16,5286 \\
\hline
\end{tabular}




\begin{tabular}{|c|c|c|c|}
\hline RELAÇÃO & MÉDIA & DESVIO PADRÃO & COEF. VARIAÇÃO (\%) \\
\hline $\mathrm{P} / \mathrm{Cu}$ & 0,1324 & 0,0533 & 40,3209 \\
\hline $\mathrm{P} / \mathrm{Fe}$ & 0,1159 & 0,0295 & 25,4895 \\
\hline P/Mn & 0,0829 & 0,0140 & 16,9758 \\
\hline $\mathrm{P} / \mathrm{Zn}$ & 0,1161 & 0,0314 & 27,0705 \\
\hline $\mathrm{K} / \mathrm{N}$ & 5,6806 & 1,0934 & 19,2482 \\
\hline $\mathrm{K} / \mathrm{P}$ & 9,5401 & 1,7970 & 18,8367 \\
\hline $\mathrm{K} / \mathrm{Ca}$ & 3,0952 & 0,5377 & 17,3715 \\
\hline $\mathrm{K} / \mathrm{Mg}$ & 9,1152 & 1,8498 & 20,2942 \\
\hline $\mathrm{K} / \mathrm{S}$ & 82,9571 & 38,8900 & 46,8797 \\
\hline K/B & 1,9049 & 0,1445 & 7,5876 \\
\hline $\mathrm{KJCu}$ & 1,3048 & 0,7082 & 54,2771 \\
\hline $\mathrm{K} / \mathrm{Fe}$ & 1,0693 & 0,1003 & 9,3822 \\
\hline K/Mn & 0,7742 & 0,0792 & 10,2354 \\
\hline $\mathrm{K} / \mathrm{Zn}$ & 1,0659 & 0,0697 & 6,5462 \\
\hline $\mathrm{Ca} / \mathrm{N}$ & 1,8361 & 0,1362 & 7,4205 \\
\hline $\mathrm{Ca} / \mathrm{P}$ & 3,0849 & 0,2184 & 7,0816 \\
\hline $\mathrm{Ca} / \mathrm{K}$ & 0,3334 & 0,0748 & 22,4544 \\
\hline $\mathrm{Ca} / \mathrm{Mg}$ & 2,9621 & 0,3995 & 13,4873 \\
\hline $\mathrm{Ca} / \mathrm{S}$ & 26,0050 & 10,1939 & 39,2000 \\
\hline $\mathrm{Ca} / \mathrm{B}$ & 0,6304 & 0,1143 & 18,1371 \\
\hline $\mathrm{Ca} / \mathrm{Cu}$ & 0,4112 & 0,1822 & 44,3103 \\
\hline $\mathrm{Ca} / \mathrm{Fe}$ & 0,3586 & 0,1001 & 27,9326 \\
\hline $\mathrm{Ca} / \mathrm{Mn}$ & 0,2561 & 0,0490 & 19,1409 \\
\hline $\mathrm{Ca} / \mathrm{Zn}$ & 0,3584 & 0,1029 & 28,7089 \\
\hline $\mathrm{Mg} / \mathrm{N}$ & 0,6241 & 0,0425 & 6,8087 \\
\hline $\mathrm{Mg} / \mathrm{P}$ & 1,0488 & 0,0705 & 6,7221 \\
\hline $\mathrm{Mg} / \mathrm{K}$ & 0,1131 & 0,0218 & 19,2606 \\
\hline $\mathrm{Mg} / \mathrm{Ca}$ & 0,3424 & 0,0455 & 13,2855 \\
\hline $\mathrm{Mg} / \mathrm{S}$ & 9,0228 & 4,0393 & 44,7678 \\
\hline $\mathrm{Mg} / \mathrm{B}$ & 0,2135 & 0,0300 & 14,0782 \\
\hline $\mathrm{Mg} / \mathrm{Cu}$ & 0,1385 & 0,0550 & 39,7314 \\
\hline $\mathrm{Mg} / \mathrm{Fe}$ & 0,1205 & 0,0249 & 20,6807 \\
\hline
\end{tabular}




\begin{tabular}{|l|c|c|c|}
\hline RELAÇÃO & MÉDIA & DESVIO PADRÃO & COEF. VARIAÇÃO (\%) \\
\hline $\mathrm{Mg} / \mathrm{Mn}$ & 0,0866 & 0,0120 & 13,9407 \\
\hline $\mathrm{Mg} / \mathrm{Zn}$ & 0,1209 & 0,0279 & 23,0801 \\
\hline $\mathrm{S} / \mathrm{N}$ & 0,0801 & 0,0316 & 39,5473 \\
\hline $\mathrm{S} / \mathrm{P}$ & 0,1343 & 0,0527 & 39,2727 \\
\hline $\mathrm{S} / \mathrm{K}$ & 0,0152 & 0,0092 & 60,9177 \\
\hline $\mathrm{S} / \mathrm{Ca}$ & 0,0434 & 0,0164 & 37,8678 \\
\hline $\mathrm{S} / \mathrm{Mg}$ & 0,1304 & 0,0579 & 44,4434 \\
\hline $\mathrm{S} / \mathrm{B}$ & 0,0282 & 0,0155 & 55,0640 \\
\hline $\mathrm{S} / \mathrm{Cu}$ & 0,0183 & 0,0103 & 56,1982 \\
\hline $\mathrm{S} / \mathrm{Fe}$ & 0,0165 & 0,0109 & 66,2604 \\
\hline $\mathrm{S} / \mathrm{Mn}$ & 0,0116 & 0,0066 & 56,7051 \\
\hline $\mathrm{S} / \mathrm{Zn}$ & 0,0166 & 0,0112 & 67,6032 \\
\hline $\mathrm{B} / \mathrm{N}$ & 2,9709 & 0,4539 & 15,2808 \\
\hline $\mathrm{B} / \mathrm{P}$ & 4,9880 & 0,7249 & 14,5339 \\
\hline $\mathrm{B} / \mathrm{K}$ & 0,5274 & 0,0409 & 7,7568 \\
\hline $\mathrm{B} / \mathrm{Ca}$ & 1,6225 & 0,2523 & 15,5504 \\
\hline $\mathrm{B} / \mathrm{Mg}$ & 4,7612 & 0,7098 & 14,9081 \\
\hline $\mathrm{B} / \mathrm{S}$ & 42,7900 & 18,1541 & 42,4260 \\
\hline $\mathrm{B} / \mathrm{Cu}$ & 0,6824 & 0,3542 & 51,9115 \\
\hline $\mathrm{B} / \mathrm{Fe}$ & 0,5631 & 0,0589 & 10,4639 \\
\hline $\mathrm{B} / \mathrm{Mn}$ & 0,4075 & 0,0417 & 10,2538 \\
\hline $\mathrm{B} / \mathrm{Zn}$ & 0,5629 & 0,0654 & 11,6303 \\
\hline $\mathrm{Cu} / \mathrm{N}$ & 5,0388 & 1,6946 & 33,6314 \\
\hline $\mathrm{Cu} / \mathrm{P}$ & 8,4964 & 2,9445 & 34,6540 \\
\hline $\mathrm{Cu} / \mathrm{K}$ & 0,9431 & 0,4309 & 45,6981 \\
\hline $\mathrm{Cu} / \mathrm{Ca}$ & 2,7737 & 0,9856 & 35,5336 \\
\hline $\mathrm{Cu} / \mathrm{Mg}$ & 8,1165 & 2,8262 & 34,8209 \\
\hline $\mathrm{Cu} / \mathrm{S}$ & 76,3917 & 50,8170 & 66,5215 \\
\hline $\mathrm{Cu} / \mathrm{B}$ & 1,7838 & 0,7847 & 43,9918 \\
\hline $\mathrm{Cu} / \mathrm{Fe}$ & 1,0054 & 0,4870 & 48,4416 \\
\hline $\mathrm{Cu} / \mathrm{Mn}$ & 0,7072 & 0,2829 & 40,0108 \\
\hline $\mathrm{Cu} / \mathrm{Zn}$ & 1,0086 & 0,4974 & \\
\hline & & & \\
\hline & & & \\
\hline & & & \\
\hline & & & \\
\hline & & & \\
\hline & & & \\
\hline & & & \\
\hline
\end{tabular}




\begin{tabular}{|c|c|c|c|}
\hline RELAÇĀO & MÉDIA & DESVIO PADRÃO & COEF. VARIAÇÃO(\%) \\
\hline $\mathrm{Fe} / \mathrm{N}$ & 5,3412 & 1,0231 & 19,1556 \\
\hline $\mathrm{Fe} / \mathrm{P}$ & 8,9728 & 1,7087 & 19,0434 \\
\hline $\mathrm{Fe} / \mathrm{K}$ & 0,9415 & 0,0852 & 9,0498 \\
\hline $\mathrm{Fe} / \mathrm{Ca}$ & 2,9262 & 0,6211 & 21,2272 \\
\hline $\mathrm{Fe} / \mathrm{Mg}$ & 8,5318 & 1,4584 & 17,0936 \\
\hline $\mathrm{Fe} / \mathrm{S}$ & 79,2209 & 40,0031 & 50,4956 \\
\hline $\mathrm{Fe} / \mathrm{B}$ & 1,7910 & 0,1833 & 10,2378 \\
\hline $\mathrm{Fe} / \mathrm{Cu}$ & 1,2108 & 0,5906 & 48,7811 \\
\hline $\mathrm{Fe} / \mathrm{Mn}$ & 0,7258 & 0,0619 & 8,5397 \\
\hline $\mathrm{Fe} / \mathrm{Zn}$ & 0,9996 & 0,0518 & 5,1842 \\
\hline $\mathrm{Mn} / \mathrm{N}$ & 7,3151 & 1,0471 & 14,3149 \\
\hline $\mathrm{Mn} / \mathrm{P}$ & 12,2956 & 1,7975 & 14,6195 \\
\hline $\mathrm{Mn} / \mathrm{K}$ & 1,3014 & 0,1203 & 9,2455 \\
\hline $\mathrm{Mn} / \mathrm{Ca}$ & 4,0038 & 0,6587 & 16,4532 \\
\hline $\mathrm{Mn} / \mathrm{Mg}$ & 11,7178 & 1,5376 & 13,1226 \\
\hline $\mathrm{Mn} / \mathrm{S}$ & 108,4897 & 55,5454 & 51,1987 \\
\hline $\mathrm{Mn} / \mathrm{B}$ & 2,4749 & 0,2569 & 10,3814 \\
\hline $\mathrm{Mn} / \mathrm{Cu}$ & 1,6314 & 0,7066 & 43,3129 \\
\hline $\mathrm{Mn} / \mathrm{Fe}$ & 1,3861 & 0,1232 & 8,8885 \\
\hline $\mathrm{Mn} / \mathrm{Zn}$ & 1,3851 & 0,1369 & 9,8858 \\
\hline $\mathrm{Zn} / \mathrm{N}$ & 5,3639 & 1,1161 & 20,8074 \\
\hline $\mathrm{Zn} / \mathrm{P}$ & 9,0113 & 1,8655 & 20,7019 \\
\hline $\mathrm{Zn} / \mathrm{K}$ & 0,9412 & 0,0602 & 6,3965 \\
\hline $\mathrm{Zn} / \mathrm{Ca}$ & 2,9304 & 0,6121 & 20,8903 \\
\hline $\mathrm{Zn} / \mathrm{Mg}$ & 8,5853 & 1,7571 & 20,4661 \\
\hline $\mathrm{Zn} / \mathrm{S}$ & 79,6263 & 40,5798 & 50,9628 \\
\hline $\mathrm{Zn} / \mathrm{B}$ & 1,7951 & 0,2013 & 11,2158 \\
\hline $\mathrm{Zn} / \mathrm{Cu}$ & 1,2213 & 0,6289 & 51,5001 \\
\hline $\mathrm{Zn} / \mathrm{Fe}$ & 1,0025 & 0,0524 & 5,2313 \\
\hline $\mathrm{Zn} / \mathrm{Mn}$ & 0,7273 & 0,0686 & 9,4369 \\
\hline
\end{tabular}


Tabela 18 - Média, Desvio Padrão e Coeficiente de Variação (Normas) para os nutrientes e para suas relações dois a dois, considerando Peciolo - $3^{\mathrm{a}}$ coleta (início de maturação das bagas).

\begin{tabular}{|c|c|c|c|}
\hline NUTRIENTES & MÉDIA & DESVIO PADRÃO & COEF. VARIAÇÃO (\%) \\
\hline$N(\%)$ & 0,9280 & 0,2244 & 24,1845 \\
\hline$P(\%)$ & 0,7220 & 0,1279 & 17,7209 \\
\hline$K(\%)$ & 6,9000 & 0,5765 & 8,3550 \\
\hline $\mathrm{Ca}(\%)$ & 2,2000 & 0,7915 & 35,9809 \\
\hline $\mathrm{Mg}(\%)$ & 0,9400 & 0,2510 & 26,7019 \\
\hline$S(\%)$ & 0,1300 & 0,0374 & 28,7819 \\
\hline $\mathrm{B} \ln (\mathrm{ppm})$ & 3,3337 & 0,3531 & 10,5932 \\
\hline Cu In (ppm) & 5,3879 & 1,5033 & 27,9017 \\
\hline Fe $\ln (\mathrm{ppm})$ & 4,3396 & 0,4571 & 10,5346 \\
\hline Mn In (ppm) & 6,8096 & 0,6410 & 9,4131 \\
\hline $\mathrm{Zn} \ln (\mathrm{ppm})$ & 4,9365 & 0,1847 & 3,7417 \\
\hline RELAÇÃO & MÉDIA & DESVIO PADRÃO & COEF. VARIAÇÃO (\%) \\
\hline $\mathrm{N} / \mathrm{P}$ & 1,2780 & 0,1036 & 8,1131 \\
\hline$N / K$ & 0,1367 & 0,0431 & 31,5095 \\
\hline $\mathrm{N} / \mathrm{Ca}$ & 0,4336 & 0,0497 & 11,4619 \\
\hline $\mathrm{N} / \mathrm{Mg}$ & 0,9971 & 0,0902 & 9,0459 \\
\hline N/S & 7,2561 & 0,9063 & 12,4907 \\
\hline N/B & 0,2762 & 0,0403 & 14,6062 \\
\hline $\mathrm{N} / \mathrm{Cu}$ & 0,1790 & 0,0417 & 23,3061 \\
\hline $\mathrm{N} / \mathrm{Fe}$ & 0,2195 & 0,0768 & 35,0230 \\
\hline $\mathrm{N} / \mathrm{Mn}$ & 0,1368 & 0,0325 & 23,7801 \\
\hline $\mathrm{N} / \mathrm{Zn}$ & 0,1891 & 0,0520 & 27,5137 \\
\hline$P / N$ & 0,7865 & 0,0629 & 8,0038 \\
\hline $\mathrm{P} / \mathrm{K}$ & 0,1063 & 0,0274 & 25,8027 \\
\hline $\mathrm{P} / \mathrm{Ca}$ & 0,3417 & 0,0510 & 14,9250 \\
\hline $\mathrm{P} / \mathrm{Mg}$ & 0,7818 & 0,0661 & 8,4547 \\
\hline $\mathrm{P} / \mathrm{S}$ & 5,7146 & 0,9028 & 15,7980 \\
\hline $\mathrm{P} / \mathrm{B}$ & 0,2160 & 0,0244 & 11,2917 \\
\hline
\end{tabular}




\begin{tabular}{|c|c|c|c|}
\hline RELAÇÃO & MÉDIA & DESVIO PADRÃO & COEF. VARIAÇÃO (\%) \\
\hline $\mathrm{P} / \mathrm{Cu}$ & 0,1398 & 0,0300 & 21,5024 \\
\hline $\mathrm{P} / \mathrm{Fe}$ & 0,1702 & 0,0482 & 28,3617 \\
\hline $\mathrm{P} / \mathrm{Mn}$ & 0,1068 & 0,0215 & 20,1294 \\
\hline $\mathrm{P} / \mathrm{Zn}$ & 0,1469 & 0,0307 & 20,9503 \\
\hline $\mathrm{K} / \mathrm{N}$ & 7,7889 & 1,9270 & 24,7407 \\
\hline K/P & 9,8731 & 2,2925 & 23,2196 \\
\hline $\mathrm{K} / \mathrm{Ca}$ & 3,4336 & 1,0922 & 31,7905 \\
\hline $\mathrm{K} / \mathrm{Mg}$ & 7,8369 & 2,3939 & 30,5473 \\
\hline KIS & 56,7520 & 16,7836 & 29,5735 \\
\hline K/B & 2,0960 & 0,3404 & 16,2424 \\
\hline $\mathrm{K} / \mathrm{Cu}$ & 1,4032 & 0,5599 & 39,9059 \\
\hline $\mathrm{K} / \mathrm{Fe}$ & 1,5949 & 0,0990 & 6,2091 \\
\hline $\mathrm{K} / \mathrm{Mn}$ & 1,0171 & 0,0905 & 8,8981 \\
\hline $\mathrm{K} / \mathrm{Zn}$ & 1,3963 & 0,0786 & 5,6295 \\
\hline $\mathrm{Ca} / \mathrm{N}$ & 2,3310 & 0,2757 & 11,6932 \\
\hline $\mathrm{Ca} / \mathrm{P}$ & 2,9884 & 0,5256 & 17,5876 \\
\hline $\mathrm{Ca} / \mathrm{K}$ & 0,3266 & 0,1431 & 43,8242 \\
\hline $\mathrm{Ca} / \mathrm{Mg}$ & 2,3187 & 0,2966 & 12,7923 \\
\hline $\mathrm{Ca} / \mathrm{S}$ & 16,9055 & 2,6255 & 15,5304 \\
\hline $\mathrm{Ca} / \mathrm{B}$ & 0,6489 & 0,1589 & 24,4862 \\
\hline $\mathrm{Ca} / \mathrm{Cu}$ & 0,4197 & 0,1192 & 28,4028 \\
\hline $\mathrm{Ca} / \mathrm{Fe}$ & 0,5245 & 0,2478 & 47,2499 \\
\hline $\mathrm{Ca} / \mathrm{Mn}$ & 0,3251 & 0,1162 & 35,7665 \\
\hline $\mathrm{Ca} / \mathrm{Zn}$ & 0,4499 & 0,1788 & 39,7469 \\
\hline $\mathrm{Mg} / \mathrm{N}$ & 1,0098 & 0,0975 & 9,6559 \\
\hline $\mathrm{Mg} / \mathrm{P}$ & 1,2864 & 0,1106 & 8,6037 \\
\hline $\mathrm{Mg} / \mathrm{K}$ & 0,1391 & 0,0482 & 34,7058 \\
\hline $\mathrm{Mg} / \mathrm{Ca}$ & 0,4367 & 0,0533 & 12,2106 \\
\hline $\mathrm{Mg} / \mathrm{S}$ & 7,3223 & 1,1028 & 15,0615 \\
\hline $\mathrm{Mg} / \mathrm{B}$ & 0,2797 & 0,0519 & 18,5613 \\
\hline $\mathrm{Mg} / \mathrm{Cu}$ & 0,1788 & 0,0325 & 18,2109 \\
\hline $\mathrm{Mg} / \mathrm{Fe}$ & 0,2232 & 0,0835 & 37,4254 \\
\hline
\end{tabular}




\begin{tabular}{|c|c|c|c|}
\hline RELAÇÃO & MÉDIA & DESVIO PADRÃO & COEF. VARIAÇÃO (\%) \\
\hline $\mathrm{Mg} / \mathrm{Mn}$ & 0,1391 & 0,0394 & 28,3220 \\
\hline $\mathrm{Mg} / \mathrm{Zn}$ & 0,1917 & 0,0575 & 30,0365 \\
\hline $\mathrm{S} / \mathrm{N}$ & 0,1395 & 0,0179 & 12,8306 \\
\hline$S / P$ & 0,1786 & 0,0290 & 16,2362 \\
\hline S/K & 0,0191 & 0,0067 & 35,1672 \\
\hline $\mathrm{S} / \mathrm{Ca}$ & 0,0606 & 0,01171 & 19,3202 \\
\hline $\mathrm{S} / \mathrm{Mg}$ & 0,1391 & 0,0212 & 15,2879 \\
\hline S/B & 0,0385 & 0,0071 & 18,4329 \\
\hline $\mathrm{S} / \mathrm{Cu}$ & 0,0252 & 0,0072 & 28,4090 \\
\hline $\mathrm{S} / \mathrm{Fe}$ & 0,0308 & 0,0121 & 39,4149 \\
\hline S/Mn & 0,0192 & 0,0055 & 28,6848 \\
\hline$S / Z n$ & 0,0265 & 0,0084 & 31,8003 \\
\hline $\mathrm{B} / \mathrm{N}$ & 3,6795 & 0,5149 & 13,9949 \\
\hline $\mathrm{B} / \mathrm{P}$ & 4,6788 & 0,5642 & 12,0593 \\
\hline $\mathrm{B} / \mathrm{K}$ & 0,4881 & 0,0862 & 17,6643 \\
\hline $\mathrm{B} / \mathrm{Ca}$ & 1,6045 & 0,3284 & 20,4721 \\
\hline $\mathrm{B} / \mathrm{Mg}$ & 3,6828 & 0,7331 & 19,9060 \\
\hline $\mathrm{B} / \mathrm{S}$ & 26,6614 & 4,7335 & 17,7541 \\
\hline $\mathrm{B} / \mathrm{Cu}$ & 0,6660 & 0,2239 & 33,6315 \\
\hline $\mathrm{B} / \mathrm{Fe}$ & 0,7808 & 0,1622 & 20,7738 \\
\hline $\mathrm{B} / \mathrm{Mn}$ & 0,4935 & 0,0707 & 14,3331 \\
\hline $\mathrm{B} / \mathrm{Zn}$ & 0,6778 & 0,0949 & 14,0062 \\
\hline $\mathrm{Cu} / \mathrm{N}$ & 5,8387 & 1,3710 & 23,4818 \\
\hline $\mathrm{Cu} / \mathrm{P}$ & 7,4109 & 1,5562 & 20,9997 \\
\hline $\mathrm{Cu} / \mathrm{K}$ & 0,7939 & 0,2610 & 32,8777 \\
\hline $\mathrm{Cu} / \mathrm{Ca}$ & 2,5491 & 0,7503 & 29,4365 \\
\hline $\mathrm{Cu} / \mathrm{Mg}$ & 5,7683 & 1,2196 & 21,1433 \\
\hline $\mathrm{Cu} / \mathrm{S}$ & 42,9074 & 14,3543 & 33,4541 \\
\hline $\mathrm{Cu} / \mathrm{B}$ & 1,6238 & 0,4681 & 28,8284 \\
\hline $\mathrm{Cu} / \mathrm{Fe}$ & 1,2699 & 0,4315 & 33,9836 \\
\hline Cu/Mn & 0,7912 & 0,2145 & 27,1091 \\
\hline $\mathrm{Cu} / \mathrm{Zn}$ & 1,0942 & 0,3168 & 28,9559 \\
\hline
\end{tabular}




\begin{tabular}{|c|c|c|c|}
\hline RELAÇÃO & MÉDIA & DESVIO PADRÃO & COEF. VARIAÇÃO(\%) \\
\hline $\mathrm{Fe} / \mathrm{N}$ & 4,9218 & 1,3446 & 27,3203 \\
\hline $\mathrm{Fe} / \mathrm{P}$ & 6,2296 & 1,5979 & 25,6506 \\
\hline Fe/K & 0,6288 & 0,0382 & 6,0785 \\
\hline $\mathrm{Fe} / \mathrm{Ca}$ & 2,1678 & 0,7102 & 32,7629 \\
\hline $\mathrm{Fe} / \mathrm{Mg}$ & 4,9549 & 1,6495 & 33,2904 \\
\hline $\mathrm{Fe} / \mathrm{S}$ & 36,0385 & 12,0967 & 33,5661 \\
\hline $\mathrm{Fe} / \mathrm{B}$ & 1,3214 & 0,2487 & 18,8265 \\
\hline $\mathrm{Fe} / \mathrm{Cu}$ & 0,8873 & 0,3835 & 43,2238 \\
\hline Fe/Mn & 0,6404 & 0,0776 & 12,1311 \\
\hline $\mathrm{Fe} / \mathrm{Zn}$ & 0,8781 & 0,0753 & 8,5824 \\
\hline $\mathrm{Mn} / \mathrm{N}$ & 7,6019 & 1,5531 & 20,4307 \\
\hline $\mathrm{Mn} / \mathrm{P}$ & 9,6584 & 1,8460 & 19,1127 \\
\hline $\mathrm{Mn} / \mathrm{K}$ & 0,9894 & 0,0898 & 9,0807 \\
\hline $\mathrm{Mn} / \mathrm{Ca}$ & 3,3480 & 0,9735 & 29,0776 \\
\hline $\mathrm{Mn} / \mathrm{Mg}$ & 7,6362 & 1,9884 & 26,0389 \\
\hline $\mathrm{Mn} / \mathrm{S}$ & 55,5912 & 15,8250 & 28,4668 \\
\hline $\mathrm{Mn} / \mathrm{B}$ & 2,0645 & 0,3377 & 16,3610 \\
\hline $\mathrm{Mn} / \mathrm{Cu}$ & 1,3559 & 0,4324 & 31,8934 \\
\hline $\mathrm{Mn} / \mathrm{Fe}$ & 1,5799 & 0,1920 & 12,1534 \\
\hline $\mathrm{Mn} / \mathrm{Zn}$ & 1,3787 & 0,1076 & 7,8095 \\
\hline $\mathrm{Zn} / \mathrm{N}$ & 5,5424 & 1,1653 & 21,0260 \\
\hline $\mathrm{Zn} / \mathrm{P}$ & 7,0201 & 1,3011 & 18,5339 \\
\hline $\mathrm{Zn} / \mathrm{K}$ & 0,7180 & 0,0410 & 5,7225 \\
\hline $\mathrm{Zn} / \mathrm{Ca}$ & 2,4379 & 0,6891 & 28,2691 \\
\hline $\mathrm{Zn} / \mathrm{Mg}$ & 5,5557 & 1,4421 & 25,9577 \\
\hline $\mathrm{Zn} / \mathrm{S}$ & 40,3974 & 10,7708 & 26,6623 \\
\hline $\mathrm{Zn} / \mathrm{B}$ & 1,4970 & 0,1968 & 13,1489 \\
\hline $\mathrm{Zn} / \mathrm{Cu}$ & 0,9925 & 0,3465 & 34,9159 \\
\hline $\mathrm{Zn} / \mathrm{Fe}$ & 1,1452 & 0,0948 & 8,2815 \\
\hline $\mathrm{Zn} / \mathrm{Mn}$ & 0,7288 & 0,0568 & 7,8035 \\
\hline
\end{tabular}




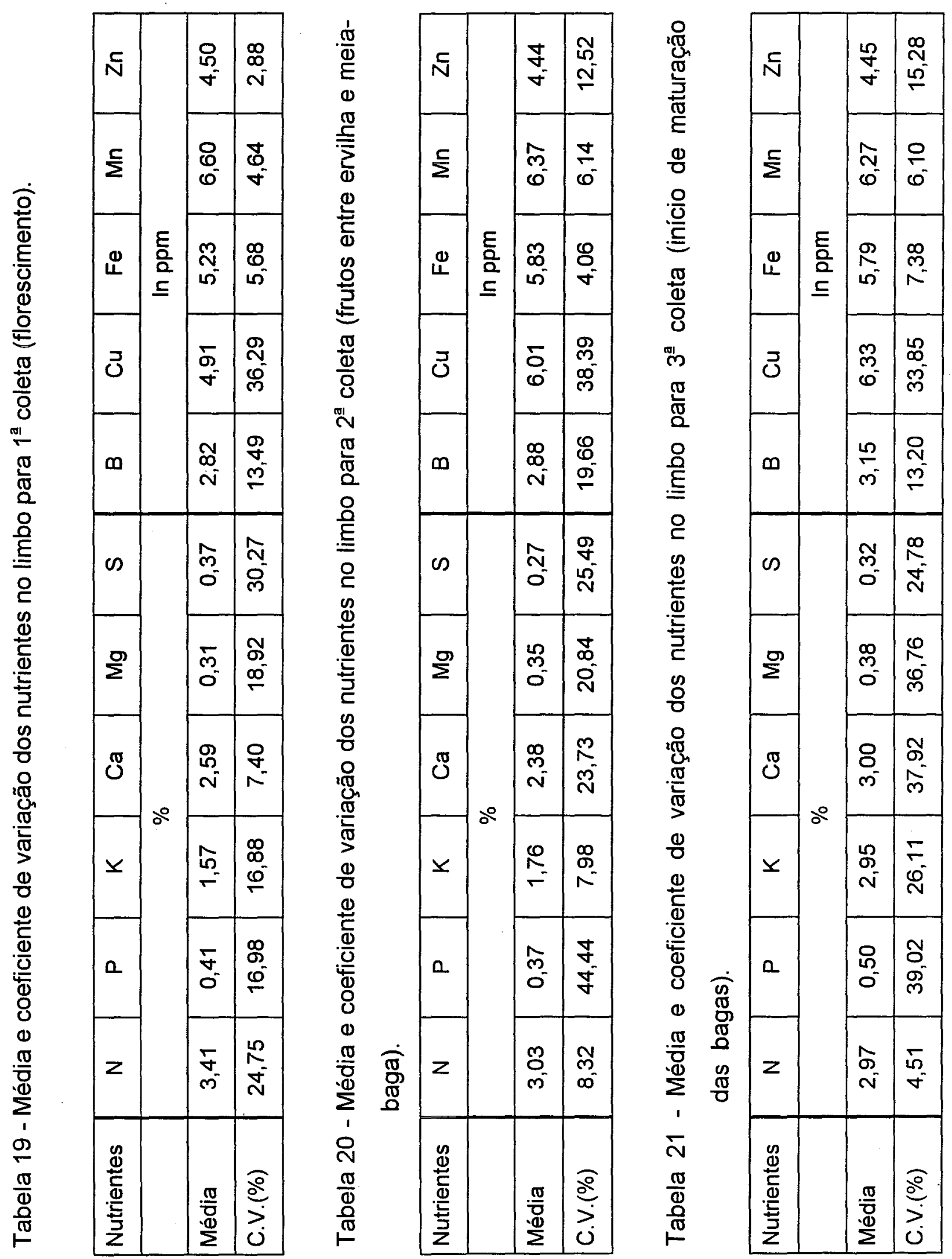




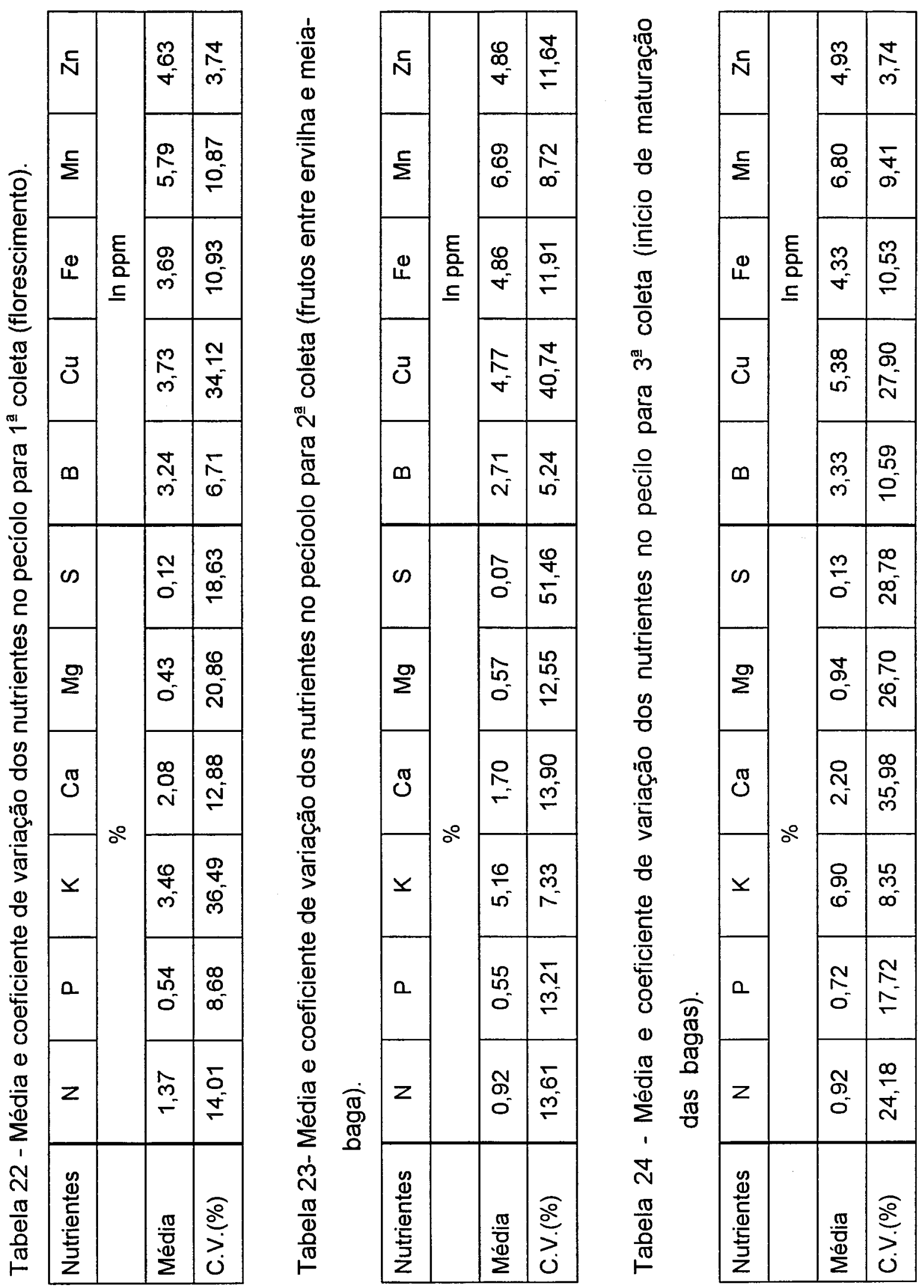


Os valores dos coeficientes de variação obtidos das análises de limbos foliares mostram que, tanto para os macro quanto para os micronutrientes, todos os valores encontrados estão abaixo de 50 . Os maiores valores obtidos foram na $2^{\mathrm{a}}$ coleta para $\mathrm{P}(44,44 \%)$ e Cu $(38,39 \%)$.

Sabe-se que quanto maior o coeficiente de variação, ou seja, maior a amplitude de variação dos valores dos nutrientes, maiores são os desequilibrios nutricionais. As Tabelas 25 e 26 mostram as seqüências decrescentes de coeficientes de variação para macro e micronutrientes no limbo e pecíolo, para as três épocas de coleta e servem para melhor entendimento a respeito de problemas nutricionais que poderão ocorrer na região.

Guilherme (1995) amostrando vinhedos na região de Jales, encontrou altos coeficientes de variação para alguns macro $(\mathrm{Mg})$ e micronutrientes $(\mathrm{Cu})$ e que estes desequilibrios nutricionais poderiam comprometer a produção.

A avaliação adequada do estado nutricional de um vinhedo evitará futuros comprometimentos.

Para o estabelecimento das normas para a metodologia DRIS, foram utilizados os resultados de análise foliar dos vinhedos com produtividade igual ou acima de 20 t/ha, relacionados a seguir:

JUN 04 (21t/ha), JUN 15 (34t/ha), JUN 16 (35t/ha), JUN 17 e JUN 18 ambos com 20t/ha.

As tabelas $27,28,29,30,31$ e 32 mostram os índices DRIS, Índice de Balanço Nutricional (IBN) e seqüências de deficiência a excesso nutricional para cada vinhedo amostrado, na região de Jundiai, considerando limbos e pecíolos nas três épocas de coleta, respectivamente. 
Tabela 25 - Sequência decrescente de coeficiente de variação para macro e micronutrientes no limbo, para as três coletas (florescimento, frutos entre ervilha e meia-baga e início da maturação das bagas).

\begin{tabular}{|l|l|l|}
\hline \multirow{2}{*}{ Coletas } & \multicolumn{2}{|c|}{ Seqüência } \\
\cline { 2 - 3 } & \multicolumn{1}{|c|}{ Macronutrientes } & \multicolumn{1}{c|}{ Micronutrientes } \\
\hline Primeira & $\mathrm{S}>\mathrm{N}>\mathrm{Mg}>\mathrm{P} \cong \mathrm{K}>\mathrm{Ca}$ & $\mathrm{Cu}>>\mathrm{B}>>\mathrm{Fe}>\mathrm{Mn}>\mathrm{Zn}$ \\
\hline Segunda & $\mathrm{P}>>\mathrm{S}>\mathrm{Ca}>\mathrm{Mg}>>\mathrm{N}>\mathrm{K}$ & $\mathrm{Cu}>\mathrm{B}>\mathrm{Zn}>\mathrm{Mn}>\mathrm{Fe}$ \\
\hline Terceira & $\mathrm{P}>\mathrm{Ca}>\mathrm{Mg}>\mathrm{K}>\mathrm{S}>>\mathrm{N}$ & $\mathrm{Cu}>\mathrm{Zn}>\mathrm{B}>\mathrm{Fe}>\mathrm{Mn}$ \\
\hline
\end{tabular}

Tabela 26 - Sequência decrescente de coeficiente de variação para macro e micronutrientes no pecíolo, para as três coletas (florescimento, frutos entre ervilha e meia-baga e início da maturação das bagas).

\begin{tabular}{|l|l|l|}
\hline \multirow{2}{*}{ Coletas } & \multicolumn{2}{|c|}{ Seqüencia Decrescente } \\
\cline { 2 - 3 } & \multicolumn{1}{|c|}{ Macronutrientes } & \multicolumn{1}{|c|}{ Micronutrientes } \\
\hline Primeira & $\mathrm{K}>\mathrm{Mg}>\mathrm{S}>\mathrm{N}>\mathrm{Ca}>\mathrm{P}$ & $\mathrm{Cu}>>\mathrm{Fe} \cong \mathrm{Mn}>\mathrm{B}>\mathrm{Zn}$ \\
\hline Segunda & $\mathrm{S}>>\mathrm{Ca} \cong \mathrm{N} \cong \mathrm{P}>\mathrm{Mg}>\mathrm{K}$ & $\mathrm{Cu}>>\mathrm{Fe} \cong \mathrm{Zn}>\mathrm{Mn}>\mathrm{B}$ \\
\hline Terceira & $\mathrm{Ca}>\mathrm{S}>\mathrm{Mg}>\mathrm{N}>\mathrm{P}>\mathrm{K}$ & $\mathrm{Cu}>\mathrm{B} \cong \mathrm{Fe}>\mathrm{Mn}>\mathrm{Zn}$ \\
\hline
\end{tabular}

Estas variações que estão ocorrendo nas seqüências podem. ser justificadas pelas alterações dos níveis dos nutrientes na planta durante o ciclo da cultura e da concentração diferenciada nos diferentes órgãos da videira. 


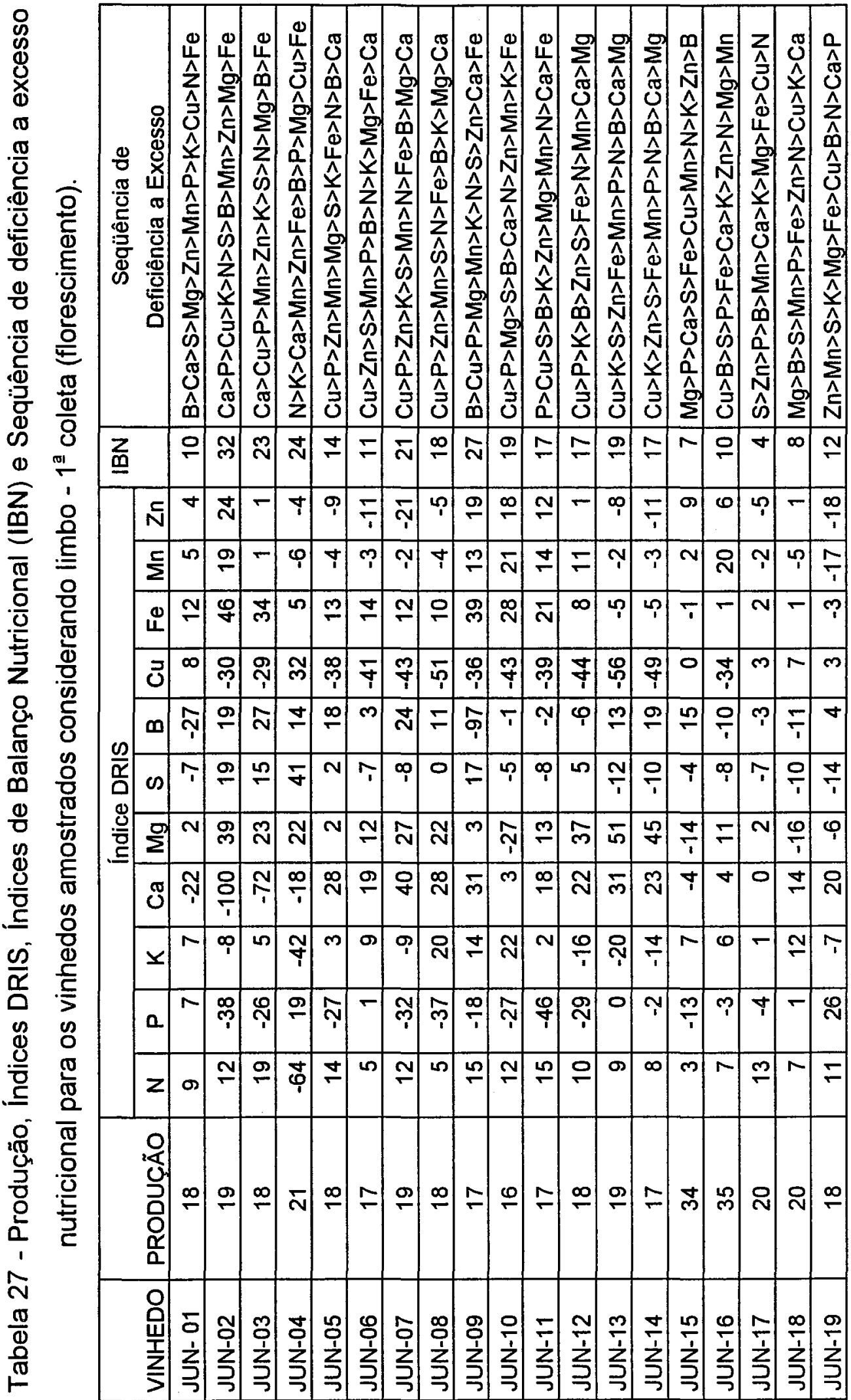




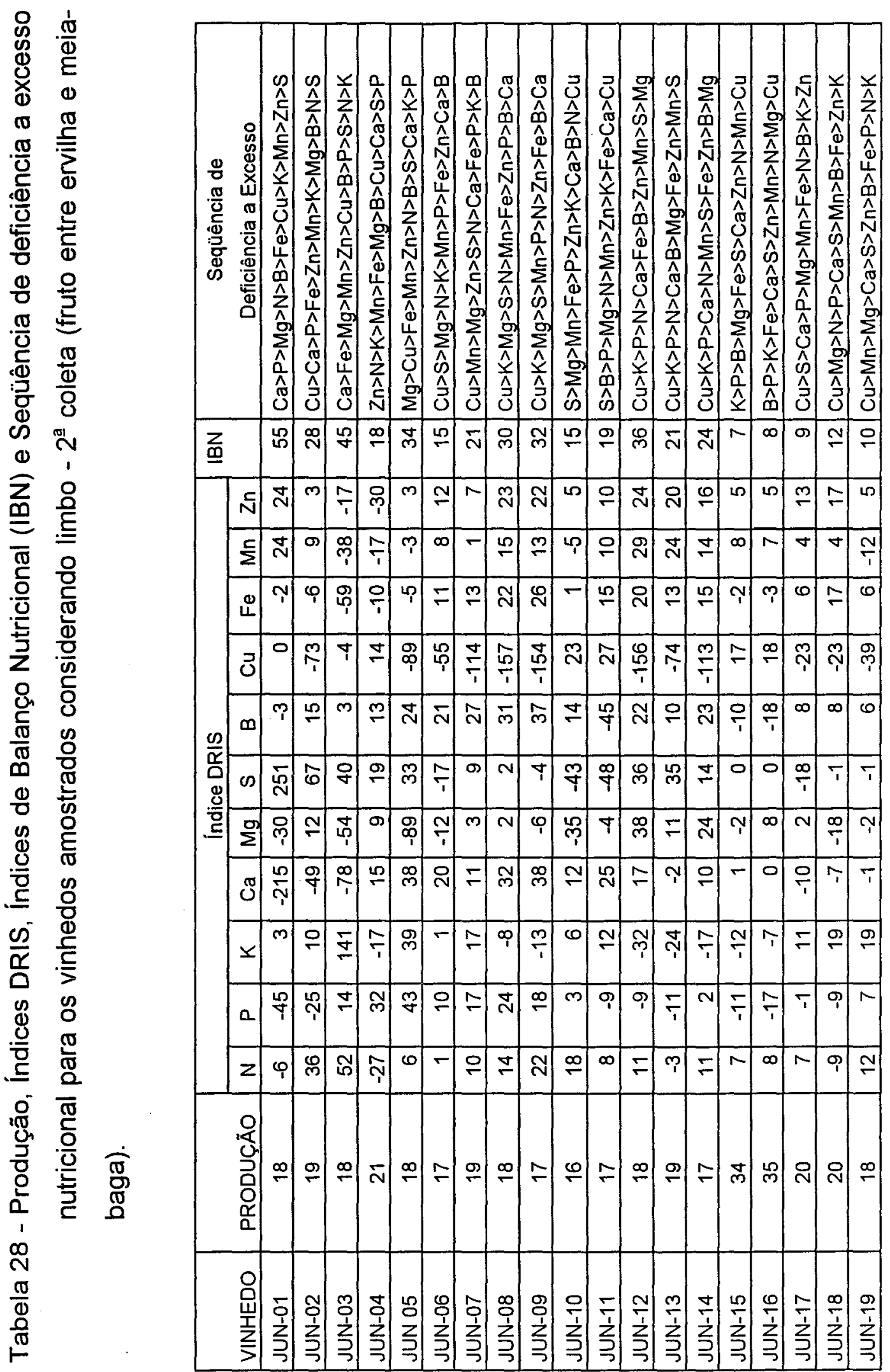




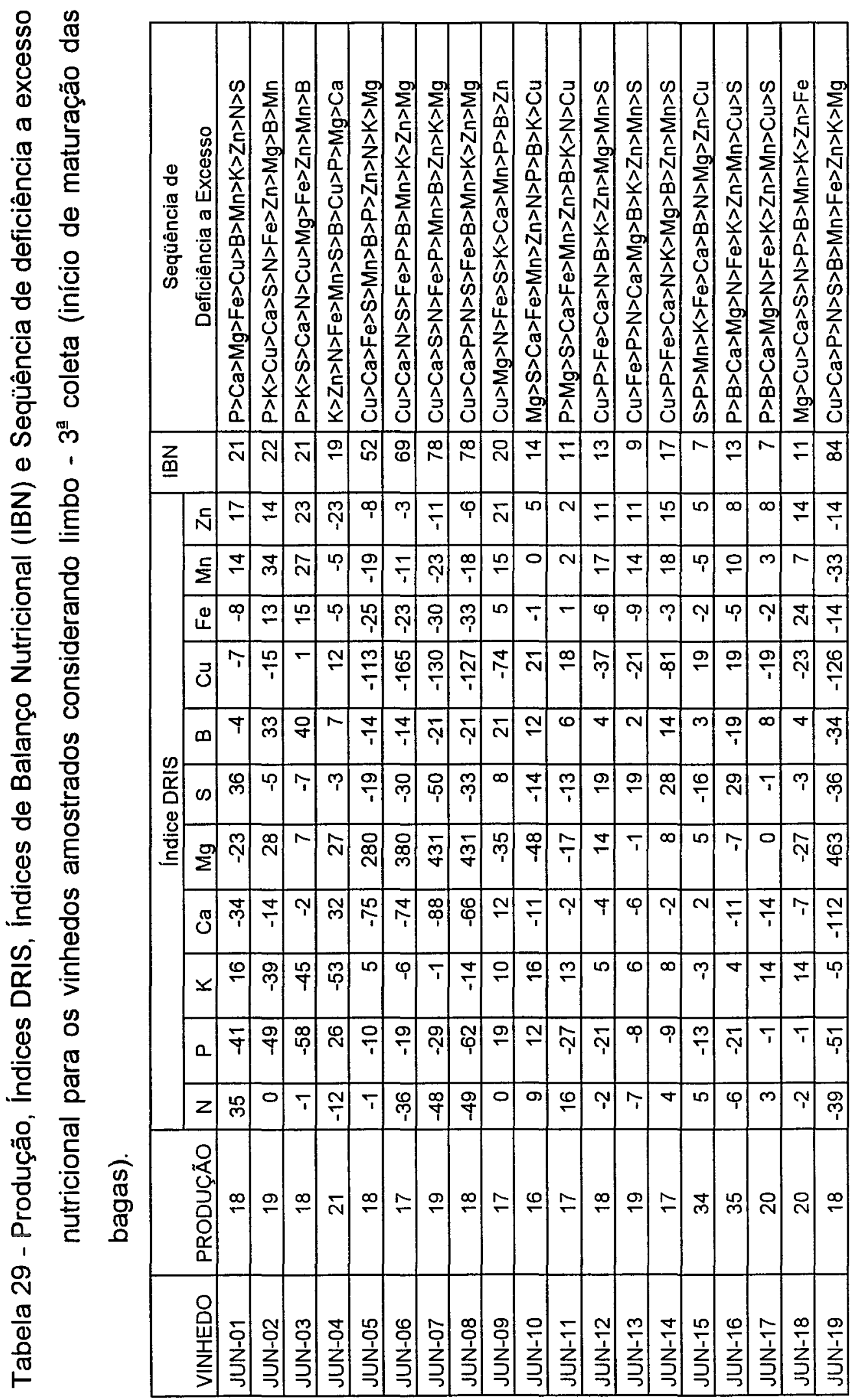




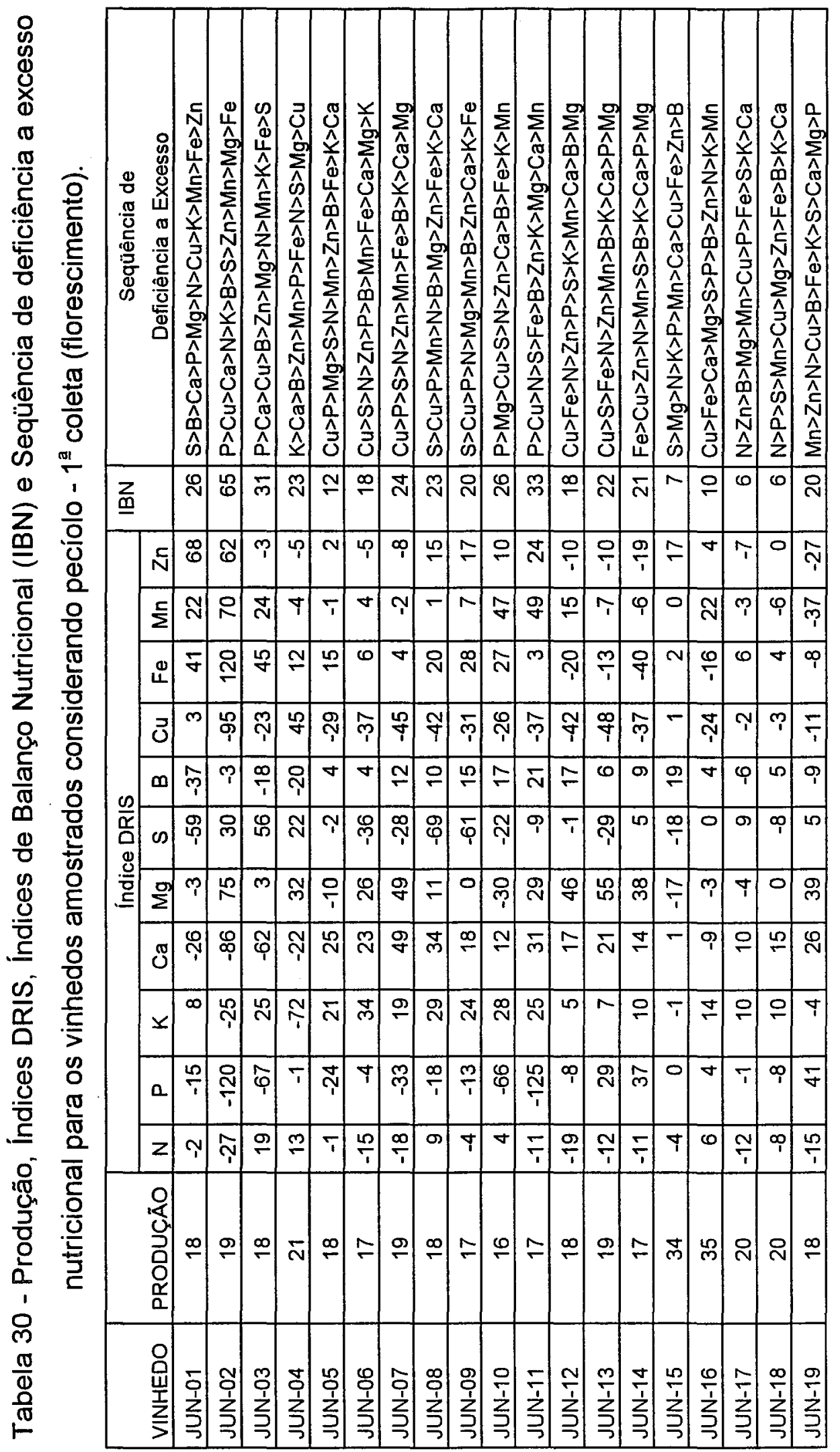




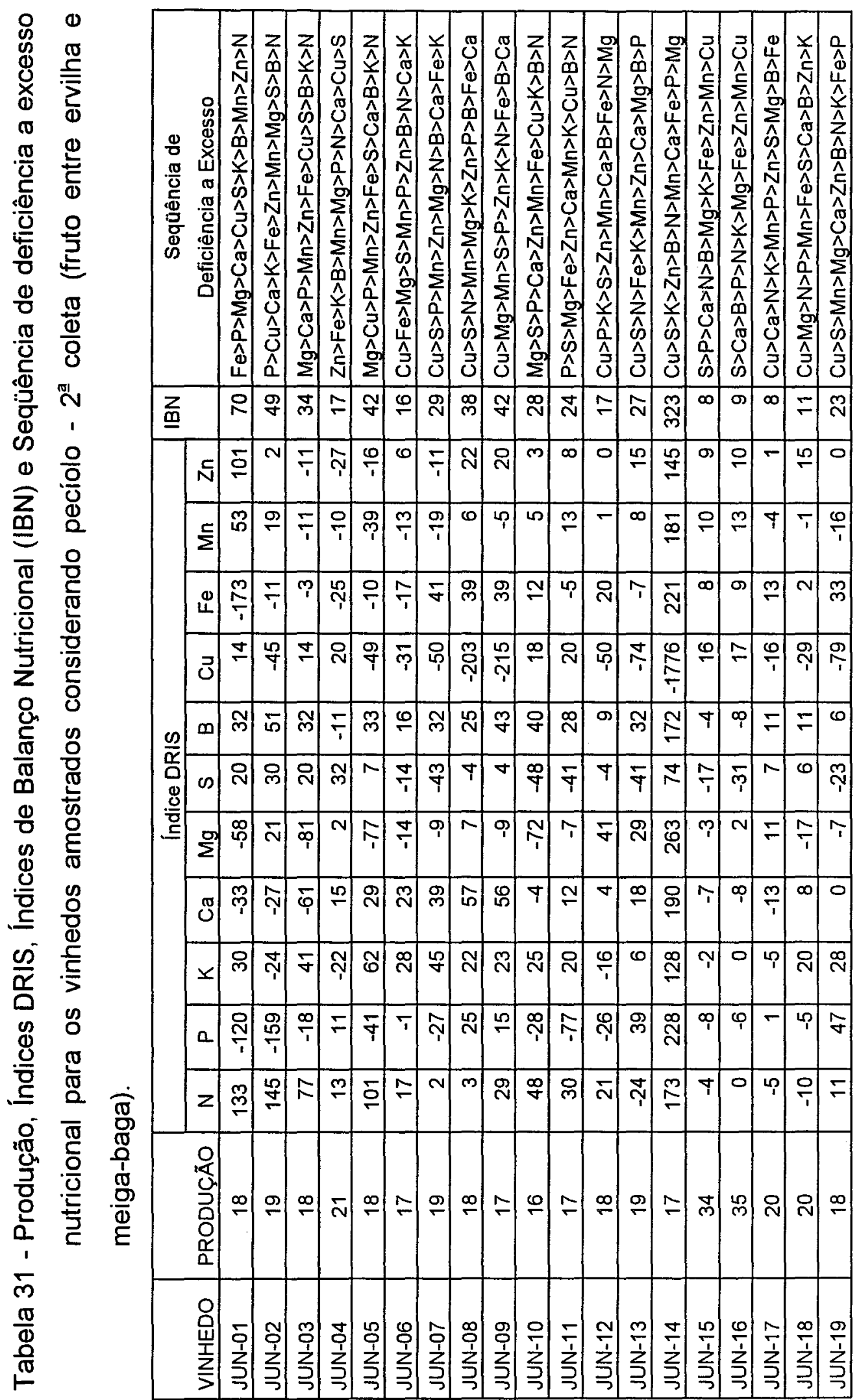




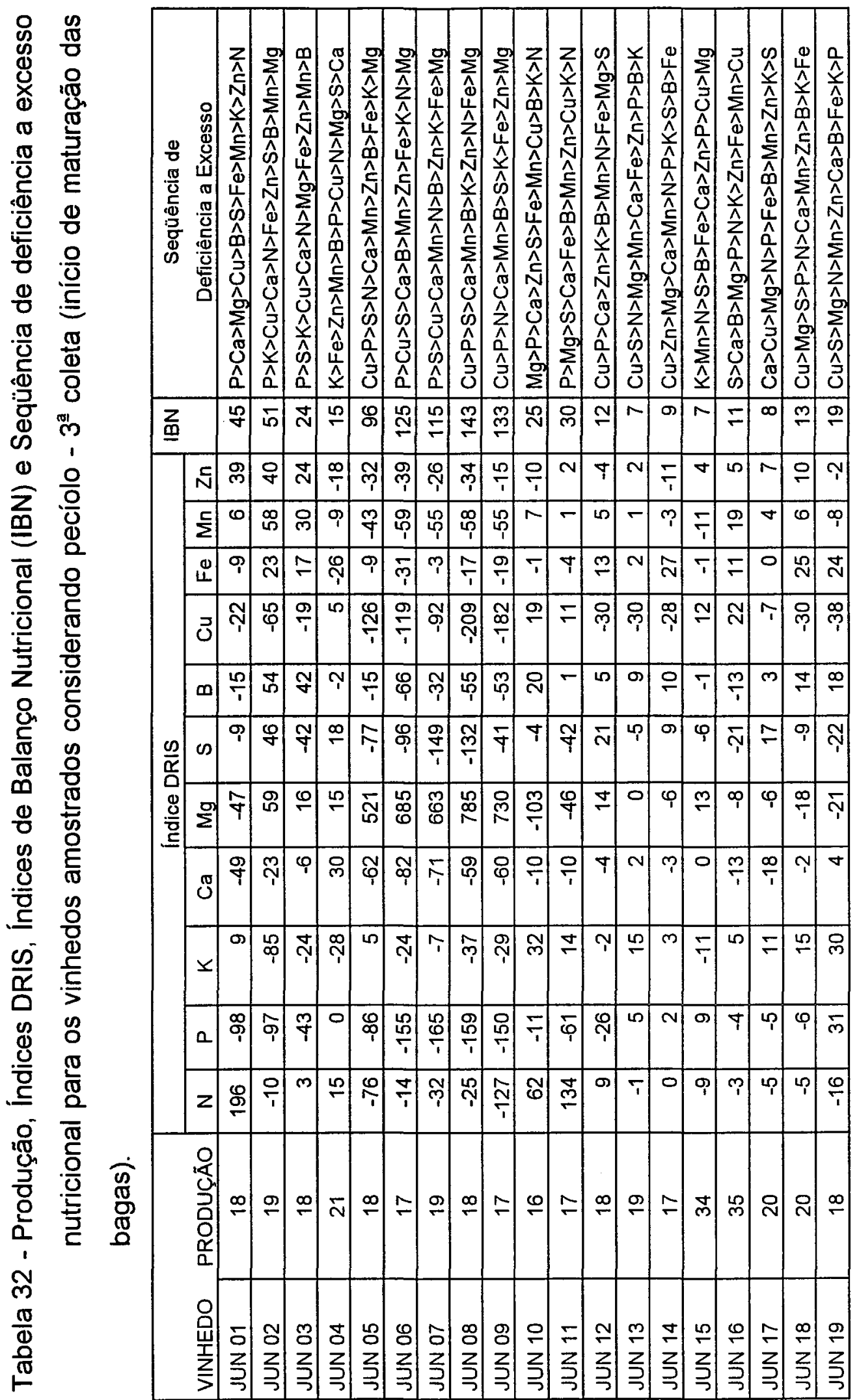


O índice de Balanço Nutricional corresponde à soma dos valores absolutos dos índices DRIS de cada nutriente dividido pelo número de nutrientes estudados, que neste trabalho foram $11(\mathrm{~N}, \mathrm{P}, \mathrm{K}, \mathrm{Ca}, \mathrm{Mg}, \mathrm{S}, \mathrm{B}, \mathrm{Cu}$, $\mathrm{Fe}, \mathrm{Mn}$ e Zn).

Os vinhedos amostrados, com produtividade igual ou superior a 20t/ha (JUN 04, JUN 15, JUN 16, JUN 17, e JUN 18) apresentaram uma amplitude de variação de IBN no limbo de 04 a 32, para a 1"a coleta, de 07 a 55 para a $2^{\text {a }}$ coleta e de 07 a 84 para a $3^{\text {a }}$ coleta. No peciolo as amplitudes foram de 06 a 65 , de 08 a 323 e de 07 a 143 para a $1^{\text {a }}, 2^{\text {a }}$ e $3^{\text {a }}$ coletas, respectivamente.

Os índices de Balanço Nutricional (IBN) de referência para os vinhedos amostrados para limbo e pecíolo, nas três épocas de coleta estão mostrados nas Tabelas 33, 34, 35, 36, 37 e 38, respectivamente.

Estes resultados se assemelham aos de Guilherme (1995) para limbo, sendo diferentes para peciolo, que trabalhou com vinhedos na região de Jales, SP.

Os resultados deste trabalho estão de acordo com Guilherme (1995) e Christensen et al. (1982) que observaram ser o florescimento a melhor época de coleta. 
Tabela 33 - Índice de Balanço Nutricional de referência para os vinhedos amostradas limbo - $1^{\text {a }}$ coleta (florescimento).

\begin{tabular}{|l|c|c|}
\hline İ́ndice de balanço Nutricional & \multicolumn{2}{|c|}{ Número de vinhedos } \\
\cline { 2 - 3 } & Produtividade Baixa & Produtividade Alta \\
\hline Adequado $(0-11)$ & 01 & 04 \\
\hline Desequilibrado $(>11)$ & 13 & 01 \\
\hline
\end{tabular}

Tabela 34 - Índice de Balanço Nutricional de referência para os vinhedos amostradas limbo $-2^{\text {a }}$ coleta (frutos entre ervilha e meia baga).

\begin{tabular}{|l|c|c|}
\hline \multirow{2}{*}{ Índice de balanço Nutricional } & \multicolumn{2}{|c|}{ Número de vinhedos } \\
\cline { 2 - 3 } & Produtividade Baixa & Produtividade Alta \\
\hline Adequado $(0-10)$ & 01 & 04 \\
\hline Desequilibrado $(>10)$ & 13 & 01 \\
\hline
\end{tabular}

Tabela 35 - Índice de Balanço Nutricional de referência para os vinhedos amostradas limbo - $3^{\mathrm{a}}$ coleta (início de maturação das bagas).

\begin{tabular}{|l|c|c|}
\hline \multirow{2}{*}{ Índice de balanço Nutricional } & \multicolumn{2}{|c|}{ Número de vinhedos } \\
\cline { 2 - 3 } & Produtividade Baixa & Produtividade Alta \\
\hline Adequado $(0-11)$ & 01 & 03 \\
\hline Desequilibrado $(>11)$ & 13 & 02 \\
\hline
\end{tabular}


Tabela 36 - Índice de Balanço Nutricional de referência para os vinhedos amostrados peciolo $-1^{\text {a }}$ coleta (florescimento).

\begin{tabular}{|l|c|c|}
\hline Índice de balanço Nutricional & \multicolumn{2}{|c|}{ Número de vinhedos } \\
\cline { 2 - 3 } & Produtividade Baixa & Produtividade Alta \\
\hline Adequado $(0-10)$ & 00 & 03 \\
\hline Desequilibrado $(>10)$ & 15 & 01 \\
\hline
\end{tabular}

Tabela 37 - Índice de Balanço Nutricional de referência para os vinhedos amostrados peciolo - $2^{\mathrm{a}}$ coleta (frutos entre ervilha e meiabaga).

\begin{tabular}{|l|c|c|}
\hline \multirow{2}{*}{ İndice de balanço Nutricional } & \multicolumn{2}{|c|}{ Número de vinhedos } \\
\cline { 2 - 3 } & Produtividade Baixa & Produtividade Alta \\
\hline Adequado $(0-12)$ & 00 & 04 \\
\hline Desequilibrado $(>12)$ & 14 & 01 \\
\hline
\end{tabular}

Tabela 38 - Índice de Balanço Nutricional de referência para os vinhedos amostrados pecíolo - $3^{\mathrm{a}}$ coleta (início de maturação das bagas).

\begin{tabular}{|l|c|c|}
\hline \multirow{2}{*}{ Índice de balanço Nutricional } & \multicolumn{2}{|c|}{ Número de vinhedos } \\
\cline { 2 - 3 } & Produtividade Baixa & Produtividade Alta \\
\hline Adequado $(0-8)$ & 01 & 02 \\
\hline Desequilibrado $(>8)$ & 14 & 02 \\
\hline
\end{tabular}


O método DRIS permitiu determinar a melhor época, o melhor órgão da planta para amostragem, as desordens nutricionais e os índices de referências para Balanço Nutricional.

O florescimento e o limbo foram considerados a época e o órgão ideais, pois foram os que melhor refletiram o estado nutricional da videira, ou seja, apresentaram os valores dos índices de balanço nutricional (IBN) mais coerentes. O IBN determinado foi 11 , considerado como referencia para os vinhedos de alta produtividade.

Os indices DRIS podem variar de valores negativos a positivos, sendo que em termos de balanço, os índices negativos indicam deficiência de nutrientes, quando iguais a zero indicam que os nutrientes estão em equilibrio e quando positivos indicam que os elementos estão em excesso. A natureza e o grau dos fatores limitantes da produção podem ser verificados pelas sequências de deficiência a excesso dos fatores. Dessa maneira, pode-se determinar a ordem pela qual os nutrientes estão limitando a produtividade.

Observou-se que quando no balanço nutricional houver nutrientes deficientes, a ordem de grandeza dos índices é que orientará a escolha dos melhores tratamentos, visando o aumento da produção, concordando com as observações de Sumner (1977c).

A importância do DRIS para a cultura da videira 'Itália' se dá, principalmente pelo fato de ser uma cultura perene onde as desordens nutricionais ocorridas durante seu ciclo afetam as plantas cumulativamente ao longo dos anos, além do fato dessas correções de deficiência ou excesso, muitas vezes não poderem ser feitas durante o ciclo da cultura, tornando a diagnose um fator fundamental no início do mesmo. 


\section{CONCLUSÕES}

Os resultados obtidos nas condições experimentais do presente trabalho permitiram chegar às seguintes conclusões:

- O método DRIS foi considerado adequado;

- O estádio de florescimento foi a melhor época de amostragem;

- O limbo foliar foi o melhor órgão da planta a ser amostrado;

- Cinco vinhedos foram considerados em equilíbrio nutricional;

- O índice de balanço nutricional (IBN) para os cinco vinhedos em equilíbrio nutricional foi 11 ;

- Os dezenove vinhedos amostrados, foram considerados adequados para o cálculo das normas;

- O DRIS refletiu as condições locais do levantamento e os vinhedos apresentaram variabilidade quanto à ordem e o grau de limitação dos nutrientes na produtividade; 


\section{REFERÊNCIAS BIBLIOGRÁFICAS}

AHMED, S.H. A comparative study of petiole and leaf blade anlysis in Anab-eShashi grape (Vitis vinifera L.). South Indian Horticulture, v.37, n.6, p.317322, 1989/ Resumo em Horticultural Abstracts, v. 61, n.5, p.420, may. $1991 /$

ALEXANDER, K.MC.E. \& WOODHAM, R.C. Chemical composition on leaf tissues of sultana vines grown in solutions deficients in macroelements. Vitis, Siebeldigen, v.9, n.3, p.207, 1970.

ATALAY, I.Z. Petiole and leaf blade relationships for the determination of phosphorus status of Thompson Seedless grapes. Fertlizer and Agriculture, Paris, v.42, n.97, p.13-18, 1988.

ATALAY, I.Z. The petiole and leaf blade relationships for the determination of phosphorus and zinc status of vineyards. Vitis, Siebeldigen, v.17, n.2, p.147-151, 1978. 
BATAGLIA, O.C. DRIS-Citros - Uma alternativa para avaliar a nutrição das plantas. Laranja, Cordeirópolis, v.10, n.2, p.565-576, 1989.

BATAGLIA, O.C. \& DECHEN, A.R. Critérios alternativos para diagnose foliar. in: Simpósio Avançado de Química e Fertilidade do Solo, I, Piracicaba, 1986. Anais. Campinas, Fundação Cargil, 1986. p.115-136.

BEAUFILS, E.R. Diagnosis and Recommendation Integrated System (DRIS). A general scheme for experimentation and calibration based on principles developed from research in plant nutrition. University of Natal, Pietermaritzburg, South Africa, 132p. Soil Science Bulletin, 1, 1973.

BIBLINA, L.I. Characteristics of vine nutrition and some diagnostic problems. Agrokhimyia, -Moscow, 11:138-141, 1968. Resumo em Horticultural Abstracts, Farnaham Royal, v.40, n.1, p.96, mar. 1970.

CHRISTENSEN, L.P.; KASIMATIS, A.N.; JENSEN, F.L. Grapevine nutrition and fertilization in San Joaquim Valley. Berkeley, Universidade of California, 1982, 40p. 
COOK, A.; LYNN, C.D.; KISSLER, J.J. Boron deficiency in California vineyards. American Journal Enology and Viticulture, St. Joseph, v.11, n.4, p.185-194, 1960.

CUMMINGS, G.A. Variation in the concentration of certain elements in muscadine grape leaves related to season, leaf portion and age. Journal of the American Society for Horticultural Science, v.102, n.3, p.339-342, $1977 /$ Resumo em Horticultural Abstracts, v.47, n.12, p.943, dec. 1977 I

DAL BÓ, M.A.; BECKER, M.; BASSO, C.; STUKER, H. Levantamento do estado nutricional da videira em Santa Catarina por análise de solo e tecido. Revista Brasileira de Ciência do Solo, Campinas, n.13, p.335340, 1989.

DECHEN, A.R. \& CARMELLO, Q.A. Interpretação para macro e micronutrientes no solo e na folha. $1^{\text {a }}$. ed. Piracicaba, ESALQ, Departamento de Química, 1985, 2p.

DELMAS, J. Recherches sur la nutrition minérale de la vigne, Vitis vinifera var. Merlot, en aquiculture. Bordeaux, 1971, 266p. (M.S. Universidade de Bordeaux I). 
DEPARDON, L. \& BURON, P. Av. sujet du diagnostic foliare de la vigne. Cas particulier de la potasse. Comptes Rendus des Séances de l'Academie de Agriculture de France, Paris, n.40, p.652-656, 1954.

DULAC, J. Quinze ans a'essair de jumure sur la vigne à cruscades (Aude). IN: COLLOQUIUM EUROPEAN CONTRÔLE NUTRITION MINERALE FERTILITY VITICULTURE ARBORICULTURE, I., Comptes Rendus, s.n.t., p.197-200, 1965/ Resumo em Horticultural Abstracts, v.36, n.3, p.507, 19651

ESCANO, C.R.; JONES, C.A.; VEHARA, G. Nutrient diagnosis in corn grown on Hydric Dystrandepts: II Comparition of two sistems of tissue diagnosis. Soil Science Society American Journal, Madison, n.45, p.1140-1144, 1981.

FREGONI, M. Importanza del boro nella nutrizione dela vite. Vignevini, Bologna, v.4, n.6/7, p.35-37, 1977.

FUNDAÇÃO INSTITUTO BRASILEIRO DE GEOGRAFIA E ESTATÍSTICA. Anuário Estatístico do Brasil. Rio de Janeiro: IBGE, 1996, v.56.

GALLO, J.R. \& RIBAS, W.C. Análise foliar de diferentes combinações enxertocavalo para dez variedades de videira, Bragantia, Campinas, n.21,p.397410, 1962. 
GÄRTEL, W. A report on the recognition of magnesium deficiency in vines. Landwirtschafiliche Forschung Sonderheff, n.13, p.45-58, 1959/ Resumo em Horticultural Abstracts, v.33, n.4, p.775, dec., 1961/

GÄRTEL, W. The diagnostic value of leaf analysis for identifying nutritional disorders in vines. In: COLLOQUIUM EUROPEAN CONTRÔLE NUTRITION MINERALE FERTILITY VITICULTURE ARBORICULTURE, I., 1964. Comptes Rendus, s.n.t., p.197-200, 1965/ Resumo em Horticultural Abstracts, v.36,n.3, p.507, sept. 1966/

GERGOLETTI, I.F. Avaliação do estado nutricional da videira 'Itália', em três estádios de desenvolvimento em São Miguel Arcanjo, SP, utilizando o método DRIS. Piracicaba, 1995, 84p. (Mestrado - Escola Superior de Agricultura "Luiz de Queiroz"-USP).

GOH, K.M. \& MALAKOUTI, M.J. Preliminary nitrogen, phosphorus, potassium, calcium and magnesium DRI norms and indices for apple orchards in Canterbury, New Zeland. Communications in Soil Science and Plant Analysis, New York, v.23, p.13/14, p.1371-1385, 1992.

GONÇALVES, J.S.; AMARO, A.A.; MAIA, M.L.; SOUZA, S.A.M. Estrutura de produção e de mercado da uva de mesa brasileira. Agricultura em São Paulo, São Paulo, v.43, n.1, p.43-93, 1996. 
GONZALO, GIL, S.; RODRIGUEZ, S.J.; GONZÁLEZ, M.S.; SUÁREZ, F.D.; URZÚA, H. Evolución estacional de nutrients minerales en hojas de vid (Vitis vinifera L.). Agricultura Técnica, Santiago do Chile, v.33, n.2, p.45$53,1973$.

GROMAKOVSKIJ, K.J. Diagnosis of the nutrient status of grape vines by means of leaf analysis. Sadovodstvo, n.7, p. 30-32, 1962l Resumo em Horticultural Abstracts, v.33, n.1, p.67, mar., 1963/

GUILLÉN, M.G.; FERNANDEZ, F.G. \& CARO, M. Evolución anual de nutrients en hojas de frutales. IV: vid (parral). Anales de Edafologia y Agrobiologia, Madrid, n.24, p.327-341, 1965.

GUILHERME, M.A.S. Avaliação do estado nutricional da videira 'Itália', em três estádios de desenvolvimento, na região de Jales-SP, utilizando o método DRIS. Piracicaba, 1995, 81p. (Mestrado - Escola Superior de Agricultura "Luiz de Queiroz"-USP).

HANSON, R.G. DRIS evaluation of N, P, K status of determinent soybeans in Brazil. Communications Soil Science Plant Analysis, New York, v.12, n.9, p.933-948, 1981. 
HERNANDO, V. \& MENDIOLA, J. Yields in a acordance with foliar analysis of vineyards in two different areas (La mancha and la rioja). In: COLLOQUIUM EUROPEAN CONTRÔLE NUTRITION MINERALE FERTILITY VITICULTURE ARBORICULTURE, I., 1964. Comptes Rendus, s.n.t., p.201-205, 1965/ Resumo em Horticultural Abstracts, v.36, n.3, p.507, sept. 1966/

HIROCE, R. \& TERRA, M.M. Teores de macronutrientes em pecíolo e limbo na videira "Niagara Rosada". In: CONGRESSO BRASILEIRO DE FRUTICULTURA, 7., Florianópolis, 1983. Anais. Florianópolis, SBF/EMPASC, 1984, p.1184-1187.

HONDA, N.; OKAZAKI, M; FUJIWARA, S.; NAKAO, H.; SHIBUKUWA, H. 1971. Seasonal variation of the content of major nutritional elements in leaves of Muscat Bailey A. Sci. Rep. Fac. Agric., Okayama, v.46, n.3, p.27-41.

JONES, C.A. Proposed modifications of the diagnosis and recomendation integrated system (DRIS) for interpreting plant analyses. Communications Soil Science Plant Analysis, New York, n.12, p.785-974, 1981.

JONES, C.A. \& BOWEN, J.E. Comparative DRIS and crop log analysis diagnosis of surgacane tissue analysis. Agronomy Journal, Madison, n.73, p.941-944, 1981. 
JONES, M.B.; CENTER, D.M.; VAUGHN, C.E.; BELL, F.L. Using DRIS to assay nutrients in subclover. California Agricultural, Berkeley, 40:19-21, 1986.

KANNEMBERG, J. Leaf analysis in viticulture as an aid for diagnosis of nitrogen requirement. Mitteilungen Klosterneuburg Rebe und Wein, Obstbau und Früchteverwertung, v.40, n.1, p.23-28, 1990/ Resumo: Horticultural Abstracts, v.62, n.3, p.240, mar., 1992/

KOSMA, P. ; PÓLYÁK, D.; DIOFÁSI, L. The effect of the metod of training and severity of pruning vines on the NPK content of the leaves. Kértészeti Eggytem Kozteményei Kozteményei, v.33, n.1, p.135-154, 1969/ Resumo em Horticultural Abstracts, v.40, n.4, p.985, dec., 1970/

KOVANCI, I. \& ATALAY, I.Z. Petiole and leaf blade relationships for the determination of phosphorus status in Thompson Seedless grapes. Dogã Turk Tarim ve Ormancilik Devgisi, v.11, n.1, p.30-35, 1987/ Resumo em Horticultural Abstracts, v.57, n.12, p.986, dec., 1987 I

KUNIYUKI, H.; TERRA, M.M.; HIROCE, R.; COSTA, A.S. Clorose das folhas e escurecimento dos frutos da videira associados à deficiência de boro. Summa Phytopathologica, Campinas, v.8, n.1/2, p.27-29, 1982. 
LEITE, R.A. Avaliação do estado nutricional do cafeeiro Conilon no Estado do Espírito Santo utilizando diferentes métodos de intepretação de análise foliar. Viçosa, 1993, 87p (M.S. Universidade Federal de Viçosa).

MALAVOLTA, E.; VITTI, G.C.; DE OLIVEIRA, S.A. Avaliação do Estado Nutricional das plantas. Piracicaba, POTAFOS, 1997, 319p.

MEYER, J.H. Advances in the interpretation of foliar analysis of sugarcane in the South African Sugar Industry. South African Sugar Journal, Durban, v.59, n.11, p.569-585, 1975.

SCHALLER, K. Assessment of nutrient status of grapevines by leaf analysis in four P-fertilization studies with special regard to the DRIS system. Mitteilungen Klosterneuburg rebe und Wein, Obstbau und Fruchteverwertung, v.38, n.4, p.151-163, 1988/ Resumo em Horticultural Abstracts, v. 58, n. 11, p.. 920, nov., $1988 /$

SAUER, M.R. Boron content of sultana vines in the Mildura area. Australian Journal Agriculture Research, 9:123-128, 1958/ Resumo em Horticultural Abstracts, v.28, n.3, p.374, sept., 1959/

SETZER, J. Atlas climático e ecológico do Estado de São Paulo. São Paulo, Instituto Geológico e Geográfico, 1966, 61p. 
SHIKHAMANY, S.D. \& SATYANARAYANA, G. Comparative study of petiole and leaf blade analysis in Anab-e-Shahigrape (Vitis vinifera L.). Indian Journal of Horticulture, v.28, n.4, p.264-269, 1971/ Resumo em Horticultural Abstracts, v.43, n.12, p. 829, dec., 1973/

SOUSA, J.S. I. de. Uvas para o Brasil. São Paulo, Melhoramentos, 1996. 2 ed., $791 \mathrm{p}$.

SUMNER, M.E. A new aproach for predicting nutrients needs for increase crop yields. Fertilizer Soil, Peoria, n.22, p.68-78, 1978.

SUMMER, M.E. Application of Beaufils' Diagnostic índices to maize data published in the literature irrespective of age and conditions. Plant and Soil, The Hague, n.46, p.359-369, 1977.

SUMMER, M.E. Preliminary NPK foliar diagnostic norms for wheatl Communications in Soil Science Plant Analysis, New York, n.8, p.2:149167, 1977a.

SUMNER, M.E. Use of the DRIS system in foliar diagnosis of crops at high yield level. Communications Soil Science Plant Analysis, New York, n.8, p.252-268, 1977b. 
SUMNER, M.E. Effect of corn leaf sampled of N, P, K, Ca and Mg content and calculated Dris índices. Communications Soil Science Plant Analysis, New York, n.8, p.269-280, 1977c.

SUMNER, M.E. \& BEAUFILS, E.R. Diagnosis of the NPK requirements of sugarcane irrespective of plant age and season using Beaufils' System (DRIS), Proceedings of South African Sugar Technologistis Association, Mounth Edgecombe, n.6/7, p.1-5, 1975.

TERRA, M.M.; PIRES, E.J.P.; NOGUEIRA, N.A.M. Tecnologia para a produção de uva Itália na região noroeste do Estado de São Paulo. Campinas, CATI, 1993, 51p. (Documento Técnico, 97).

TRANI, P.E. \& DRUGOWICH, M.I. comp. Análise do solo e análise foliar. Campinas, SAAVATI, Centro de Comunicação Rural, 1989, 4p.

ULRICH, A. Potassium content of grape leach petioles and blades contrasted with soil analysis as an indicator of the potassium status of the plant. Proceedings of Horticultural Science, Saint Joseph, 41:204-212, 1942.

VANEK, G.; MOSNýýY, V.; KOLÓYOVÁ, V. Evidence of magnesium deficiency in vines. Pol'nohospodárstvo, 13:185-192, $1967 /$ Resumo em Horticultural Abstracts, v.38, n.11, p.773, mar., 1967I 
WALWORTH, J.L. \& SUMNER, M.E. The diagnosis and recomendation integrated system. In: STEWART, B.A. Advances in Soil Science, New York, Springer-Verlag, p.150-188, 1987.

ZAMBELLO, JR., E. Aplicação do Sistema Integrado de Diagnose e Recomendação para diferentes solos e épocas de amostragem foliar em soqueiras de cana-de-açúcar (Saccharum ssp.). Piracicaba, 1979, 95p. (Mestrado - Escola Superior de Agricultura "Luiz de Queiroz" - USP).

ZAMBELLO, JR. E. \& ORLANDO, $\mathrm{F}^{\circ}$, J. Aplicação do Sistema Integrado de Diagnose e Recomendação (DRIS) em soqueiras de três variedades de cana-de-açúcar. STAB. Açúcar, Álcool e Subprodutos, Piracicaba, n.3, p.23-28, 1979.

ZAMBELLO, JR. E. \& ORLANDO, $\mathrm{F}^{\circ}$, J. Sistema Integrado de Diagnose e Recomendação (DRIS) aplicado a cana-planta com e sem irrigação. In: CONGRESSO NACIONAL DOS TÉCNICOS AÇUCAREIROS DO BRASIL, 1., Maceió, 1979. Anais. Maceió, STAB, 1980. p.353-356.

ZAMBELLO, JR. E. \& ORLANDO $\mathrm{F}^{\circ}$, J. Diagnosis and Recomendation Integrated System (DRIS) applied to various sugarcane tissues. In: CONGRESS OF THE INTERNATIONAL SOCIETY OF SUGARCANE TECHNOLOGISTS, 17., Manila, 1979. Proceedings. Manila, The Executive Committee of the ISSCT, p.446-457, 1980a. 